Costing Adaptation through Local Institutions Village Survey Results: Ethiopia

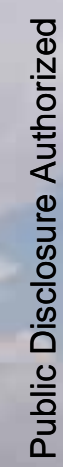




\section{Costing Adaptation through Local Institutions}

Village Survey Results: Ethiopia 
C 2011 The International Bank for Reconstruction and Development/

The World Bank

1818 H St., NW

Washington, DC 20433 U.S.A.

Telephone: 202-473-1000

Internet: www.worldbank.org/sdcc

E-mail: feedback@worldbank.org

All rights reserved.

\section{February 2011 (date of publication)}

This synthesis report is based upon work that has been commissioned by the World Bank as part of the work program on the role of local institutions in climate change adaptation. The results reported in the paper are preliminary and subject to revision. The analysis, results, and views expressed in the paper are those of the authors alone and do not represent the position of the World Bank or any of its member countries.

Papers in this series are not formal publications of the World Bank. They are circulated to encourage thought and discussion. Copies are available from the World Bank Social Development Department by calling 202-473-3641.

The World Bank does not guarantee the accuracy of the data included in this work. The boundaries, colors, denominations, and other information shown or any map in this work do not imply any judgment on the part of the World Bank concerning the legal status of any territory or the endorsement or acceptances of such boundaries.

\section{RIGHTS AND PERMISSIONS}

The material in this publication is copyrighted. Copying and/or transmitting portions or all of this work without permission may be a violation of applicable law. The International Bank for Reconstruction and Development/The World Bank encourages dissemination of its work and will normally grant permission to reproduce portions of the work promptly.

For permission to photocopy or reprint any part of this work, please send a request with complete information to the Copyright Clearance Center Inc., 222

Rosewood Drive, Danvers, MA 01923, USA; telephone 978-750-4470; Internet: www.copyright.com 


\section{CONTENTS}

ACKNOWLEDGEMENTS

SUMMARY Xii

CALI-Objectives $\quad$ xii

Study Organization xii

Main Results $\quad$ xii

Vulnerability Differs between Households xii

Hazards are not only Climate Related xii

Individual and Communal Strategies are Adopted xii

Extension Agencies Reach many Households xiii

Policy Recommendations xiii

More Emphasis should be given to Activities to Improve Coping Capacity xiii

Policies should have an Integral Approach and not Focus on Climate Adaptation Only xiii

Successful Development requires a Stable Enabling Market Environment xiii

Targeting of Interventions is Essential xiv

CALI Results Support the Strategies of the Ethiopian Safety Net Programs xiv

1. INTRODUCTION

Background and Objectives of the CALI Project 1

Objectives of the CALI Project 1

Organization of the CALI Study 2

Data were Collected on Strategies Adopted...

... the Role of Institutions...

.... and the Cost of Adaptation Options 2

The Focus is on Past Household Behavior 2

Objectives of the Report 2

Organization of the Report 3

2. COUNTRY CONTEXT: ETHIOPIA 4

Climatological Effects-Regional Effects on Rainfall and Temperature 4 
Ethiopia is Vulnerable to Climate Variability

Rainfall and Temperature Patterns show Large Regional Differences...

... but in all Regions Rainfall Trends are Declining...

... Temperature Trends are Increasing...

... and Predictions show that the Situation Continues to get Worse...

... due to which the Expected Frequency of Droughts will Increase

Livelihood and Economic Effects of Climate Change

Agriculture is Hit the Hardest

Vulnerability is Caused by Many Factors, like Low Coping Capacity...

... and Exposure to Climate and Other Hazards

Climate Change Adaptation in Ethiopia

Households are Aware of Climate Change

Lowland Adaptation Strategies

Highland Adaptation Strategies

Strategy Choice Depends on Wealth Levels

Are Climate Change Adaptation Strategies Affected by Gender?

Some Questions Remain Unanswered

Policy Framework and Climate Adaptation Initiatives in Ethiopia

Climate Change is Becoming an Integral Component of Government Policy

Coordination of Activities is Important

Local Institutions are Increasingly Recognized as Important

The Costing Estimates are a First Step and Should be Interpreted with Care

3. DATA COLLECTION AND STUDY AREA CHARACTERISTICS 12

Costing Methodology 12

Step 1: Distinguish Four Categories of Adaptation Strategies 12

Step 2: Disentangle the Different Cost Elements 12

Data Collection

Criteria for the Selection of Villages 13

$\begin{array}{ll}\text { Organization of the Fieldwork } & 14\end{array}$

Vulnerability

Vulnerability Depends on Exposure, Sensitivity and Coping Capacity 14

Vulnerability Depends on Many Factors 14

Consider Two Types of Vulnerability Analysis $\quad 15$

Description of Study Area and Study Villages 15

Fentale Woreda_Lowland Village 15

The Pastoral Village of Haro Kersa Faces Severe Periods of Drought 16

Gola has Recently Transformed to Agropastoralism but Faces Flood Hazards 16

Kalu Woreda-Midland Village 16

The Midland Villages Face Droughts but Also High Food Prices and Diseases 17

Kalu Woreda-Highland Village 17

Next to Climate Variability, the Highland Villages Face Soil Erosion Problems 18 
4. VULNERABILITY PROFILES AND ADAPTATION PRACTICES 19

Household Vulnerability $\quad 19$

Village Vulnerability Profiles 19

Households in Haro Kersa own many Cattle but are in a Vulnerable Situation 19

Gola is in a Vulnerable Situation, but this is Expected to Change in the Future 19

Midland and Highland Villages have Lower Vulnerability than Lowland Villages 20

Geographical and Wealth Differences among the Villages are Substantial 20

Vulnerability Profiles Differ Substantially among the Six Villages 20

Vulnerability Levels are Confirmed by the Length of the Hunger Period 21

Drought is the Major Hazard for Most Farmers

High Temperatures Affect Water Availability and Labor Productivity 22

Many Important Hazards are Only Indirectly Climate-Related 23

Household Vulnerability Profiles 23

Household clusters show vulnerability classes 23

Most Households have Limited Options to Fall Back On 24

Climate-Related Hazards are Important for the Households 25

Vulnerability and Adaptation 26

On Average 8.5 Strategies per Household $\quad 27$

Top Five Strategies Contain Three Communal and Two Individual Strategies 27

Responsibility for Strategy Choice is Gender Specific 27

Villages and Clusters Adopt Mixed Strategies 28

Without an Improved Enabling Environment, Household Strategies may not Sustain 29

Strategies are Adopted Especially to Reduce Drought Hazards 29

Cost Estimates are Difficult to Interpret 30

The More Vulnerable Groups Invest Less Money and Time than the Better-Off Groups 30

Institutional Access and Climate Adaptation 32

Households are in Contact with many Institutions, but not all are Relevant for Adaptation 32

Extension Agencies and Local Authorities Provide Most Assistance 32

Extension Agencies Focus Especially on Agricultural and Communal Strategies 32

Village Community Serves Especially the Better-Off Household Types 34

The Sample of Villages Contains only a Small Number of NGOs 34

Cooperatives, Religious Communities, and Women's Groups are Almost Absent 34

Assistance Given is Especially in Terms of Training 34

Only a Few Households Report Receiving Food Aid 35

Cash is Provided by NGOs and Microfinance Institutions 35

Climate Hazards Affect Institutional Activities

The Network of Extension Agencies is an Important Asset for Ethiopia 35

Institutions Face Financial, Managerial, Infrastructural, Training, and Legal Constraints 35

Do Institutions Have to Give Direct Aid or Create an Enabling Environment? 36

CALI Results Support the Strategies of Ethiopia's Development Programs 36

Costing Adaptation 36

Implementing Strategies Requires Cooperation 36

Adoption of Low-Cost Strategies Depends on their Expected Benefits 38

Adoption of High-Cost Strategies Requires a Cash Income or Institutional Assistance 38

More Expensive Communal Strategies Face Financial and Managerial Constraints 39

Assistance from Formal and Informal Institutions may Relieve Adoption Constraints 39 
5. CONCLUSIONS AND POLICY IMPLICATIONS 40

Vulnerability to Climate Change $\quad 40$

Adaptation to Climate Change 40

$\begin{array}{ll}\text { Institutional Access } & 41\end{array}$

Policy Recommendations 44

More Emphasis Should be Given to Activities to Improve Coping Capacity 42

Education and Training Provide People with the Skills to Make Balanced Decisions 42

Policies Should Have an Integral Approach and not Focus on Climate Adaptation Only 43

Target Assistance at the Household Members Who Make the Decisions 43

Successful Development Requires a Stable Enabling Market Environment 43

Targeting of Interventions is Essential in Freeing Marginalized Groups from the Poverty Trap 43

Do Institutions Have to Give Direct Aid or Create an Enabling Environment? 44

CALI Results Support the Strategies of the Ethiopian Safety Net Programs 44

REFERENCES

APPENDIX 1. METHODOLOGY AND RESEARCH FRAMEWORK 47

A1.A. Methodology and Costing Framework $\quad 47$

A1.B. Household Questionnaire $\quad 52$

Rationale of the Questionnaire $\quad 52$

Notes on how to conduct the questionnaire 54

Question 1: $\quad 55$

Question 2: $\quad 55$

Question 3: $\quad 55$

Question 4: $\quad 55$

Question 5: $\quad 56$

Question 6: $\quad 56$

Question 7: $\quad 56$

Question 8: $\quad 57$

Question 9: $\quad 57$

A1.C. Institutional Stakeholder Questionnaire $\quad 74$

A1.D. Focus Group Discussion 77

APPENDIX 2. DATA ANALYSIS $\quad 79$

A2.A. Descriptive Analysis of the Households 79

A2.B. Descriptive Analysis of the Clusters 87

A2.C. Strategies Adopted for Kebelle and Clusters 94

A2.D. Institutional Access for Kebelle and Clusters 100

APPENDIX 3. SUMMARY OF FOCUS GROUP DISCUSSIONS 107

A. Selection of Villages and Participants 107

B. Manifestations and Effects of Climate-Related Hazards 108

$\begin{array}{ll}\text { Declining and Variable Rainfall and Effects } & 108\end{array}$

$\begin{array}{lr}\text { Rising Heat and Effects } & 108\end{array}$

$\begin{array}{lr}\text { Flood Risk and Effects } & 108\end{array}$

\begin{tabular}{l} 
Other Hazards and Effects \\
\hline
\end{tabular}

C. Gendered Effects of Drought and Food Shortage in the Household 109 
D. Adaptation Strategies 109

$\begin{array}{lr}\text { Crop Selection } & 109\end{array}$

$\begin{array}{ll}\text { Early and Late Tillage Practices } & 110\end{array}$

$\begin{array}{lr}\text { Livestock Production and Sales } & 110\end{array}$

$\begin{array}{lr}\text { Migration } & 110\end{array}$

$\begin{array}{ll}\text { Child Labor Hiring } & 111\end{array}$

Water Harvesting and Irrigation Practices 111

$\begin{array}{ll}\text { Credit } & 111\end{array}$

$\begin{array}{ll}\text { Firewood and Charcoal Selling } & 111\end{array}$

E. Institutional Assistance 111

APPENDIX 4. SUMMARY OF INSTITUTIONAL STAKEHOLDER INTERVIEWS 112

A. Main Climate-Related Hazards in the Area 112

B. Institutions Involved

C. Type of Assistance the Households Need to Adapt 113

D. Main Constraints on Institutional Activities 113

E. Effect of Climate Hazards on Stakeholders' Activities 114

\section{BOXES}

Box 1. Gender Effects of Climate-Related Hazards 26

Box 2. Experiences with Temporary Migration 29

Box 3. High Interest Rates Charged by Money Lenders 30

\section{FIGURES}

Figure 1. Mean Annual Rainfall and Temperature Distribution Over Ethiopia 5

Figure 2. Year-to-Year Variability of Annual Rainfall Over Northern Half of Ethiopia Expressed in Normalized Deviation

Figure 3. Year-to-Year Variability of Annual Rainfall In Southwest Ethiopia Expressed in Normalized Deviation

Figure 4. Year-to-Year Annual Mean Minimum Daily Temperature Variability and Trends Over Ethiopia

Figure 5. Projected Mean Temperature Change Across Ethiopia, 2030, 2050, And 2080

Figure 6. MKP Livelihood Zone Boundary of Fentale Woreda $\quad 16$

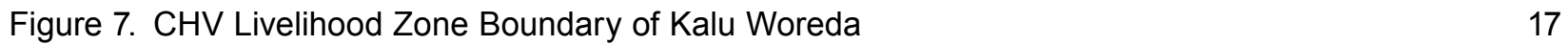

Figure 8. SWB Livelihood Zone Boundary of Kalu Woreda 17

Figure 9. SWS Livelihood Zone Boundary of Kalu Woreda 18

Figure 10. Spider Diagrams of the Village Scores on the Vulnerabilty Characteristics 21

Figure 11. Spider Diagrams of the Average Cluster Scores on the Main Vulnerability Characteristics $\quad 25$

Figure 12. Percentage of Times Households Choose a Particular Adaptation Option 28

Figure 13. Percentage of Households in the Different Villages and from the Different Clusters Receiving Assistance from Any of the Main Institutions

Figure 14. Overview of Costs and Investments Needed to Implement Adaptation Strategies 


\section{TABLES}

Table 1. The Villages Selected for the Village Surveys 13

Table 2. Overview of Months in which Households (\%) Face a Food Shortage 22

Table 3. Distribution of Clusters Over the Different Villages $\quad 24$

Table 4. Characteristics of Clusters 24

Table 5. Average Ranking of Hazards (1 = Most Important; $10=$ Least Important) 26

Table 6. Cost Estimates of the Adaptation Strategies (Birr) 31

Table A.1. Main Demographic Characteristics of the Study Sites $\quad 79$

Table A.2. Differences in Education and Migration $\quad 80$

Table A.3. Main Activities of Households in the Study Sites 80

Table A.4. Main Types of Crops Grown 81

Table A.4B. Details on Area Cultivated and Land Owned 82

Table A.5. Livestock Ownership $\quad 82$

Table A.6. Asset Ownership $\quad 83$

Table A.1B. Detailed Demographic Characteristics of the Study Sites 84

Table A.2B. Detailed Education Characteristics of the Study Sites 85

Table A.7. Average Ranking of Hazards and Observations on Whether the Hazard has Become More Threatening 86

Table B.1. Distribution of Clusters Over the Different Villages $\quad 87$

Table B.2. Main Demographic Characteristics of the Clusters $\quad 87$

Table B.3. Household Characteristics $\quad 87$

Table B.4. Education Characteristics $\quad 88$

Table B.5. Agricultural Characteristics $\quad 89$

Table B.5B. Details and Area Cultivated $\quad 90$

Table B.6. Livestock Characteristics $\quad 91$

Table B.7. Average Ranking of Hazards and Observations on Whether the Hazard
has Become More Threatening

Table B.8. Households Facing Food Shortages in Particular Months (\%) 93

Table C.1. Percentage of Households from Clusters and Villages Adopting Particular Strategies 94

Table C.2. Ranking of Adaptation Options for Clusters and Villages 96

Table C.3. Cost Estimates of Adaptation Options (Birr) for the Options that had a Positive Cost Estimate for at Least 10 Observations (in Birr) 98

Table C.4. Average Cost Estimates of Adaptation Options for the Clusters and Villages for the Most Important Strategies (in Birr) 99

Table D.1. Households in a Cluster or Village Holding Contacts with Certain Institutions (\%) 100

Table D.2. Number of Times a Household Receives Assistance from a Certain Institution as Percentage of the Households In a Cluster or Village 101

Table D.3. Percentage of Times a Households Receives Assistance from a Certain Institution, if it Adopts a Certain Strategy

Table D.4. Ranking of Times Households Receive Assistance from a Certain Institution, if it Adopts a Certain Strategy

Table D.5. Number of Times a Certain Type of Assistance is Received as \% of the Times Assistance is Given

Table D.6. Number of Times a Certain Type of Assistance is Received as \% of the Number of Households

Table D.7. Type of Assistance Institutions are Giving to Households (\%) ${ }^{*}$

Table D.8. Type of Assistance Households Receive, if it Adopts a Certain Strategy (\%) 106 


\section{PHOTOS}

Photo 1: Cropfarming

$\begin{array}{ll}\text { Photo 2: Livestock Raising } & 71\end{array}$

Photo 3: Hired Labor $\quad 71$

$\begin{array}{ll}\text { Photo 4: Fisheries } & 71\end{array}$

$\begin{array}{ll}\text { Photo 5: Handicrafts } & 71\end{array}$

Photo 6: Trade and Commerce $\quad 71$

Photo 7: Civil Servant $\quad 72$

Photo 8: Other $\quad 72$

Photo 9: Drought Due to Less Rainfall During Rainy Season $\quad 72$

Photo 10: Human Disease $\quad 72$

Photo 11: Prolonged Periods of Drought During Rainy Season $\quad 72$

Photo 12: Animal or Crop Pests and Diseases $\quad 72$

Photo 13: Floods Due to Excessive Rainfall $\quad 73$

Photo 14: Decreasing Soil Fertility $\quad 73$

Photo 15: Damage Due to Excessively Heavy Showers $\quad 73$

Photo 16: Problems with Input Purchase or Output Sales $\quad 73$

Photo 17: Extreme Temperatures Leading to e.g. Scorched Crops 73

Photo 18: High Food Prices $\quad 73$ 



\section{ACKNOWLEDGEMENTS}

The "Costing Adaptation through Local Institutions" (CALI) study was a joint effort by the World Bank Social Development Department (SDV), University of Michigan, Royal Haskoning and Wageningen University. The overall study, comprising three individual case study reports from Ethiopia, Mali and Yemen, as well as a synthesis report, was designed and implemented in close collaboration with regional colleagues from AFTAR, AFTEN, MNSEN and MNSAR.

The study was overseen by a core team led by Nicolas Perrin (ECS4), Robin Mearns (SDV), Minna Kononen (SDV), Anne Kuriakose (SDV) and Arun Agrawal (University of Michigan). Research partners in Ethiopia were Royal Haskoning and Shebelle Consulting and the study team was led by Dr. Arjan Ruijs and Gert Jan Prins from Royal Haskoning and Dr. Kiddist Gebreselassi and Asfaw Mekonnen from Shebelle
Consulting. Support in methodology, field survey design, workshop organization as well as overall coordination was provided by Dr. Arjan Ruijs and Mark de Bel.

We could not have completed this work without the continuous logistical support provided by Mustafa Pajazetovic (SDV) and Carmen Martinel (SDV). Financial support was provided by the BankNetherlands Partnership Program (BNPP).

Additionally, participants in the workshops in Ethiopia provided important technical expertise and insight and included: D. Danano (MORAD), G. Jembere (NMA), B. Lanedri (World Bank), W. Soer (World Bank), T. Alemu (AAU), T. Mekonnen (Shebelle Consult), D. Spielman (IFPRI), B. Adenew (EEA), M. Malo (FAO), S.Regassa (Oxfam USA), S. Tilahun (WFP), B.Mamo (PCDP$\mathrm{MoFa}$ ), I. Campbell (World Bank), S.Bekele (IWMI), J. MacAskill (USAID-LIU), Z. Mekuria (LIU), M. McCartney (IWMI), S. Margulis (World Bank), E. Dwumfonr (World Bank), K. Shemsu (WFP-VAM), Fanaye (EEA) and E. Nigatu (World Bank). 


\section{SUMMARY}

\section{CALI-Objectives}

This report presents the results of the World Bankfunded project on Costing Adaptation through Local Institutions (CALI). The objectives of the CALI-project are (1) to identify the costs of adaptation through local institutions, and (2) to investigate the institutions that support households in adapting to climate variability, the efforts and costs required to realize the adaptation options, and how they facilitate adaptation to climate variability. The study has been carried out in Ethiopia, Mali, and Yemen. This report discusses the results for Ethiopia.

\section{Study Organization}

In Ethiopia, village surveys were conducted in six villages and two expert workshops were organized to discuss the organization of the study and to evaluate the draft results. Based on household surveys, focus group discussions, and institutional stakeholder interviews, we assessed household vulnerability, analyzed the strategies households adopt to reduce the hazards faced, and evaluated the assistance households receive from institutions. Vulnerability profiles were formulated, which show that household vulnerability differs substantially among and within villages. The size and diversity of income and the ability to flexibly decide on alternative measures to mitigate the adverse climate effects—which depends on, for example, level of education and dependency ratio- have effects on the adaptation options households adopt and the type of institutional assistance they receive.

\section{MAIN RESULTS}

\section{Vulnerability Differs between Households}

The results show that the lowland kebelle are most vulnerable, whereas the midland kebelle are in a somewhat better situation. In the lowland kebelle, exposure is high and coping capacity low. In the midland kebelle, coping capacities are somewhat better and exposure seems to be lower. In all regions, however, exposure is high due to rainfall variability and droughts. The dependence on one source of income is a threat to livelihoods in all regions.

\section{Hazards are not only Climate Related}

Next to the climate hazards, droughts, and rainfall variability, increasing food prices and other non-climate related hazards also threaten livelihoods. Development strategies should not entirely focus on reducing climate hazards. Making development strategies climate-proof is important, but keeping track of the integral effects of sustainable development remains of key importance.

\section{Individual and Communal Strategies are} Adopted

The main strategies adopted by the farmers are selection of drought-resistant seeds and adaptation of planting dates and cropping density. Communal strategies—such as irrigation, water management, soil fertility improvement, and reforestation programs-also are important. The required coordination and investments often cannot be borne by the households themselves 
without institutional assistance. Income diversification techniques - like handicrafts, market trade, and trade in non-timber forest products-are adopted by only a few households. Temporary migration is not seen by many households as an appropriate adaptation strategy. One reason is that local markets are imperfect; that is, the market environment is not equally accessible for everybody in terms of physical and institutional access. In particular, infrastructure (road and telecommunication) is missing or in bad condition, market conditions are poor, market information is missing, credit facilities are unfavorable to poor households, and legal support is often inaccessible to rural households. In many cases, both men and women decide about adoption of adaptation strategies. For financial decisions, like market sales or draw-down on livestock or savings, and in pastoral areas, men have a larger vote. On the other hand, women make decisions in some areas, such as handicrafts, consumption decisions, and charcoal and timber sales. Women also have an important vote regarding home-garden agriculture. In promoting particular strategies, institutions should target the household members making the decisions.

\section{Extension Agencies Reach many Households}

Extension agencies and local authorities provide the most assistance to households in Ethiopia. Extension agencies reach almost all households in the areas where they operate. Their focus is on promoting agricultural and communal strategies to reduce sensitivity to climate variability. The better-off households seem to receive more assistance than the marginalized households. Even though institutional stakeholders indicate that no distinction is made between household types, marginalized groups may have more difficulties in accessing institutional assistance. Assistance received by the households, both for individual farming and for communal strategies, is frequently for training, which can help improve the household's skills.

\section{POLICY RECOMMENDATIONS}

\section{More Emphasis should be given to Activities to Improve Coping Capacity}

The results show that most strategies adopted focus on reducing sensitivity to the exposure to climate change. Less attention is paid to activities to improve coping capacity, like handicrafts, commerce, nontimber forest products, or charcoal/timber sales. One of the constraints to successful development of such income diversification techniques is the malfunctioning market environment. Next to that, the capacity of households to cope with climate change can improve if they have the skills and opportunities to make balanced decisions themselves. Education and training are necessary to obtain these skills. The results show that the younger generation receives more education than their parents and that the difference in education received between boys and girls seems to disappear. Next to that, assistance received from institutions is in most cases in terms of training.

Policies should have an Integral Approach and not Focus on Climate Adaptation Only

The study showed that households perceive climate variability - less rainfall during the rainy season, prolonged periods of drought and increased temperatures-as being an important hazard. Non-climate-related hazards, however, also are important. Soil erosion, overgrazing, deforestation, and lack of organic fertilizer use are equally important causes for reduced yields and reduced water storage in the soil. High food prices and human, animal, and crop diseases also are considered to be important and threatening to livelihoods in rural areas. As a result, focusing development policies on climate variability alone will not solve the problems of rural households. They should follow an integral approach in which the major limiting factors are identified and appropriate bottom-up strategies are designed with the objective to create an environment in which development can be sustained. Dealing with only one element of vulnerability will not yield satisfactory results.

\section{Successful Development requires a Stable Enabling Market Environment}

One of the reasons why income diversification initiatives often are unsustainable is that the basic facilities for markets to function properly are missing. Among other things, this requires improved roads, telecommunication, market information, availability of farm inputs, credit facilities, legal services, and veterinary facilities. It also includes improved market and 
meteorological information dissemination and disaster management plans, which would provide households with the information needed to make deliberate choices. Institutional stakeholders are particularly cognizant of malfunctioning markets. Farmers also recognize the problem of missing markets, particularly in terms of the hazards of high food prices and the problem of high price fluctuations during the year. These problems, however, cannot be solved by them, but require investments from the authorities.

\section{Targeting of Interventions is Essential}

The results show that marginalized households adopted less communal strategies and were less involved in the assistance provided by (informal) community institutions from the village. In targeting aid, it is important that marginalized groups receive special attention. As marginalized groups already are in a more vulnerable situation and have lower capabilities of improving the situation themselves, it is important that they are explicitly considered in development policies. Bottom-up strategies proposed by communities themselves should be adequately reviewed, as they may not involve the more marginal households. Next, particular strategies are adopted by men, but for other strategies women make the decisions. For example, small-scale income diversification strategies are the responsibility of women. In order to assure that these strategies are adopted, institutions should carefully target their assistance to those making the decisions.

\section{CALI Results Support the Strategies of the Ethiopian Safety Net Programs}

Looking at why rural households are in a vulnerable situation, it follows that this is only partly caused by climate variability. Even if exposure to climate change is high, households having a high coping capacity or adopting strategies that reduce their sensitivity to climate change may not be vulnerable. For Ethiopia, refocusing development policies toward climate change adaptation is not necessary. Making development strategies climate-proof is important, but the main focus should be on removing the factors limiting sustainable development. This helps create an environment in which investments are sustainable, markets function properly, and households have the opportunity to take initiatives to improve their own lives. In this respect, the situation in Ethiopia, as illustrated by our research, is positive. Many of the adaptation strategies adopted by the survey households focus on removing some of these limiting factors. These strategies already fit within the existing institutional programs or are planned for implementation. Activities to diversify income, set up water management techniques, implement sustainable agriculture, improve education, and strengthen infrastructure are already promoted for a long time by many governmental and development agencies. The Ethiopian safety net programs, executed through the extension agencies, already seem to have a good overview of the strategies households adopt and the most pressing needs of the households. The insights obtained from the CALI study support the focus of these programs. The CALI results show that for selecting activities, these programs, jointly with the households, should select a set of strategies that are climate proof, reduce sensitivity to climate change, and increase coping capacity. They should target the most vulnerable households, as well as enable the creation of an institutional and market environment in which initiatives can be sustained. 


\section{INTRODUCTION}

\section{BACKGROUND AND OBJECTIVES OF THE CALI PROJECT}

Climate change is a global phenomenon. Observations across countries shows that people perceive recent changes in their environment as an impact of climate change, and in particular changes in temperatures, rainfall, and other weather patterns such as the timing and occurrence of seasons. Although a lot of this evidence is anecdotal and needs scientific confirmation, we can assume that most people are making rational statements and therefore do relate the changes to their lifetime experiences. It is also becoming clearer that the people most affected by the immediate impacts of climate change are the world's most vulnerable people, and that the people and countries that are the least responsible for the occurrence of climate change carry most of its burden, at least in the short run. To what extent does climate change affect households in different regions of the world and regions with similar climatic conditions?

\section{Objectives of the CALI Project}

The Social Development Department of the World Bank commissioned a study on costing of climate change adaptation in Yemen, Mali, and Ethiopia. The project's aim is to provide recommendations to decision makers in development projects and government agencies regarding the risks, costs, and benefits of adaptation options in rural context, and the institutional investments necessary to facilitate cost-effective adaptation.

This study is a reflection of the increasing engagement of the World Bank on the issue of climate change, and its observations that:

- The poor, natural resource communities, and households bear most of the impacts of climate change.

- An understanding of local adaptation processes is highly important for informing sound macroeconomic policies.

- Adaptation is about more than techniques and infrastructure; it also involves institutions and socioeconomic factors.

- In prioritizing future adaptation options, it is crucial to analyze the costs and benefits of concrete, historical adaptation strategies.

The CALI study falls within this wider framework of the World Bank Social Development Department's work on climate change. CALI has a more narrow focus, namely:

1. To identify the main adaptation strategies adopted by households in the study areas;

2. To investigate which institutions support households to adapt to climate variability, and how the institutions facilitate adaptation to climate variability; and

3. To identify important adaptation cost elements and estimate adaptation costs (labor, material, and cash) for the households. 


\section{ORGANIZATION OF THE CALI STUDY}

The study involves an assessment of the adaptation options rural households pursue and what the perceived costs of these adaptation options are for them and for the involved institutions. In doing so, the differential access/ adoption of various vulnerability groups is investigated as well as the drivers for adopting particular strategies. For this, respondents were not asked which adaptation strategies they would like to practice, but rather the adaptation options they were already practicing.

\section{Data were Collected on Strategies Adopted...}

In order to obtain information about the adopted strategies, respondents were asked to indicate the use of particular techniques or adaptation options. The importance of each option was then based on the number of households that adopted them. Employing particular adaptation options depends on the importance of the perceived climate hazards-for example, drought, rainfall variability, flood, increasing heat-versus price, market, health, or other hazards. In doing so, visual aids were used to help respondents rank a list of potential hazards.

\section{... the Role of Institutions...}

To obtain more insight on the role of institutions, we investigated the institutions supporting households to adapt to climate variability. We specifically looked at the efforts and inputs provided for the adoption of adaptation strategies and how they facilitated adaptation to climate variability. Institutions we focused on included local authorities, extension agencies, NGOs, cooperatives, religious institutions, and informal village groups (such as Equb, Edir, and Debo). Respondents were asked to indicate the institutions they have contacts with and those that have been helpful in climate adaptation. For the identified institutions, respondents indicated the duration and purpose of contact and type of assistance obtained from the institutions.

\section{... and the Cost of Adaptation Options}

To obtain more information about the cost of adaptation options, we estimated the costs that households incurred for each of the strategies adopted. A costing framework was developed to capture the labor, material, and cash costs that households incurred during the first year they adopted a strategy.

\section{The Focus is on Past Household Behavior}

The project focused on the manner in which rural households dealt with climate-related hazards in the past, irrespective of whether these hazards might change in the future. For decades, farmers have been facing severe climate-related hazards like extreme droughts and rainfall, rainfall fluctuations, and temperature fluctuations. These hazards are likely to intensify in the future. The focus of the project is not on how households will respond to these climate hazards, but on how they have responded in the past through the various adaptation strategies and the costs of these adaptation strategies. While it might be expected that households would like to adopt some strategies, the study revealed which were important and which were not. For example, small-scale irrigation is an adaptation strategy that is often initiated or channeled through external institutions, but is rationed among the households based on various criteria. It is inaccessible for some households, even though they would like to benefit from irrigation. As a result, the list of strategies presented in this report should not be interpreted as being the best or most wanted strategies to cope with climate variability. It reflects current practice in Ethiopia and shows what households currently do themselves or with institutional assistance.

\section{OBJECTIVES OF THE REPORT}

The CALI study is the outcome of a series of meetings, consultation workshops, and institutional contacts concerning the study design, data collection, and the interpretation of the results. Primary and secondary data were collected in order to achieve the research objectives. Primary data was collected using household questionnaires, focus group discussions, and stakeholder interviews; quantitative estimation was carried out through data obtained from these sources. Secondary data was collected from published and unpublished sources to complement the primary data.

This document is the final country report for Ethiopia prepared within the framework of the Costing 
Adaptations through Local Institutions Project (CALI), as implemented by Royal Haskoning and LEI

Wageningen UR in the Netherlands and several national consultants in Ethiopia, Mali, and Yemen. The objective

of this report is to present an overview of the main findings of the CALI study in Ethiopia and to provide policy recommendations.

\section{ORGANIZATION OF THE REPORT}

Chapter 2 presents a brief description of climate change, its effects, adaptations, and climate change actions in
Ethiopia. Chapter 3 describes the methodological organization of the study, including research sites, the approaches, and the contents of the questionnaires. Chapter 4 presents the main findings. Chapter 5 provides the main conclusions drawn from the analysis and policy recommendations, mainly focusing on the key adaptation strategies and relevant institutions. 


\section{COUNTRY CONTEXT: ETHIOPIA}

Understanding the effects of climate change, the adaptation strategies in place, and the stakeholders involved is an important step toward formulating strategies to reverse the declining situation of rural households in Ethiopia. Before discussing which adaptation strategies are adopted, we discuss which issues are at stake.

\section{CLIMATOLOGICAL EFFECTS-REGIONAL EFFECTS ON RAINFALL AND TEMPERATURE}

\section{Ethiopia is Vulnerable to Climate Variability}

As in the rest of the world, climate variability and climate change are also occurring in Ethiopia. The severity of the impact varies across regions. According to the National Meteorology Agency (NMA 2007), Ethiopia is among the countries that are vulnerable to climate variability due to their low adaptive capacitythat is, low level of socioeconomic development, high population growth, inadequate infrastructure, and lack of institutional capacity — and heavy reliance on natural resource-based activities that are highly climate sensitive. Although all sectors in Ethiopia may be affected by climate change, agriculture, water, energy, and health are considered the most sensitive.

Rainfall and Temperature Patterns show Large Regional Differences...

Climate variability and change in the country is mainly manifested through the variability and decreasing trend in rainfall and increasing trend in temperature (NMA 2001). Figure 1 shows that the northeastern and southeastern parts of the country are facing lower rainfall and higher temperature levels than the rest of the country.

...but in all Regions Rainfall Trends are
Declining...

Figures 2 and 3 indicate a trend of variable annual rainfall both in the northern half and southwest parts of Ethiopia. The degree of rainfall variability seems to be higher in the northern region than in the southwest. The figures also show a declining trend of annual rainfall in the northern and south-western parts of Ethiopia. ... Temperature Trends are Increasing...

Figure 4 shows an increasing trend in the annual mean minimum temperature. The warming trend, coupled with variable and declining annual rainfall, affects the agriculture sector's vulnerability to climate variability. The major climate hazards observed in many parts of the livelihood zones in Ethiopia include drought, flood, and livestock and human diseases (LIU/DMFSS 2008). Relatively minor climate hazards include frost, hailstorm, excessive rain, and strong wind. Although floods are more of a lowland phenomenon, floods in the lowlands are partly attributable to activities in the highlands.

... and Predictions show that the Situation Continues to get Worse...

Temperature predictions indicate that the situation will continue to get worse. Figure 5 shows the projected trend in temperature $\left({ }^{\circ} \mathrm{C}\right)$ over the coming decades. 
FIGURE 1. MEAN ANNUAL RAINFALL AND TEMPERATURE DISTRIBUTION OVER ETHIOPIA

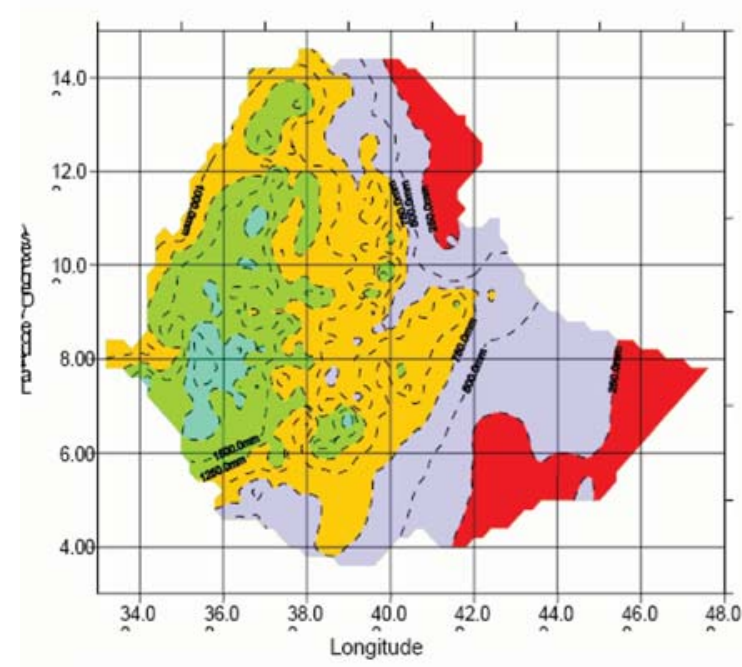

Figure ? Cumulative Mean Annual Rainfall (mm)

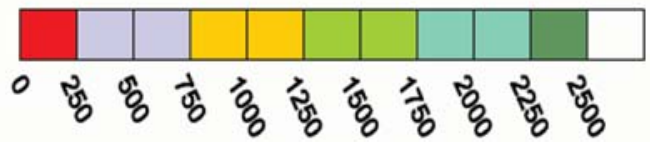

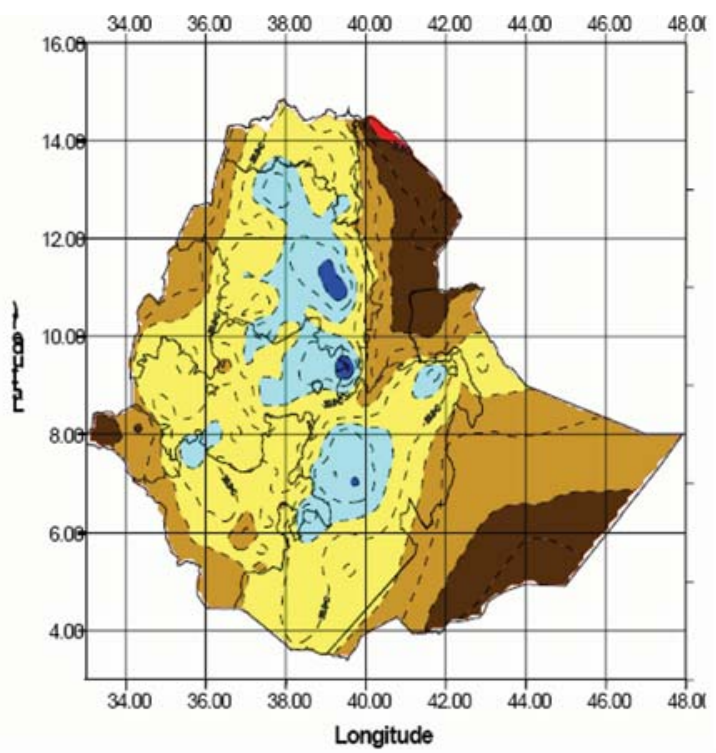

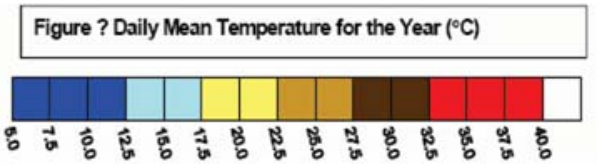

Source: NMA, 2001.

FIGURE 2. YEAR-TO-YEAR VARIABILITY OF ANNUAL RAINFALL OVER NORTHERN HALF OF ETHIOPIA EXPRESSED IN NORMALIZED DEVIATION

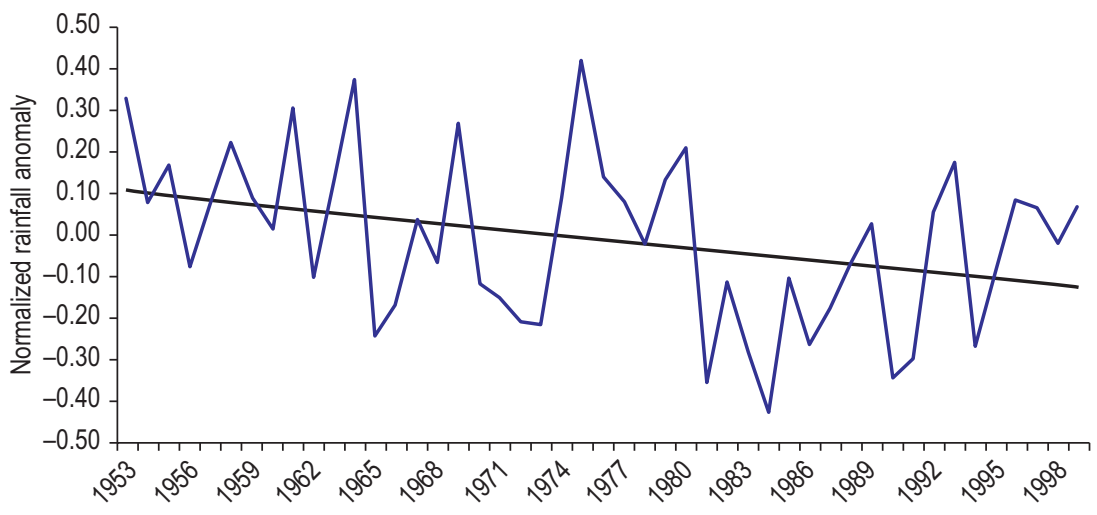

Source: NMA, (2001).

... due to which the Expected Frequency of

Droughts will Increase

As a result of the variable and declining annual rainfall and increasing warming trend, the frequency of drought has been increasing in the country over the past decades. The success of any effort to assist household adaptation to climate-related hazards is conditioned by whether the households perceive the problem and its urgency. Studies indicate that farmers perceive a change in climate. 
FIGURE 3. YEAR-TO-YEAR VARIABILITY OF ANNUAL RAINFALL IN SOUTHWEST ETHIOPIA EXPRESSED IN NORMALIZED DEVIATION

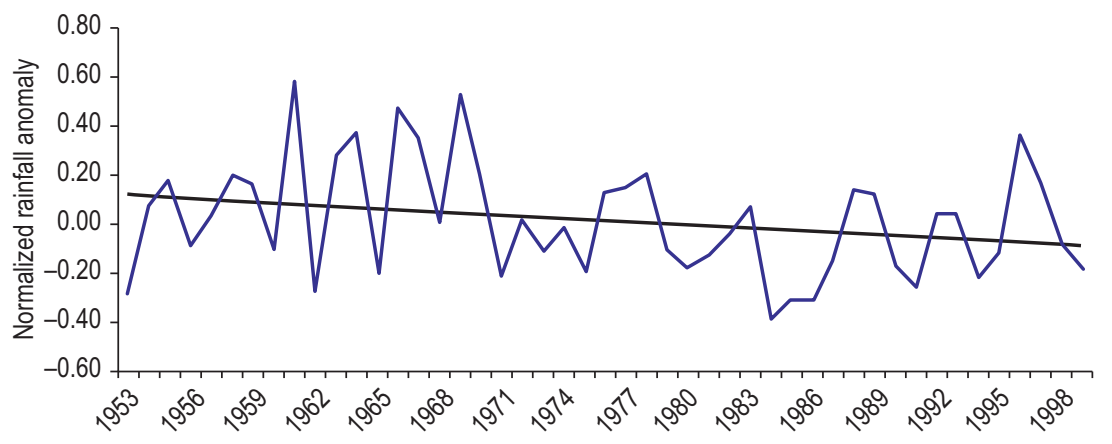

Source: NMA, (2001).

FIGURE 4. YEAR-TO-YEAR ANNUAL MEAN MINIMUM DAILY TEMPERATURE VARIABILITY AND TRENDS OVER ETHIOPIA

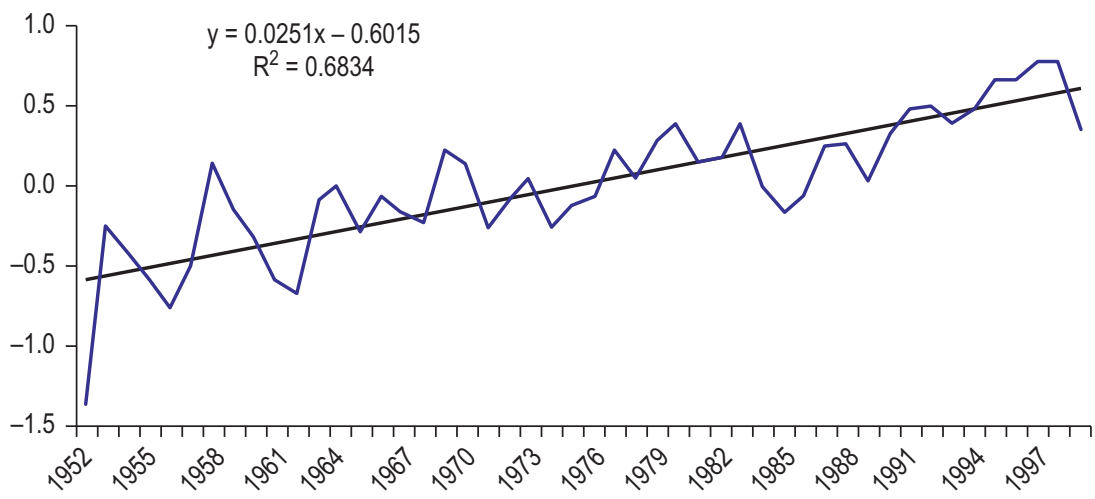

Source: NMA, (2001).

According to IFPRI (2006), 53 percent of the farmers in the highlands of the Nile River basin perceived increased temperature and 61 percent perceived declining precipitation over the past 20 years.

\section{LIVELIHOOD AND ECONOMIC EFFECTS OF CLIMATE CHANGE}

\section{Agriculture is Hit the Hardest}

The agricultural sector is among the sectors that are most vulnerable to climate-related hazards due to its dependence on rainfall patterns. Rainfall variability, scorching heat, and severe weather events cause direct crop and livestock losses and reduced productivity. Observation also suggests that the working capabilities of people and plowing oxen are affected by the increasing heat, forcing both to recess for shade earlier than normal during the day. Furthermore, the risk associated with rainfall variability and extreme weather events cause small-scale farmers to be reluctant to adopt productivity boosting technologies (NCCCF and Oxfam America 2009). Such climate hazards also threaten life and assets, and thereby affect household productivity and adaptive capacity. 
FIGURE 5. PROJECTED MEAN TEMPERATURE CHANGE ACROSS ETHIOPIA, 2030, 2050, AND 2080
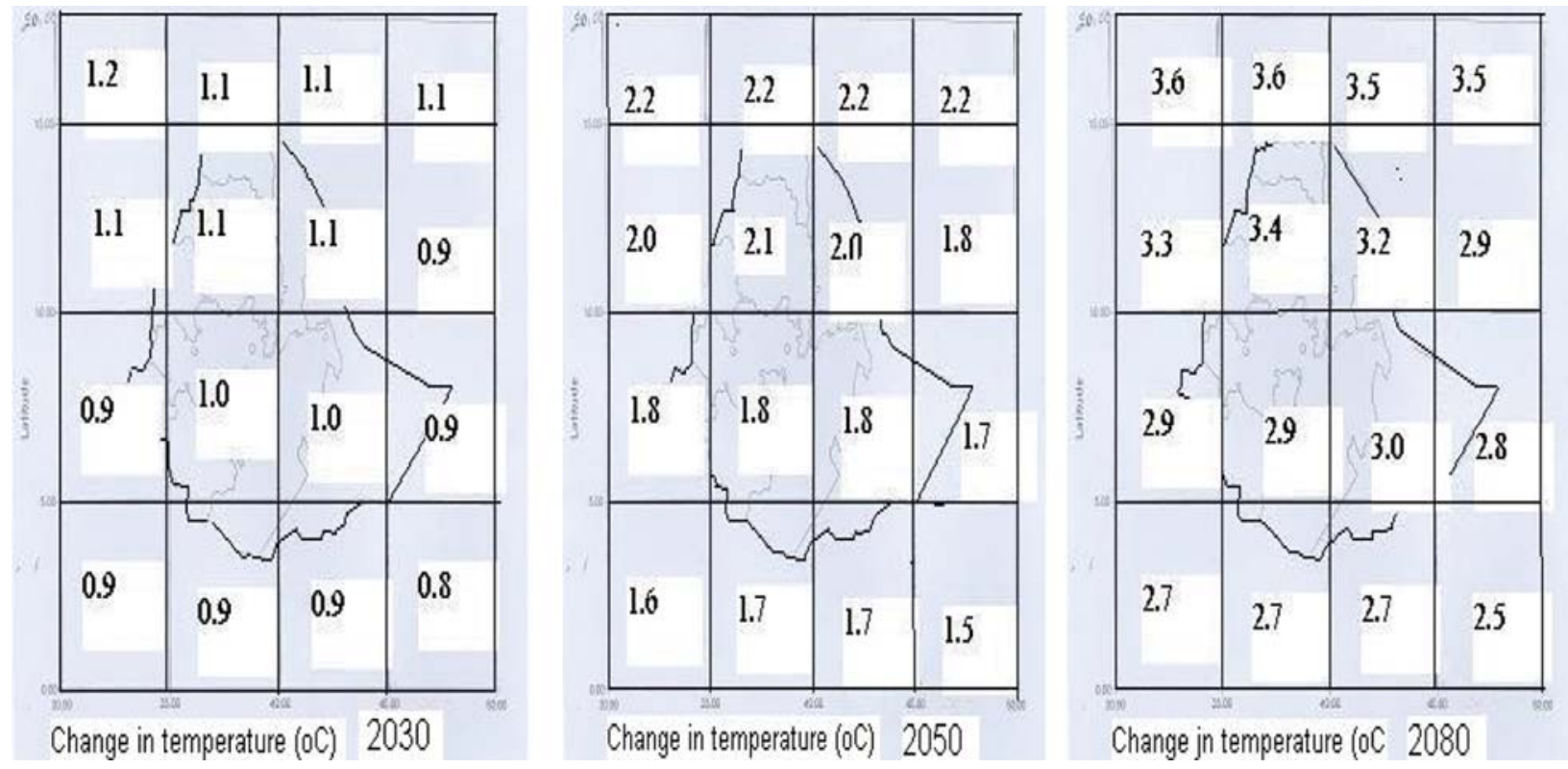

Source: NMA, (2001)

Vulnerability is Caused by Many Factors, like Low Coping Capacity...

The agricultural sector is the mainstay of the Ethiopian economy, contributing 52 percent of GDP and generating 85 percent of its foreign exchange earnings (CSA 2004), the adverse effects of climate variability and change on the agricultural sector have implications for the overall economy. NMA (2007) showed that the GDP growth rate and agricultural GDP growth rate are correlated with rainfall fluctuations. The varying rainfall and temperature patterns in the different regions in Ethiopia, as well as differences in the level of socioeconomic development, imply that the regions differ in their vulnerability and adaptive capacity to changing climaterelated hazards. Based on a vulnerability index that accounts for sensitivity, exposure, and adaptive capacity, Deressa et al. (2008) found that the Afar, Somali, Tigray, and Oromiya regions were more vulnerable to climate change than other regions of the country. This corresponds with results from Admassie et al. (2008) that the arid, semi-arid, and subhumid lowlands are more vulnerable than the highland areas. The vulnerability of Afar and Somali can be attributed to their low level of rural service and infrastructural development, and that of Tigray and Oromiya to the higher frequency of drought and floods, lower access to technology, fewer institutions, and lack of infrastructure. This raises the question whether households with a higher degree of institutional contact and access to rural services have a lower level of vulnerability than those with a lower degree of institutional contact and access to rural services. This question is relevant particularly in a setting where many rural services and institutional contacts are inadequate and are rationed among households even within a village.

\section{... and Exposure to Climate and Other Hazards}

If the trend of warming and drying continues, vulnerability among the agricultural farming and pastoral livelihoods is expected to increase. The key climate-induced vulnerabilities of households in the lowlands are shortage and variability of rainfall, decline in crop production, chronic water shortages, floods, livestock and human diseases, conflicts over pasture and water, and livestock and crop price fluctuations (SC-UK/DPPFSB/DPPA 2008; SC-UK/DPPA 2008). In some parts of the 
midland/lowland areas, the recently declining and irregular trend of the belg rain is likely to increase vulnerability. In the highland areas the main climate-related vulnerabilities relate to erratic rainfall, drought, hailstorms, frost, strong winds, land degradation, and pests and livestock diseases affecting crop and livestock production (LIU/DMFSS 2008).

Overall, climate variability and climate change will adversely affect crop yields, resulting in income fluctuations and declining food security.

\section{CLIMATE CHANGE ADAPTATION IN ETHIOPIA}

\section{Households are Aware of Climate Change}

Awareness and adaptation to climate-related hazards are influenced by the experience with prolonged climate hazards such as higher mean temperature and lower precipitation (Deressa et al. 2008). In many instances, households are aware of some of the climate-related hazards they are facing and their consequences, and as a result they have developed strategies to deal with such hazards. Identifying the key adaptation strategies and factors explaining a household's choice of a particular climate adaptation strategy is important for designing and/or scaling-up interventions for better climate adaptation.

\section{Lowland Adaptation Strategies}

Studies from the DPPA showed that the main adaptation strategies in the lowlands include livestock sales and slaughter, inter-household support, casual labor employment and migration, change in herd composition, reducing expenditures on non-essentials/non-food items, reducing food consumption, livestock migration, increasing firewood/charcoal sales, increasing wild food consumption, lopping trees for fodder, seeking food aid rations in towns, and digging wells at river banks (SC-UK/DPPFSB/DPPA 2008; SC-UK/DPPA 2008).

\section{Highland Adaptation Strategies}

In highland areas, important adaptation mechanisms include planting disease and drought-resistant short cycle crops, labor migration, firewood/charcoal sales, livestock sales, and agricultural wage labor. Related responses include reducing expenditures on nonessentials, reducing educational expenses, increasing school drop outs, remittances from relatives, and reducing the frequency and/or size of meals (LIU/DMFSS 2009). Deressa et al. (2008) identified the use of various crop varieties, tree planting, soil conservation, early and late planting, and irrigation as the main climate adaptation strategies in the Nile Basin of Ethiopia.

\section{Strategy Choice Depends on Wealth Levels}

A household's choice of a particular climate adaptation strategy can be influenced by the resource demands (e.g. labor, other inputs) the strategies pose, as well as the household's access to resources. According to Deressa et al. (2008), higher household wealth (indicated by farm and non-farm income and livestock holding), level of education, access to extension and weather information, diversified agriculture, and social capital increase the likelihood of climate change awareness and adaptation. Whereas the above study indicates that wealth is important for climate awareness and adaptation, the question arises whether there is a potential reverse causation running from adaptation to wealth such that wealth might have actually resulted from adaptation. Since non-farm income is considered an indicator of wealth in the study, there is a question of whether labor income - e.g. through labor migration - is an adaptation strategy itself or an outcome of other adaptation strategies.

\section{Are Climate Change Adaptation Strategies Affected by Gender?}

Deressa et al. (2008) further reports that male-headed households have a higher likelihood of adoption of adaptation strategies, which raises the question of whether climate adaptation strategies are affected by gender. The positive adaptation effect of being maleheaded and larger family sizes are indicators that climate adaptation strategies may be more labor demanding. Moreover, lack of information on climate change impacts and adaptation options, lack of financial resources, and labor and land constraints explain why farmers do not adopt adaptation measures. 


\section{Some Questions Remain Unanswered}

The above study does not address two relevant issues. First, the nexus between the various vulnerability groups and the specific climate adaptation strategy they tend to choose needs to be explored. Second, an important component of factors explaining farmers' choice of adaptation strategies and the degree of adoption of a particular strategy is the cost associated with the particular strategy and the institutional assistance received. Hence, designing a framework for costing and estimating the cost associated with the specific adaptation strategies is relevant in the effort toward addressing climate adaptation issues among the most vulnerable groups.

\section{POLICY FRAMEWORK AND CLIMATE ADAPTATION INITIATIVES IN ETHIOPIA}

\section{Climate Change is Becoming an Integral Component of Government Policy}

Since the effect of climate change is becoming evident, climate change adaptation becomes an integral component of government policy. As an initial step toward addressing climate issues, Ethiopia ratified both the UNFCCC and Kyoto Protocol (NMA 2007). The National Meteorology Agency (NMA) developed the NAPA document for Ethiopia as a component of Ethiopia's commitment to the UNFCCC and Kyoto Protocol to develop and implement climate change adaptation programs. The NAPA aimed at identifying urgent adaptation activities that address current and anticipated adverse effects of climate change and building on synergies with other relevant environmental and development programs (NMA 2007). The NAPA document identified eleven priority areas, one of which is capacity building for climate change adaptation. The CALI project fits into this priority area.

\section{Coordination of Activities is Important}

A recent climate adaptation and mitigation initiative is the National Climate Change Conference organized by the National Climate Change Forum (NCCF and Oxfam America 2009) in Addis Ababa in 2009. Various stakeholders-including government offices, local and international nongovernmental organizations, religious organizations, diplomats, donors, UN offices, the private sector, and academicians-from various institutions participated. The conference demonstrated the common understanding among a wide range of stakeholders that climate change is happening, with extreme weather events affecting mainly agriculture and water supply, and as a major driver of poverty requires urgent action (NCCF and Oxfam America 2009). The conference participants stressed the existing opportunities for responding to climate-related challenges, which at the same time brings about development benefits. It is suggested that efforts toward climate adaptation at all levels need to be coordinated by an umbrella organization, which requires the establishment of a National Climate Change and Development Center at a government level to act as an executive arm of the NCCF. Biodiversity conservation is a potential opportunity for Ethiopia's efforts to enhance climate adaptation and mitigation efforts. Adaptation should also be seen as a means to sustainable development rather than as an end.

Local Institutions are Increasingly

Recognized as Important

In line with this, there is an increasing recognition of the role of local institutions in assisting household efforts to climate adaptation. Institutions can assist households through enhancing sharing of skills and information, providing resources and enhancing organized efforts necessary for climate change awareness and adaptation. Various governmental and nongovernmental stakeholder institutions are currently working on climate-related issues in Ethiopia. These include the Ministry of Agricultural and Rural Development (MoARD) through its Early Warning System Department and Natural Resource Management Department, NMA, NCCF, Environmental Protection Authority (EPA), Oxfam America, World Food Program (WFP), Ethiopian Development Research Institute (EDRI), Ethiopian Economic Association (on the social dimensions of climate change), International Food Policy Research Institute (IFPRI), and Environmental Policy Forum (EPF). MoARD has been contributing to early warning and relief programs as well as initiating and supervising various household and community level climate adaptation practices. To this end, the woreda-level 
agricultural and rural development offices have been playing an active role in many parts of the country.

\section{International Efforts Support Local Institutions}

Moreover, various World Bank and other donor-funded projects including the Productive Safety Net Program (PSNP), Pastoral Community Development Program (PCDP), and irrigation and drainage projects are under way to assist household and community-level adaptation to climate hazards. Their activities include engagement in various watershed management practices, as well as infrastructure development practices through cash-forwork arrangements for the poor. Such activities are coordinated through the woreda-level agricultural and rural development offices. EDRI, IFPRI, NMA, EPF, EPA, and FSS mainly focus on conducting research and knowledge sharing for better understanding of climate-related hazards, vulnerabilities, and adaptation strategies, whereas the rest are more policy and intervention-oriented.

\section{INSTITUTIONAL LANDSCAPE AND STAKEHOLDER MAPPING}

Various stakeholders and institutions have been engaged in climate adaptation and mitigation efforts at various levels. The following are the prominent ones:

- Ministry of Agriculture and Rural Development (MoARD). MoARD has been involved in various early warning, emergency relief, and rehabilitation activities. This has been facilitated through the woreda-level agricultural and rural development offices, which are in close contact with the rural households and communities. The donor-funded productive safety net and community development activities, which aim at making resource transfers more predictable and productive by moving away from the relief support orientation, are channeled through MoARD. The recently formed National Climate Change Forum (NCCF) is chaired by the state minister of MoARD.

- National Meteorological Agency. The NMA formulated the National Adaptation Program of Action (NAPA) report. Through a number of workshops at the national and regional levels, a long list of adaptation options has been proposed. These adaptation options include early warning systems, water irrigation and storage facilities, capacity building, and water harvesting. The agency provides vital weather- and climate-related data, as well as longterm trends generated from its numerous meteorological stations throughout the country.

- Environmental Protection Authority (EPA). The authority has been involved in developing strategies for various environmental protection activities in which climate is only a small component. With a recent recognition of the need to coordinate climate change efforts, the Authority is taking a more active role in coordinating these efforts. The authority has recently been mandated to develop national adaptation and mitigation strategies.

- National Climate Change Forum. In January 2009, a national climate change conference was organized by Oxfam America in order to bring together the different players working on climate change.

- Livelihood Information Unit / Disaster Prevention and Preparedness E Prevention Agency. The LIU and DPPC have been collecting information on the vulnerable areas and the different hazards Ethiopia is facing. Their information and databases feed into the actions taken by MoARD to provide food aid to those households facing severe food shortages. It also feeds into the activities of the WFP.

- Productive Safety Net Program (PSNP). The PSNP is a large, multi-donor program embedded within MoARD. The project provides community development services and food aid to a large number of woredas in Ethiopia. In these villages, the communities indicate which services they would like to have developed. The people assist with the realization of these services in exchange for food or cash payments. The program is a long-term development project, and consists at the moment of about 30,000 village projects. One of the objectives is to develop rural areas and to help the most vulnerable households with food aid.

- Pastoral Communities Development Program (PCDP). This long-term poverty alleviation program takes place in the pastoral areas in the east, far south, and far west. It has similarities with the PSNP project in that it supports community development projects in 
exchange for cash or food. The project also provides social benefits to the communities through public service delivery.

- Irrigation and Drainage project. The Irrigation and Drainage project has four components: (1) development of 20,000 hectares of irrigated cropland; (2) agricultural development and marketing; (3) irrigation management through water user associations; and (4) project management capacity building in the different administrative levels. The project focuses on northern Ethiopia, especially the Nile Basin.

Next to the irrigation activities, it is also involved in improving drainage systems to reduce the probability of flooding.

The last three programs receive World Bank assistance and funding and are part of a larger World Bank initiative related to climate-related and livelihood issues in the various parts of Ethiopia.

\section{COSTING ADAPTATION TO CLIMATE CHANGE}

\section{Complications to Cost Estimation}

The costing framework used in this study is presented in Appendix 1. Three complications in the estimation of the cost of climate adaptation are clear from the outset. First, it is difficult to disentangle the cost incurred for the adaptation strategies per se and those incurred for normal activities; for example, the labor spent on climate adaptation strategies and other daily farming activities. The problem is further complicated where labor is found to be a key input for many of the adaptation strategies in a setting where the daily working time for normal and adaptive farming activities is flexible and increasingly becoming driven by weather variability. Second, rural households do not keep records of how much labor, material, and cash they invested when they adopted a strategy due to lack of information and education. As a result, this study is forced to rely on the households' recollections for estimating adaptation costs. Obviously, the reliability of adaptation cost estimates based on households' recollections decreases with the increase in the number of years since the strategies are first adopted. Third, the current household respondents may have little or no information about the household adaptation activities and inputs used during the first year of adopting the strategy and hence are unable to give a reasonable estimate of the cost incurred for the specific strategy.

The Costing Estimates are a First Step and Should be Interpreted with Care

If reasonable cost estimates are to be obtained for rural climate adaptation efforts, it may be an option to back up the actual and less precise cost estimates with estimates from the valuation techniques for non-market goods. As latter are not covered in this study, further investigation is needed to obtain a more accurate estimation of adaptation costs. The adaptation cost estimates obtained through household recollection could only be taken as a good indicator of the degree of importance of the various inputs for a given adaptation strategy. This approach is even more important where there is a need to differentiate between the costs of the adaptation strategies farmers prefer to practice in the future (given the necessary inputs and services) and the costs of continuing the adaptation strategies that households are currently practicing. For instance, focus group discussions and stakeholder interviews show that quite a number of the highland farmers are interested in using water harvesting wells, but are unable to do this due to the lack of necessary inputs, which are inadequately delivered through the local agricultural and rural development office. Thus the adaptation costs estimated through applying household recollections only provide the costs incurred by the strategies the households have adopted given their current constraints (e.g. market, services, and information), but not what the households prefer to practice in the future if the constraints were eased. Hence, caution needs to be taken in the interpretation of the estimates and in making recommendations and extrapolations based on such estimates.

Apart from the variation in climate-related hazards and hence adaptation responses across regions, households' access to inputs, services. and information varies across regions due to infrastructural and institutional factors. This is particularly the case in many parts of the country where institutions play important roles in initiating some of the adaptation strategies. As a result, adaptation strategies and associated costs vary across regions. 


\section{DATA COLLECTION AND STUDY AREA CHARACTERISTICS}

In this chapter, we first briefly discuss the methodological approach of the study. A detailed description and background of the methodology adopted is given in the CALI Inception Report (Ruijs et al. 2009). In chapter 4, we investigate the extent to which adoption of adaptation strategies depends on the level of vulnerability of the households. In this chapter, we explain the definition of vulnerability adopted in this report and provide a description of the study area, as well as some general characteristics of the woreda and the households in the study villages.

\section{COSTING METHODOLOGY}

As discussed in chapter 1, the objective of the CALI project is to (1) identify the costs of adaptation through local institutions; and (2) investigate which institutions support households in adapting to climate variability, as well as the efforts and costs needed to realize the adaptation options and how they facilitate adaptation to climate variability. The focus of the project is on the adaptation options households currently apply or have adopted in the past in order to reduce hazards from climate variability. These hazards-which include the risk of a delayed start of the rainy season, prolonged periods of drought, flood risk, and temperature changes-are expected to become more severe and occur more frequently in the future.

\section{Step 1: Distinguish Four Categories of Adaptation Strategies}

The first step in the costing methodology is to learn which adaptation strategies are applied most frequently by rural households. We identified four types of strategies:

- Agricultural techniques to adapt to changes in rainfall regime, including seed selection, adapting planting dates, adapting fertilizer application, adapting feed techniques, improving food storage facilities, and changing pastoral systems.

- Water management techniques to adapt to changes in rainfall regime, including use of water harvesting techniques, rehabilitating terraces, improving irrigation techniques, and improving watering sites in pastoral areas.

- Techniques to diversify income sources, including temporary or permanent migration, use of alternative sources for fuelwood, home-garden agriculture, and changing the consumption pattern or drawing down livestock.

- Communal pooling techniques, including reforestation, rangeland preservation, communal food storage facilities, or local water management rules.

\section{Step 2: Disentangle the Different}

\section{Cost Elements}

Second, in the cost framework for the different adaptation options, we identify the costs needed to implement the options, including (a) monetary costs that have to be made by the household; (b) household labor requirements; 
(c) household training requirements; (d) required help from the community; (e) required help from institutions like governmental extension services or NGOs; and (f) monetary needs by assisting institutions for implementation.

Using a range of interview techniques (see next section), the study assessed a range of costs households have made in the past to adapt their strategies to (climate-related) hazards. For the institutions, we assessed which institutions contact rural households most frequently and to what extent they assist households to reduce their hazards. Next, we evaluated what type of resources these institutions need in order to perform their tasks. These estimates serve as a basis for judging the investments or assistance needed from the government or donors to promote particular adaptation interventions. It will show which entry points can be used in order to promote particular strategies.

The costing framework is shown in Appendix 1. In this appendix, the envisaged cost elements of the different adaptation options are given. The organization of the household questionnaire and the focus group discussion is based on this framework.

\section{DATA COLLECTION}

\section{Criteria for the Selection of Villages}

In the six study villages, the research approach included conducting household questionnaires, interviewing institutional stakeholders, and organizing a focus group discussion. The village surveys were conducted in six villages (kebelle). They were selected on the basis of the following criteria:

- Select a village with mainly livestock and a village with mainly agricultural farming systems.

- For the agricultural farming systems, select a village having different cropping systems.

- Select a village facing different climate hazards.

- Select a village with sufficient seasonal variation in rainfall (for example, with and without the belg rains.

- Select a village from different agroecological zones (high-, midlands and lowlands).

- Select a village from different woredas.

- Select a village covered by any of the World Bank's Productive Safety Net Programs.

For practical reasons, it was decided to choose all six villages from two woredas in order to save travel time.

On the basis of these criteria, four villages were chosen from Kalu woreda, which covers the highlands and midlands and in which the PSNP project is active. Second, two villages were chosen from Fentale woreda, which is a lowland pastoralist area in the eastern part of Ethiopia and in which the PCDP program is present. The final selection of villages from these woredas was done together with the woreda administrations and the PSNP and PCDP programs. The villages selected are shown in Table 1.

The villages were selected in such a way that they represent as wide a variety of hazards, farming systems, and

TABLE 1. THE VILLAGES SELECTED FOR THE VILLAGE SURVEYS

\begin{tabular}{|c|c|c|c|c|c|c|}
\hline & Village & Woreda & Livelihood zone $^{1}$ & Altitude & Population size ${ }^{1}$ & Distance to nearest town ${ }^{2}$ \\
\hline 1 & Haro Kersa & Fentale & $A$ & $800 \mathrm{~m}$ & 904 & $30-35 \mathrm{~km}$ \\
\hline 2 & Gola & Fentale & $A$ & $800 \mathrm{~m}$ & 2,213 & $15 \mathrm{~km}$ \\
\hline 3 & Choresa & Kalu & B & $1,450-2,000 \mathrm{~m}$ & 5,829 & $10 \mathrm{~km}$ \\
\hline 4 & Birko Debele & Kalu & $\mathrm{C}$ & $1,450-2,000 \mathrm{~m}$ & 8,571 & $20 \mathrm{~km}$ \\
\hline 5 & Keteteya & Kalu & D & $2,000-2,600 \mathrm{~m}$ & 9,338 & $45 \mathrm{~km}$ \\
\hline 6 & Hardibo & Kalu & $\mathrm{D}$ & $2,000-2,600 \mathrm{~m}$ & 7,900 & $35 \mathrm{~km}$ \\
\hline
\end{tabular}

Notes: (1) A = Minjar \& Kereyu Pastoral zone, B = Cheffa valley zone, C = South Wollo Belg zone, D = South Wollo \& Oromia eastern lowland \& cattle zone. Source: LIU/DMFSS (2008). (2) The nearest town for Haro Kersa and Gola is Matara. Distance to Addis Ababa is about $200 \mathrm{~km}$. The nearest town for the village in Kalu is Kombolche. Choresa is situated next to the main road to Kombolche. Hardibo is difficult to reach as it only has a badly maintained dirt road going to the village. 
agroecological characteristics as possible. It is noted, however, that due to the size of the country, the wide variety of farming systems, agroecological and climatological zones present in the country and even the large differences within regions, the sample cannot serve as a representative sample for which conclusions can be drawn for all household types and all regions in Ethiopia. For that, a much larger number of villages should be studied. As a consequence, results should be interpreted only for the study area and generalizations should be substantiated with care. Nevertheless, the results show interesting features that may apply for other regions as well or that are useful for asking the right research questions for other regions.

\section{Organization of the Fieldwork}

The village studies took place in June 2009, before the start of the rainy season. All interview activities were conducted simultaneously within each village. In Appendix 1, the questionnaires and organization of the focus group discussions are presented.

For the household interviews, within each village 50 randomly selected households were selected jointly with woreda authorities. The questionnaire contained three main categories of questions. The first category consisted of general questions on household size, level of education, main activities, crops cultivated, livestock raised, and assets owned. These questions were used for analyzing whether different clusters of households can be distinguished. The second category consisted of questions related to the climate and non-climate-related hazards households face and their vulnerability with respect to food shortages. The third category of questions related to the costing framework. Households were asked which adaptation strategies they had adopted, what investments had been made for this, which hazards had been reduced (if any), which institutions had been helpful, and what type of assistance they received from these institutions.

\section{VULNERABILITY}

This report investigated the extent to which households have different vulnerability profiles. Next, it assessed whether the adoption of adaptation strategies, the cost of adaptation strategies, and the institutions that assist the households differed among the different vulnerability classes. Several definitions of vulnerability exist; depending on the scale and focus of the system analyzed, different elements are part of the definition of vulnerability.

Vulnerability Depends on Exposure, Sensitivity and Coping Capacity

In general, vulnerability refers to the potential of a system to be harmed by an external stress (Kok and Jäger 2009) or to the capacity of people and communities to cope with threats to which they are exposed to (UNEP 2002). Most frameworks for vulnerability analysis distinguish between three components of vulnerability: exposure, sensitivity, and coping capacity (resilience). Exposure refers to the external stress to people or communities, which is caused by, for example, changes in rainfall and temperature patterns due to climate change. Sensitivity refers to the extent to which people or communities are susceptible to exposure to the stress. For example, farmers using irrigation are less susceptible to variations in rainfall than farmers relying on rainfed farming systems. Coping capacity refers to the ability to cope with the external stress. Factors affecting coping capacity are, for example, level of education, access to other resources, and availability of insurance. In general, high levels of exposure, high levels of sensitivity, and low levels of coping capacity result in high levels of vulnerability. High exposure, however, does not necessarily result in high vulnerability if, for example, coping capacity is high.

\section{Vulnerability Depends on Many Factors}

Sensitivity and coping capacity depend on many different factors. A number of factors affecting vulnerability are financial status, geographical location, ethnicity, gender, level of education, employment, and group affiliation. Financial status is an important factor, but it depends in itself on a number of factors. For example, farmers cultivating a relatively large area can still be in a very vulnerable situation if they only cultivate one crop and if they have no other income sources to fall back to. Even households receiving income from several activities can still be in a vulnerable situation if these activities all are correlated to the same stressor; for example, if they are all highly dependent on rainfall. 
Important factors affecting the financial status of rural households are:

- the amount of land cultivated

- agroecological and soil quality conditions

- types of crops grown and marketed (food vs. cash crops)

- amount of livestock owned

- amount of assets owned

- income earned from other activities (e.g. off-farm activities or commerce)

- remittances received from migrated household or family members.

\section{Consider Two Types of Vulnerability Analysis}

The study analyzed two types of vulnerability, depending on different clustering principles. First, it analyzed the extent to which the different villages are vulnerable to climate change. All households in a village face more or less the same exposure to climate change. The different villages, however, face different exposures.

Temperature, rainfall patterns, and agroecological characteristics-especially soil quality and level of soil erosion-differ among villages, but are more or less similar within a village, depending especially on altitude. The first vulnerability analysis assessed the extent to which exposure and coping capacity differ among villages. Sensitivity hardly differs among the different villages; almost all households have land cultivation or livestock farming as their main activity, so they are almost equally susceptible to exposure to climate variability. In this analysis, exposure depends on the hazards of climate variability — such as a late start to the rainy season, drought, floods, or heat waves - and soil characteristics such as soil quality and soil erosion. Coping capacity depends on (a) the amount of land cultivated, (b) amount of livestock owned, (c) migration rate, (d) assets owned, (e) gender of household head, (f) levels of education, and $(\mathrm{g})$ dependency ratio.

Factors (a) to (d) indicate the financial status and diversity of the income received. The larger each income source or the larger their income diversity, the higher the coping capacity. Factors (e) to (g) also are elements of coping capacity of the households. Lower education, more young children, and less adult males in the households reduce the ability to cope with changing external circumstances.
The second vulnerability analysis focuses on the elements affecting coping capacity. Results of the cluster analyses show that if agroecological and climatological conditions are included as variables in the cluster analysis, six clusters are determined replicating almost entirely the six study villages. So, it can be concluded that exposure variables are the major determinants of vulnerability classes. If exposure variables are excluded from the analysis and only the seven coping capacity variables mentioned above are considered, classes of households are distinguished, each having similar levels of coping capacity.

\section{DESCRIPTION OF STUDY AREA AND STUDY VILLAGES}

In this section, a description is given of the general characteristics of the two woreda and six villages in which the village surveys were conducted. This woreda description is based on information from the Livelihood Implementation Unit from the Ministry of Agriculture (LIU/DMFSS, 2008). The village description is based on the survey data. An analysis of the differences between the village and the effects on their levels of vulnerability is presented in chapter 4 .

\section{FENTALE WOREDA-LOWLAND VILLAGE}

Fentale woreda is predominantly pastoralist; crop production is only a recent phenomenon. A number of households from the village of Gola are participating in the Pastoral Community Development Project. Haro Kersa is not involved yet in any of the large scale development programs of the Ethiopian government.

The livelihood zone in which the survey villages are located (Figure 6), is characterized by livestock and crop production. Sheep, goats, cattle, and camels are the livestock found in the zone. There are two rainy seasons; (1) ganna, the long rainy season during July to August; and (2) arfasa, the short rainy season from March to April. Children keep goats, women collect firewood, and men make and sell charcoal. Whereas crops are traded within the zone, livestock is mainly traded outside the zone. Wealth is partly determined by the number of livestock owned. Drought, livestock diseases, and conflicts with neighbors are the main hazards affecting the zone. Shortages and the erratic distribution of rainfall cause 


\section{FIGURE 6. MKP LIVELIHOOD ZONE BOUNDARY OF FENTALE WOREDA}

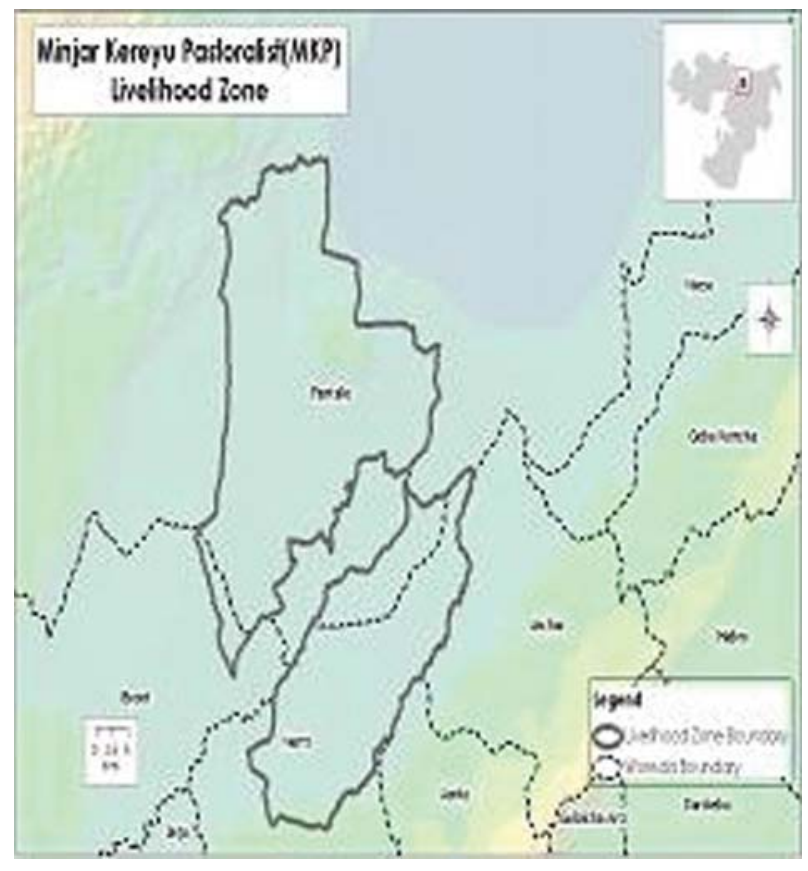

Source: LIU/DMFSS, 2008.

shortages of water and pasture for animals and stunting of crops.

\section{The Pastoral Village of Haro Kersa Faces Severe Periods of Drought}

The two lowland villages-Haro Kersa and Gola—show important differences that affect their vulnerability. Haro Kersa is a small village (see Table 1) characterized by pastoralists herding cattle. They regularly migrate to areas with better pasture land, and the distance of the migration is increasing. Haro Kersa is located in a remote area with bad road conditions, so the village is isolated. A substantial part of the households do not cultivate any land. Crops grown are mainly maize, cultivated for their own consumption. Beans and sesame also are grown; part of these crops are sold. Household size is relatively large because of polygamy — on average, eight members with a maximum of eighteen members in one family.

Furthermore, educational levels are low because children have to help with herding the cattle. Low rainfall levels and prolonged periods of drought are the major hazards for households in Haro Kersa. Droughts in combination with high temperature extremes make the cattle sensitive to diseases, thus endangering livelihoods.

\section{Gola has Recently Transformed to Agropastoralism but Faces Flood Hazards}

The village of Gola is about $15 \mathrm{~km}$ from Matara town, the woreda capital, and is less isolated than Haro Kersa. Recently a number of households shifted from pastoralism to sedentary agriculture and livestock farming in order to become less dependent on one source of income. Livestock ownership is substantially lower than in Haro Kersa. Herd composition is different, with a larger focus on small ruminants and less on cattle. Crops grown are largely maize and some vegetables. A striking feature is the young population, with every couple having to take care of on average four children. Next to the drought hazard, Gola also faces flood risks. Rainfall from the highlands reaches the area but cannot move along due to the dikes build to protect a sugar estate near Gola.

Both lowland villages are in a rather vulnerable situation, with almost all households reporting food shortages in at least some periods of the year, especially in the period January to May.

\section{KALU WOREDA-MIDLAND VILLAGE}

Kalu woreda is located in the Amhara regional state. In general, midland areas have more fertile land and lower population densities than the highlands. From an agricultural perspective, they are in a more favorable situation. Rainfall variability between midlands and highlands are similar even though the second, shorter rainy season is becoming more irregular. especially in the midlands. This regularly causes food shortages during some periods of the year. In all villages in the sample, some households participated in the Productive Safety Net Program (PSNP).

The livelihood zone in which Choresa is located (Figure 7) has a predominantly kola agroecology with a relatively reliable rainfall pattern that feeds several major rivers. Rainfed crop production-mainly during the kremt season, June to mid-September-and livestock are 


\section{FIGURE 7. CHV LIVELIHOOD ZONE BOUNDARY OF KALU WOREDA}

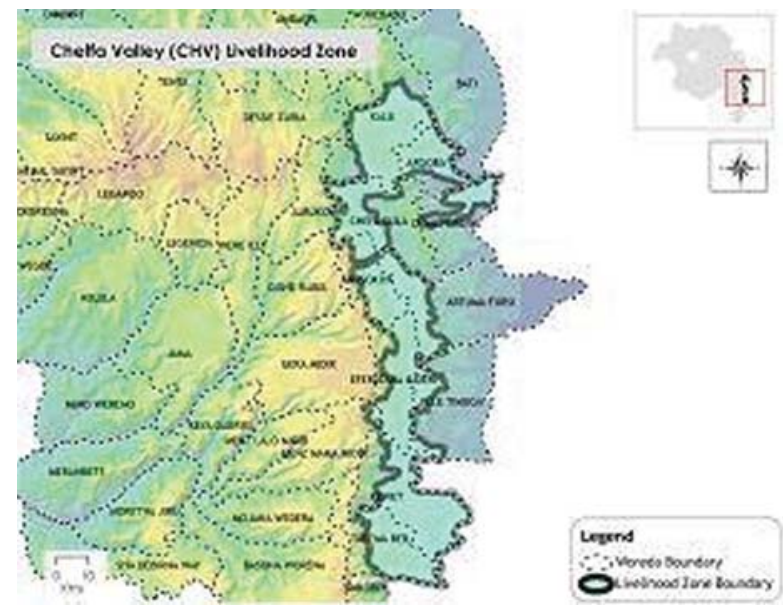

Source: LIU/DMFSS, 2008.

the main economic activities. The main food crops in the zone are maize and teff, while the main cash crops are masho (mung bean), tobacco, fruits, and vegetables. Plowing is done by men, while most weeding and part of harvesting is done by women. Cattle and goats constitute the main livestock reared in the zone. The size of arable land and oxen owned are the main wealth indicators.

The livelihood zone in which Birko Debele is situated is highly degraded (Figure 8). Crop production is the main activity. The zone is characterized by a bimodal rainfall (short belg and longer kremt rains) such that the belg harvest is the most important of the two harvest periods. Barley, faba beans, oats, and lentils are the main crops. Sheep, cattle, and equines are the major livestock for which men and children are responsible. Possession of livestock, cultivated land, and eucalyptus trees are important indicators of wealth in the livelihood zone. Important hazards in the zone include erratic belg rains leading to chronic food insecurity, hailstorms, shortage of rain, and crop and livestock diseases. Coping strategies include off-farm labor, sales of livestock and wood, obtaining loans from the better-off, and shifting consumption patterns. Due to the sometimes severe levels of soil erosion and low land availability, this zone is in a vulnerable situation.
FIGURE 8. SWB LIVELIHOOD ZONE BOUNDARY OF KALU WOREDA

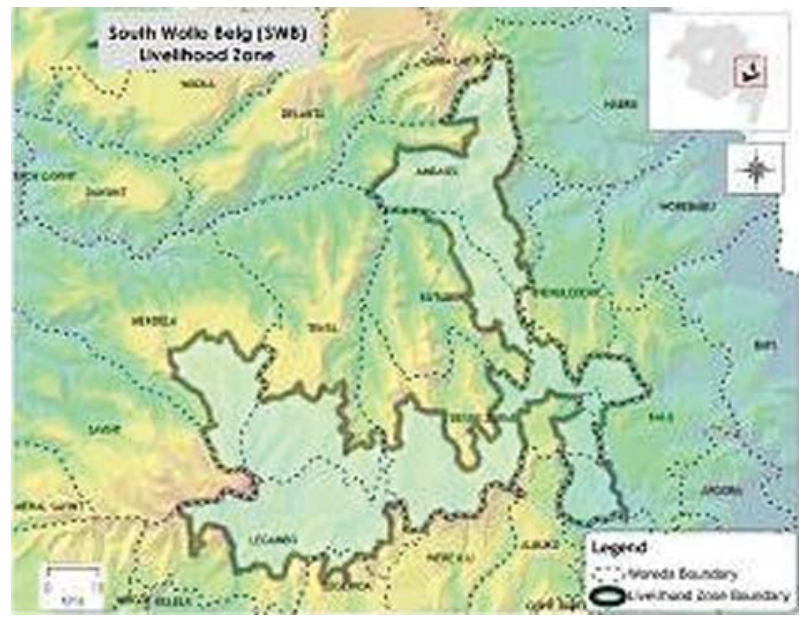

Source: LIU/DMFSS, 2008.

The Midland Villages Face Droughts but Also High Food Prices and Diseases

The villages of Choresa and Birko Debele have similar demographic and household characteristics in terms of household size (six household members), average age (23-24 years), and levels of education. Choresa is about $10 \mathrm{~km}$ from Kombolche, the main town in the woreda, and is easy to reach since it is next to the main road leading to Kombolche. In both villages, agriculture is the major activity. Crops grown include cereals (teff, sorghum, and wheat), cassava, and some onions and coffee. The village contains a relatively large number of fruit and eucalyptus trees. Only small numbers of livestock are owned; most households own traction livestock and poultry. Asset ownership is relatively large, especially in Choresa. The major hazard in the zone is drought. High food prices and human and crop diseases are also perceived as important hazards. These hazards cause food insecurity for a large part of the population, especially in July and August.

\section{KALU WOREDA-HIGHLAND VILLAGE}

The livelihood zone in Kalu woreda in which the highland villages are located (Figure 9) is characterized by rainfed crop production in the main rainy season of 


\section{FIGURE 9. SWS LIVELIHOOD ZONE BOUNDARY OF KALU WOREDA}

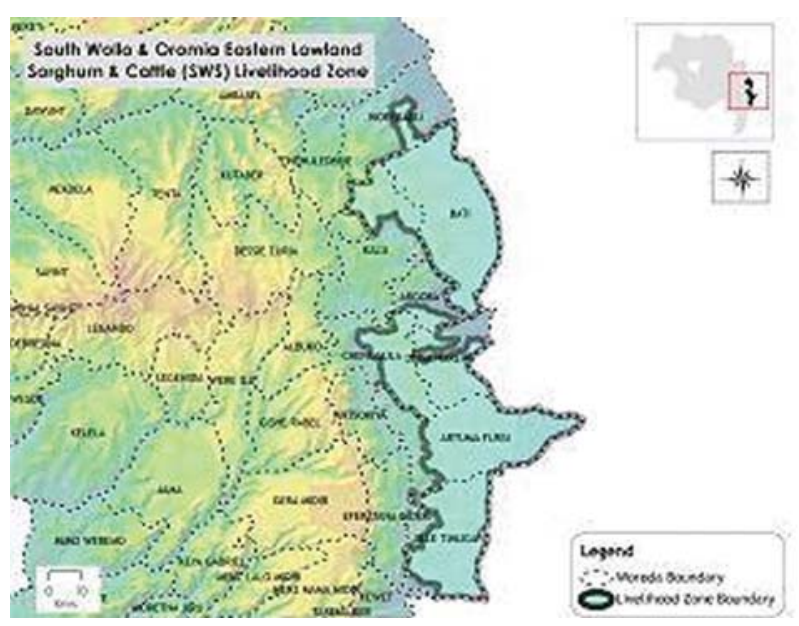

Source: LIU/DMFSS, 2008.

kremt (July-September). The area receives the lowest average annual rainfall $(726 \mathrm{~mm})$ of the livelihood zones in the Amhara region. Plowing is done by men, while weeding and harvesting are done both by men and women. The major livestock in the area include cattle, goats, and sheep. Men are responsible for looking after the cattle while, women take care of small livestock and children help with both. Livestock and cultivated landholdings are indicators of wealth in the zone.

Next to Climate Variability, the Highland Villages Face Soil Erosion Problems

The villages of Keteteya and Hardibo are both situated relatively far from the nearest town of Kombolche (about $40 \mathrm{~km}$ ). Hardibo is especially difficult to reach as it is only accessible through a bad dirt road. Both villages have similar demographic characteristics in terms of household size (five household members), average age (25-26 years), and education. Acreage cultivated is substantially lower than in the midland villages. Crops grown are especially sorghum and qat (10-20 percent of the cultivated land). Most households own eucalyptus and cypress trees. Livestock and asset ownership is similar to the midland villages.

The major hazard is less rainfall and prolonged periods of drought. Increasing food prices, decreasing soil fertility, and crop and human diseases are perceived as important hazards. These hazards cause chronic food insecurity for the majority of the households, especially in the months of July and August. 


\section{VULNERABILITY PROFILES AND ADAPTATION PRACTICES}

This chapter discusses the main results and the key messages from the data analysis. A detailed description of the data analysis is presented in Appendix A2.

As explained in chapter 2, The research distinguished clusters of households, each of which had similar vulnerability characteristics. This section describes which characteristics explain adoption of particular adaptation strategies. Do different types of households adopt different adaptation strategies and why? Do the costs of adopting a strategy differ between groups of households? Are strategies adopted for different reasons? Next, the analysis considers whether particular institutions focus on particular types of households or facilitate particular types of adaptation strategies, as well as which resources institutions need for properly targeting their work. These analyses were done both for the clusters and for the villages. By focusing on clusters, we can assess whether particular household types adopt particular types of strategies or need particular types of assistance. By focusing on the villages, we can draw conclusions about whether particular villages need more or different types of assistance than others. Both conclusions are relevant for targeting assistance.

\section{HOUSEHOLD VULNERABILITY}

\section{Village Vulnerability Profiles}

Appendix 2 shows results from the household interviews in detail. The main findings from this analysis are discussed below. Differences in wealth, activities, and vulnerability among the villages are large. Differences are especially caused by altitude (rainfall levels, soil characteristics and temperature depend on altitude), land availability, and economic and household characteristics (dependency ratio, education).

Households in Haro Kersa own many Cattle but are in a Vulnerable Situation

Looking at the six villages, the lowland village of Haro Kersa can be characterized as a pastoralist village with households owning large herds of cattle, cultivating small plots of land, having large households, and possessing low levels of education and low asset ownership (see Appendix A2.A). Due to their cattle ownership, they can be characterized as wealthy. On the other hand, they are also very vulnerable, as their wealth and daily income depends on only a single source, which is highly dependent on water availability. Their low levels of education limits their scope for organizing improvement themselves.

Gola is in a Vulnerable Situation, but this is Expected to Change in the Future

The village of Gola is in a transformation process, diversifying their activities from a pastoralist to mixed farming-livestock system. This process will result in a further diversification of their income, which will reduce their vulnerability. This, however, will take time. Currently, their high dependency ratio and the time needed to transform their farming system puts them in a vulnerable position, because yields and farming technologies are not optimal yet. The considerable reduction of livestock in the last twelve months (TLU decreased 
21 percent; see Table A.5) ${ }^{1}$ shows that this village is either in a vulnerable situation or used considerable resources for the transformation process.

\section{Midland and Highland Villages have Lower Vulnerability than Lowland Villages}

The four villages in the midlands and highlandsChoresa, Birko Debele, Keteteya, and Hardibo-have roughly similar demographic characteristics. Vulnerability in Birko Debele is partly caused by their high share (20 percent) of female-headed households, which often is an indication of higher vulnerability. This high share may indicate that a substantial share of the male household heads have migrated permanently to urban areas, leaving their families behind, have divorced their wives, or are deceased. Vulnerability in the highlands is affected by weak soil fertility and high levels of soil erosion. This is usually somewhat less of a problem in the midlands. Furthermore, acreage cultivated is substantially lower in the highlands than in the midlands. This is partly compensated by the more secure second rainfall period in the highlands.

\section{Geographical and Wealth Differences among the Villages are Substantial}

The results also show some interesting characteristics and differences among the villages.

- Girls and boys almost have the same number of years of education. In some villages, girls visit school longer than boys. For the adults, there is still a gender difference for years of education in favor of males (see Table A.2). This may be a sign that gender differences in education are declining.

- The role of women differs among the villages. Agriculture, livestock raising, and off-farm labor are in most cases executed by both men and women. Trade and commerce is more often an activity for men. For the two lowland villages, but especially for Haro Kersa, the role of women in income generating activities is much smaller (see Table A.3).

- Compared to the lowland villages, the midland and highland villages own more assets. Differences between households are, however, large (see Table A.6).

$1 \mathrm{TLU}=$ tropical livestock units; see Table A.5 for the conversion factors used.
- In only 6 percent of the households, members had currently temporarily migrated. This figure was much higher for the midland villages (16 percent in Choresa) and much lower for the lowland villages (no temporary migrants in Haro Kersa; see Table A.2). Remittances from migrated household members usually are an important source of income for many households.

\section{Vulnerability Profiles Differ Substantially among the Six Villages}

- Figure 10 summarizes in a spider diagram the main vulnerability characteristics for the different villages. ${ }^{2}$ The results are presented on a 0 to 1 scale, in which a score of 1 is the least vulnerable. The smaller the surface of the spider web, the more vulnerable the village. Illustrating vulnerability by using a spider web diagram clearly shows the multifaceted character of vulnerability. Considering a number of characteristics simultaneously provides an adequate view of vulnerability.

The following conclusions can be drawn from the spider diagrams.

- Both lowland villages are in a vulnerable situation. Their exposure to climate variability is substantial. Soil quality is low and soil erosion severe. Haro Kersa is facing severe drought risks, whereas Gola faces flood risks. Their coping capacity is low as they depend on a single source of income (cattle raising). Furthermore, they have low educational and asset levels.

- The highland villages are also in a vulnerable situation. Exposure is substantial because of soil erosion. Their coping capacity is limited due to low levels of arable land availability, migration rates, and livestock ownership. Cash earnings from the sales of cash crops (esp. qat) makes them somewhat less vulnerable.

- The midland village of Choresa seems to be the least vulnerable. Their exposure is especially related to irregular belg rains. Their relatively higher coping capacity is due to higher levels of land ownership, education, and migration. Birko Debele is in a

2 Chapter 2 explains which characteristics are considered in this vulnerability analysis. All characteristics except for climate hazard score and agroecological score are based on the village data. Climate hazards score and agroecological score are based on secondary information. 
FIGURE 10. SPIDER DIAGRAMS OF THE VILLAGE SCORES ON THE VULNERABILTY CHARACTERISTICS

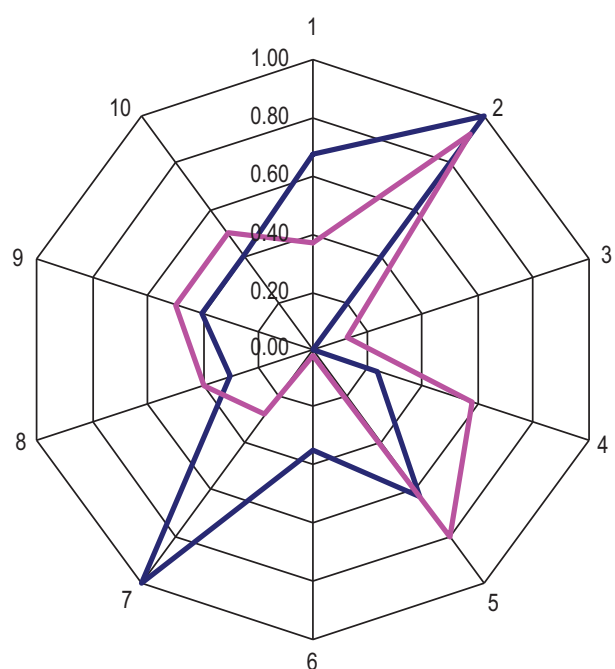

Haro Kersa Gola

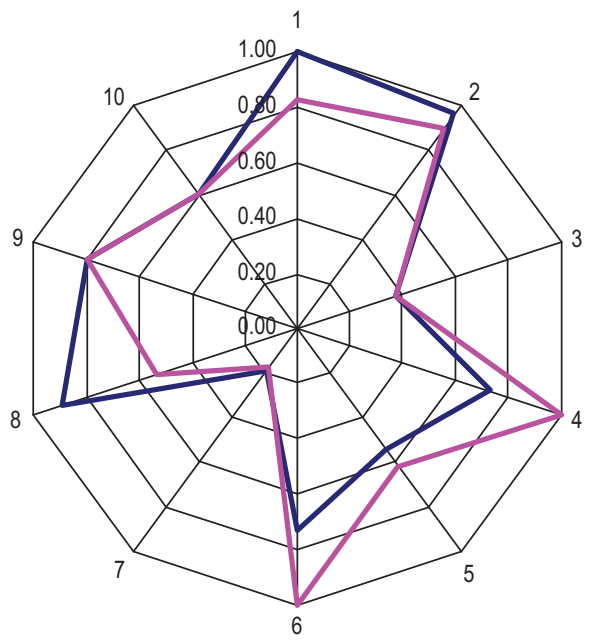

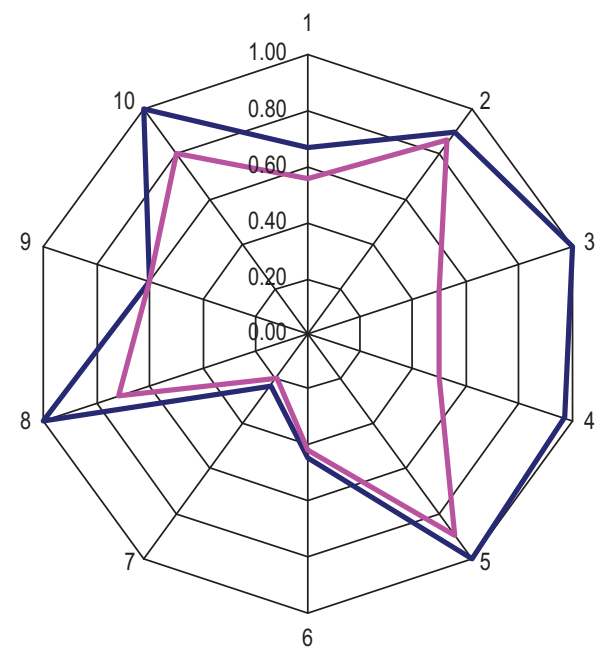

Choresa BirkoDebele

1. reverse of dependency ratio

2. male headed households

3. percentage of households from whom members migrated

4. average years of education

5. average acreage per household

6. Acreage cash and oil crops and trees

7. TLU

8. Mean asset score

9. Mean climate hazard score

10. Mean agro-ecological score more difficult position than Choresa as it has a lower migration rate, lower education rate, and less livestock. Both villages in the midland area have limited cash crop production, which limits their cash earnings.

On the basis of this analysis, it is not possible to conclude that a particular village is or is not vulnerable. For such a conclusion, other variables should be included as well and threshold levels should be given above which households no longer belong to a vulnerable group or below which they can be classified as being vulnerable.

Vulnerability Levels are Confirmed by the Length of the Hunger Period

The vulnerability of the lowland villages is confirmed by the length of the hunger period. Table 2 shows that most 
TABLE 2. OVERVIEW OF MONTHS IN WHICH HOUSEHOLDS (\%) FACE A FOOD SHORTAGE

\begin{tabular}{|c|c|c|c|c|c|c|c|c|c|c|c|c|c|c|}
\hline & Village & $\begin{array}{l}\text { No. Hh short } \\
\text { of food }\end{array}$ & May & June & July & Aug & Sept & Oct & Nov & Dec & Jan & $\mathrm{Feb}$ & Mar & April \\
\hline 1 & Haro Kersa & 49 & 88 & 41 & 4 & 0 & 2 & 2 & 2 & 35 & 90 & 61 & 45 & 51 \\
\hline 2 & Gola & 43 & 49 & 42 & 37 & 35 & 37 & 26 & 2 & 5 & 14 & 7 & 21 & 47 \\
\hline 3 & Choresa & 47 & 11 & 40 & 87 & 94 & 83 & 19 & 4 & 2 & 2 & 0 & 0 & 0 \\
\hline 4 & BirkoDebele & 37 & 14 & 46 & 92 & 86 & 68 & 27 & 0 & 0 & 0 & 0 & 0 & 0 \\
\hline 5 & Keteteya & 36 & 28 & 31 & 86 & 86 & 44 & 8 & 3 & 3 & 3 & 3 & 0 & 0 \\
\hline \multirow[t]{2}{*}{6} & Hardibo & 42 & 60 & 21 & 88 & 88 & 36 & 0 & 2 & 0 & 0 & 0 & 0 & 0 \\
\hline & Total & 254 & 43 & 37 & 63 & 63 & 44 & 13 & 2 & 8 & 20 & 13 & 12 & 18 \\
\hline
\end{tabular}

households face food shortages at least during some months. The lowland villages of Haro Kersa and Gola face food shortages during more months than the other villages. July through September is the most difficult period for the midland and highland villages. The lowland villages face the largest problems from January through May.

\section{Drought is the Major Hazard for Most Farmers}

Looking at the hazards households face, it is clear that reduced rainfall levels and prolonged periods of drought are the major hazards for all villages, except in Gola, where flood risk is the major threat. During the focus group discussion, several participants indicated that the quantity and periodicity of rainfall have changed over the past decades. The situation seems to vary between the highland, midland, and lowland areas. The highland area has two rainy seasons and therefore two production seasons: (a) the belg rains, or the short rainy season from January to June; and (b) the kiremt rains, or the long rainy season from July to September. This puts them in a better position than most of the midland and lowland areas. The belg rains, however, are almost disappearing from the highlands, especially during the past five years. One highlander expressed this trend as follows:

"before, we used to produce twice during the year but these days we are not seeing belg rains regularly; and the quantity of kiremt rains that we are getting in the past five years does not even amount to the belg rains that we used to get like ten years ago."

Farmers from the midland and lowland areas indicate that they are affected by lower rainfall levels and more fluctuations in the onset of rainy season. In all areas, the start and finish of the rainy season have become more irregular. The delayed start of the rains during the sowing period and the interruption of rains during the flowering season cause losses of labor, seed, and harvest. In the lowland pastoral areas, declining and variable rainfall levels also result in water shortages for the livestock and therefore increased incidence of animal diseases and deaths.

\section{High Temperatures Affect Water Availability and Labor Productivity}

Next to diminishing rainfall, rising temperatures also affect farming practices and yields. One elderly farmer and a mosque leader in Choresa village expressed the recent rise in temperature as follows:

"before, like 10 years ago, the farmer plowing his field and his plow oxen as well as those livestock feeding on the pasture, used to start seeking shade at around noon.

These days they do it around 10:00 AM in the morning."

In a focus group discussion in Hardibo, farmers made the link between rainfall shortages, rising temperatures and crop pests as follows:

"the rising temperatures combined with the inadequate rain is only good for the flourishing of crop pests which again causes crop loss."

As a result, farmers face a reduced number of productive working hours (both for him and his plowing oxen), whereas they would need more labor in order to cope with the effect of crop pests and the need to increase food production as insurance against the drought. 


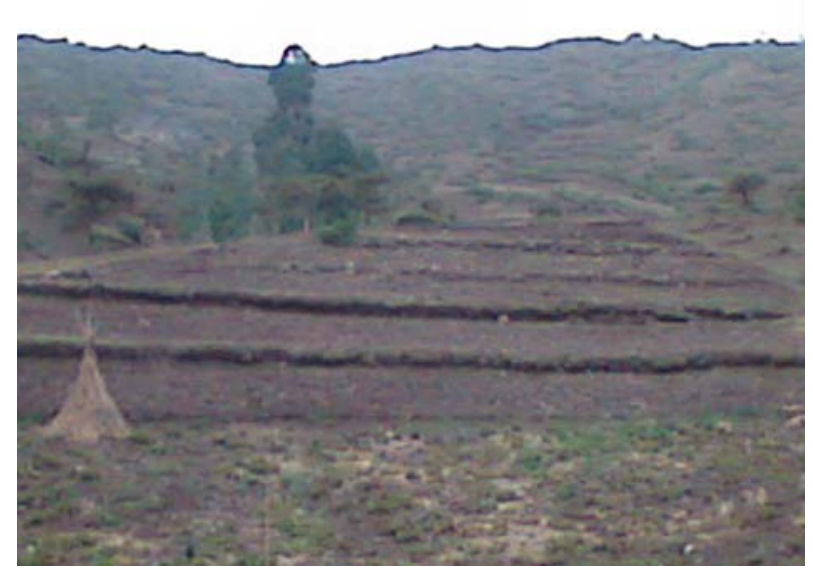

\section{Many Important Hazards are Only Indirectly Climate-Related}

Not all hazards are climate-related, however (see Table A.7). For all villages, "high food prices" are one of the major hazards. For the midland villages and for Keteteya, soil erosion also is reported to be important, whereas for Haro Kersa animal diseases are an important hazard. Even though these hazards are not directly climate-related, increased climate variability can aggravate them. Finally, in Haro Kersa, it was indicated that conflicts with neighboring villages had increased. These conflicts were especially related to water shortages and shortages of good quality grazing lands.

\section{HOUSEHOLD VULNERABILITY PROFILES}

The previous section compared vulnerability profiles of the different villages. There were considerable differences in vulnerability profiles among the lowland, midland, and highland villages. In this section, clusters of households are formed, each having similar coping capacity characteristics. Including exposure characteristics in the cluster analysis does not enhance understanding of coping capacity, as six clusters would emerge, each consisting of the households of each village. This shows that the level of exposure is an important characteristic of vulnerability. Looking at only coping capacity offers better insight into the question of which households are better able to deal with hazards themselves, and which households need more assistance.

\section{Household clusters show vulnerability classes}

Table 3 presents the distribution of households over the clusters. $^{3}$

In Appendix A2.B, some general household characteristics of the clusters are presented. The main vulnerability characteristics distinguished in this report are presented in Table 4 and Appendix A2.B. The results are also presented in Figure 11.

The clusters can be described as follows:

1. Low-educated pastoralist households. Pastoralist households, especially from Haro Kersa in the lowlands, own cattle and to a lesser extent small ruminants. They have a low dependency ratio, large household size, few female-headed households, low migration rates, low levels of education, low asset ownership, and cultivate only small plots, especially with grains and sesame for their own consumption.

2. Young agropastoralist households. Agropastoralists, especially from the lowlands and midlands, own ruminants and to a lesser extent cattle. They have a high dependency ratio, little temporary migration, low levels of education, an average number of assets owned, and cultivate mostly grains and vegetables and some fruit trees on an average acreage of farmland.

3. Large, landowning farm households. Farmers from all regions that cultivate a relatively large acreage with cereals, legumes, and potatoes. They having hardly any young children, relatively high levels of education, high migration rates, and own hardly any livestock.

4. Asset-rich farm households. Farmers from the midlands and highlands with average household characteristics. They have high levels of asset ownership and above-average education levels, cultivate especially cereals, and own a large share of fruit trees.

5. Small, poor farm households. Farmers from the midlands and highlands with below-average household size, a high percentage of female-headed

\footnotetext{
3 In all cluster analyses conducted, only 294 households were included in the clusters. In all cases, the same six households were excluded from the sample. Five of them were poor, almost landless, mainly grain producing, mostly female-headed households, owning only a few assets, and hardly any livestock or ruminants. These belong to the most vulnerable households of the sample.
} 
TABLE 3. DISTRIBUTION OF CLUSTERS OVER THE DIFFERENT VILLAGES

\begin{tabular}{lrrrrrrrr}
\multicolumn{1}{c}{ Cluster } & 1 & 2 & 3 & 4 & 5 & 6 & Total \\
\hline Haro Kersa & 43 & 4 & 2 & 1 & 0 & 0 & 50 \\
\hline Gola & 1 & 37 & 1 & 3 & 6 & 1 & 49 \\
Choresa & 0 & 12 & 1 & 16 & 15 & 6 & 50 \\
\hline Birko Debele & 0 & 12 & 1 & 6 & 15 & 14 & 50 \\
Keteteya & 0 & 2 & 1 & 6 & 27 & 14 & 48 \\
\hline Hardibo & 0 & 1 & 0 & 13 & 74 & 57 & 47 \\
\hline Total & 44 & 68 & 6 & 45 & & 294
\end{tabular}

Notes: (1) The size of the land cultivated and the size of the land occupied with trees is aggregated into one acreage indicator. For converting trees to hectares, it is assumed that 1 tree takes 0.015625 ha (or 64 trees per ha - see also Table A2.4 in Appendix A2). (2) TLU = tropical livestock units. TLU conversion factors: Cattle in herd: 0.7 , Cows: 1.0, Sheep: 0.1, Goat: 0.08, Poultry: 0.01 (Kassam et al. 1991)

TABLE 4. CHARACTERISTICS OF CLUSTERS

\begin{tabular}{|c|c|c|c|c|c|c|c|c|c|}
\hline \multirow[b]{2}{*}{ cluster } & \multirow[b]{2}{*}{$\begin{array}{l}\text { Average hh } \\
\text { size }\end{array}$} & \multirow[b]{2}{*}{$\begin{array}{l}\text { Dependency } \\
\text { ratio }\end{array}$} & \multirow[b]{2}{*}{$\begin{array}{c}\% \text { female } \\
\text { headed } h h\end{array}$} & \multirow{2}{*}{$\begin{array}{l}\text { \% households } \\
\text { from whom } \\
\text { members } \\
\text { migrated }\end{array}$} & \multirow[b]{2}{*}{$\begin{array}{l}\text { average years } \\
\text { of education }\end{array}$} & \multicolumn{2}{|c|}{$\begin{array}{c}\text { average acreage per } \\
\text { household }\end{array}$} & \multirow[b]{2}{*}{$T L U^{2}$} & \multirow[b]{2}{*}{$\begin{array}{c}\text { Mean asse } \\
\text { score }\end{array}$} \\
\hline & & & & & & $\begin{array}{c}\text { All } \\
\text { crops }\end{array}$ & $\begin{array}{l}\text { Cash + oil } \\
\text { crops, trees }\end{array}$ & & \\
\hline 1 & 8.25 & 1.1 & 5 & 0 & 0.7 & 0.9 & 0.2 & 11.8 & 10.0 \\
\hline 2 & 6.04 & 1.8 & 7 & 6 & 1.7 & 1.3 & 0.1 & 5.5 & 19.7 \\
\hline 3 & 9.17 & 0.3 & 0 & 17 & 5.3 & 4.0 & 0.4 & 0.7 & 24.3 \\
\hline 4 & 6.64 & 1.0 & 7 & 7 & 3.9 & 1.6 & 0.5 & 3.2 & 39.0 \\
\hline 5 & 4.93 & 1.0 & 24 & 5 & 2.1 & 0.9 & 0.2 & 2.3 & 13.6 \\
\hline \multirow[t]{2}{*}{6} & 4.95 & 1.1 & 16 & 12 & 2.3 & 1.1 & 0.4 & 3.0 & 26.8 \\
\hline & 6.04 & 1.2 & 14 & 6 & 2.1 & 1.2 & 0.3 & 4.4 & 21.2 \\
\hline
\end{tabular}

households, and low levels of education, asset holdings, land, and livestock ownership.

6. Average farm households. Average farm households are from the highlands and to a lesser extent the midlands. They have an above-average migration rate and tree ownership, cultivate especially cereals, and an above-average acreage of qat as a cash crop.

\section{Most Households have Limited Options to Fall Back On}

The spider diagrams in Figure 11 clearly show that all household types are at least to some extent in a vulnerable situation. The following conclusions can be drawn:

- Most household types are dependent on only one source of income and only have limited fallback options.
- Low-educated pastoralists still are in a relatively wealthy situation due to their herds. Climate change may hurt their situation, however, which is difficult to alter due to their dependence on livestock and low education levels.

- Small, poor farmers are in the worst position with limited income earning possibilities and few fallback options.

- Young agropastoralists currently are in a vulnerable situation. Once their children grow older, their scope for exploiting more income diversification activities improves.

- Asset-rich farmers can fall back on their assets in difficult years; their scope for future improvement is positive due their above average education levels.

- Large, landowning farmers have the highest coping capacity, but they only cover 2 percent of the sample. 
FIGURE 11. SPIDER DIAGRAMS OF THE AVERAGE CLUSTER SCORES ON THE MAIN VULNERABILITY CHARACTERISTICS
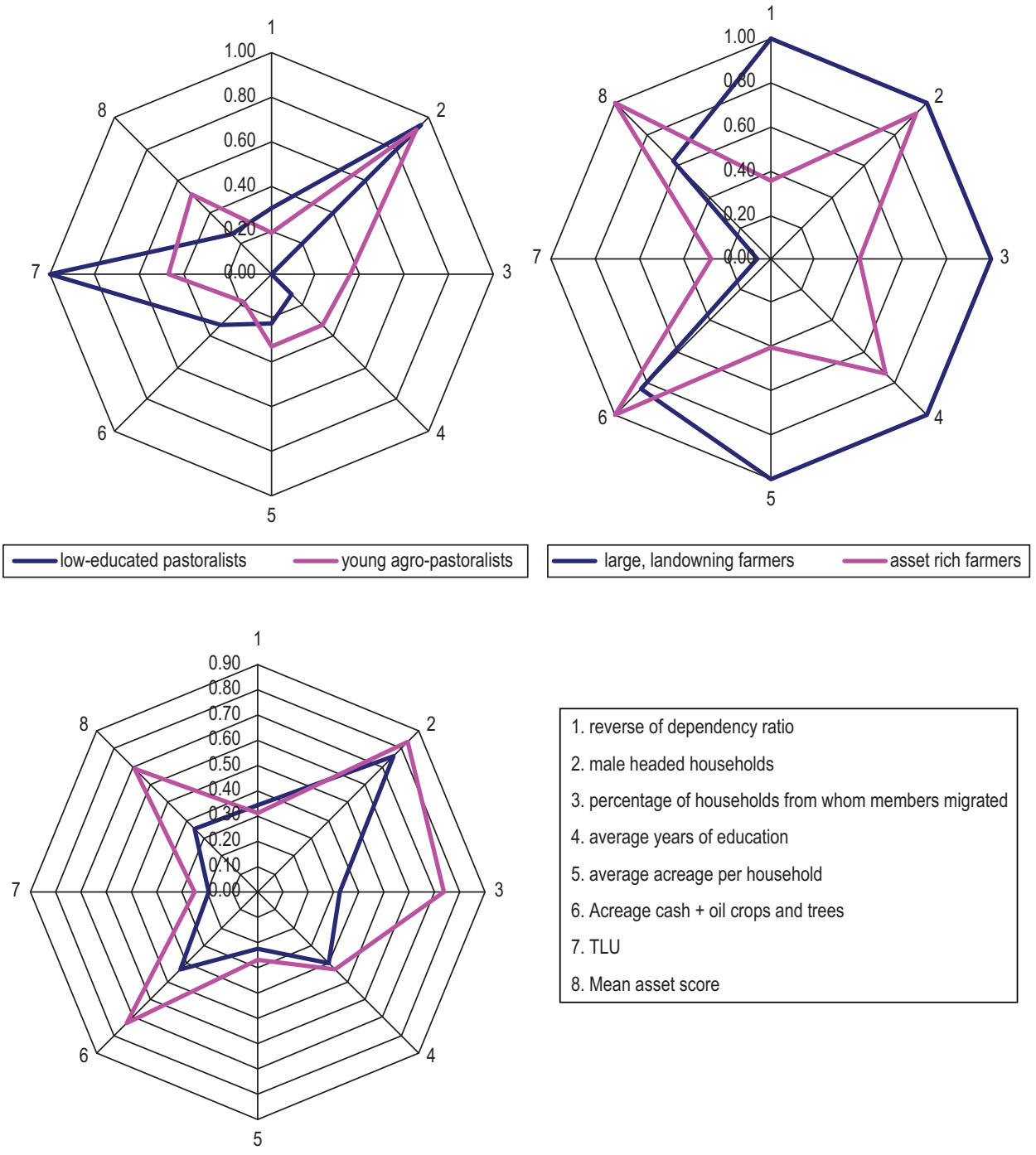

1. reverse of dependency ratio
2. male headed households
3. percentage of households from whom members migrated
4. average years of education
5. average acreage per household
6. Acreage cash + oil crops and trees
7. TLU
8. Mean asset score

- small, poor farmers

average farmers

These observations on vulnerability are confirmed by the results on the length of the hunger period (see Table B.8). On average, 84 percent of the population faces food shortages during part of the year. This is highest for the low-educated pastoralists (98 percent) and small, poor farmers (95 percent). The average length of the hunger period is 2.9 months. For the low-educated pastoralists it is about 4 months, whereas it is 2.2 months for the "average farmers" cluster.
Climate-Related Hazards are Important for the Households

Table 5 shows which hazards are the most important for the households (see also Table B.7). Less rainfall during the rainy season and prolonged periods of drought are the most important climate-related hazards. High food prices also received a high score. Rising average and extreme temperatures are a problem, especially for the pastoralists. For them, higher temperatures lead 
TABLE 5. AVERAGE RANKING OF HAZARDS $(1=$ MOST IMPORTANT; $10=$ LEAST IMPORTANT $)$

\begin{tabular}{ccccccccccc} 
Clusters & $\begin{array}{c}\text { Drought } \\
\text { due to } \\
\text { less rain- } \\
\text { fall }\end{array}$ & $\begin{array}{c}\text { Prolonged } \\
\text { periods of } \\
\text { drought }\end{array}$ & $\begin{array}{c}\text { Floods due } \\
\text { to exces- } \\
\text { sive rainfall }\end{array}$ & $\begin{array}{c}\text { Damage } \\
\text { due to } \\
\text { heavy } \\
\text { showers }\end{array}$ & $\begin{array}{c}\text { Changed } \\
\text { tempera- } \\
\text { tures }\end{array}$ & $\begin{array}{c}\text { Human } \\
\text { diseases }\end{array}$ & $\begin{array}{c}\text { Animal } \\
\text { or crop } \\
\text { diseases }\end{array}$ & $\begin{array}{c}\text { Decreasing } \\
\text { soil fertility }\end{array}$ & $\begin{array}{c}\text { Market } \\
\text { problems } \\
\text { food } \\
\text { prices }\end{array}$ \\
\hline 1 & 1 & 2 & 10 & 9 & 3 & 6 & 4 & 7 & 8 & 5 \\
\hline 2 & 2 & 3 & 5 & 10 & 4 & 6 & 7 & 8 & 9 & 1 \\
\hline 3 & 1 & 3 & 6 & 9 & 4 & 10 & 5 & 6 & 8 & 2 \\
\hline 4 & 1 & 2 & 9 & 7 & 4 & 5 & 6 & 7 & 10 & 3 \\
\hline 5 & 1 & 2 & 5 & 9 & 4 & 6 & 8 & 7 & 10 & 3 \\
\hline 6 & 1 & 2 & 8 & 9 & 6 & 7 & 5 & 4 & 10 & 3 \\
& 1 & 2 & 8 & 9 & 4 & 6 & 5 & 7 & 10 & 3
\end{tabular}

\section{BOX 1. GENDER EFFECTS OF CLIMATE-RELATED HAZARDS}

The effect of water and food shortages in the household as a result of changes in rainfall patterns appears to be linked to gender. Women are normally responsible for providing water and cooked food for their household. In a focus group discussion in Choresa, women emotionally expressed the effect of water shortages as follows:

"everyday we fight over the ever weakening spring water in the area especially during the dry season. This coupled with the long queue, it takes us more than three hours to get about 20 liters of water from a nearby spring for domestic chores, which is about double the time it used to take us 10 years ago. This causes reduced sanitation in the household especially for the children."

In a focus group discussion in Birko-Debele, a male farmer expressed that women suffer the most as a result of food shortages in the household:

"when I realize that there is not enough food in the house, I go out to the nearby town or to my friends. The woman cannot go out because the children will be waiting on her to get some food. In such cases, it is common that she cooks the little she has in the house, gives it to her children, puts some aside for the husband and goes hungry for herself. As a result the women get sick easily."

Thus, women are less mobile than their husbands during such harsh conditions. It also shows that reducing food consumption is a regularly adopted coping strategy, even though it adversely affects women.

to higher incidence of animal diseases and shortages of water.

\section{VULNERABILITY AND ADAPTATION}

In the village study, households were asked which strategies they had adopted in the past to reduce some of the hazards they faced (see Appendix A2.C). Four categories of strategies were distinguished.
- Agricultural techniques. These include the adoption of drought-tolerant or resistant crops, changing planting dates, cropping densities, fertilizer application, pesticide application, the pastoral system or the herd composition, and applying different feed techniques.

- Water management techniques. These include the use of water harvesting techniques, improvement or rehabilitation of terraces, the use of irrigation techniques, and improvement of watering sites in pastoral areas. 


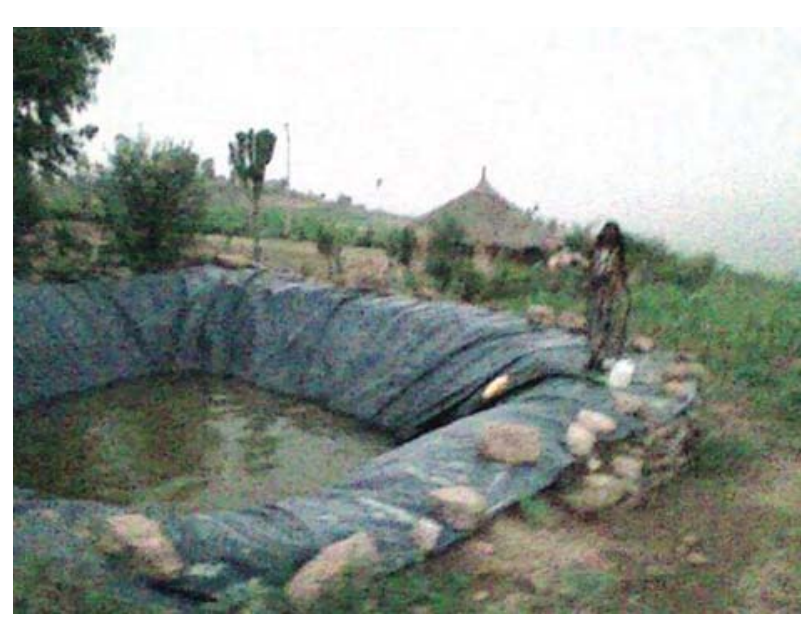

- Income diversification techniques. These include temporal or permanent migration, non-timber forest product commercialization, home-garden agriculture, increasing market sales, charcoal or timber sales, changing consumption patterns, and drawing down livestock or savings.

- Communal pooling techniques. These include restoration of homestead or mountain forests, rangeland preservation, soil erosion prevention programs, communal water harvesting techniques, or communal irrigation schemes.

\section{On Average 8.5 Strategies per Household}

On average, each household adopted 8.5 strategies. A factor analysis showed that some strategies were regularly adopted jointly or in isolation without any other strategy. The groups of strategies are:

- Crop selection, adapt planting dates, adapt cropping density, adapt tillage practice

- Adapt fertilizer application, use irrigation, set up communal irrigation schemes

- Water harvesting techniques, improve watering sites, communal water harvesting

- Change from a pastoral to sedentary agricultural system.

It is clear that these strategy combinations are related to each other. They either complement each other or are a combination of individual and communal strategies.
The first group of strategies is applied regularly. In the focus group discussions, farmers indicated that they prefer adopting early maturing sorghum varieties to the late maturing traditional one so as to make maximum use of the unreliable duration of the rainy period and to be more flexible in their planting dates. In some cases, the crop species are changed temporarily or permanently depending on the rainfall pattern. For instance, in the highland villages qat production has been expanding over the past few years along with an increase in water harvesting practices. In the highland villages, it is normal to find water harvesting wells around the house yard. In the drier midland and lowland villages, this is less common. The water harvesting practice has been integrated with home-garden production activities such as qat and vegetables, which are manually irrigated from the harvested well water.

\section{Top Five Strategies Contain Three Communal and Two Individual Strategies}

Figure 12 (and Tables C.1 and C.2) show the strategies chosen by the different household types and the villages. The top five strategies are (1) crop selection (adopt drought-tolerant crops; chosen by 78 percent of the households); (2) improve or rehabilitate terraces (adopted by 72 percent); (3) soil erosion prevention programs (chosen by 69 percent); (4) restore or preserve homestead or mountain forests (adopted by 62 percent); and (5) adapt planting dates (adopted by 51 percent).

Three of the five most important strategies are communal strategies that have to be implemented jointly with other households. This shows that institutions play an important role in improving livelihoods in the villages. This is discussed further in the next section.

\section{Responsibility for Strategy Choice is Gender Specific}

Few households use temporary or permanent migration as a strategy to reduce their exposure and sensitivity to hazards. In many cases, both men and women decide about the adoption of a strategy. For some strategies, like increasing market sales, draw-down livestock or savings, and investments in pastoral areas, men largely make the decisions. For some agricultural practices-like seed selection, planting dates, and tillage practices-men 


\section{FIGURE 12. PERCENTAGE OF TIMES HOUSEHOLDS CHOOSE A PARTICULAR ADAPTATION OPTION}
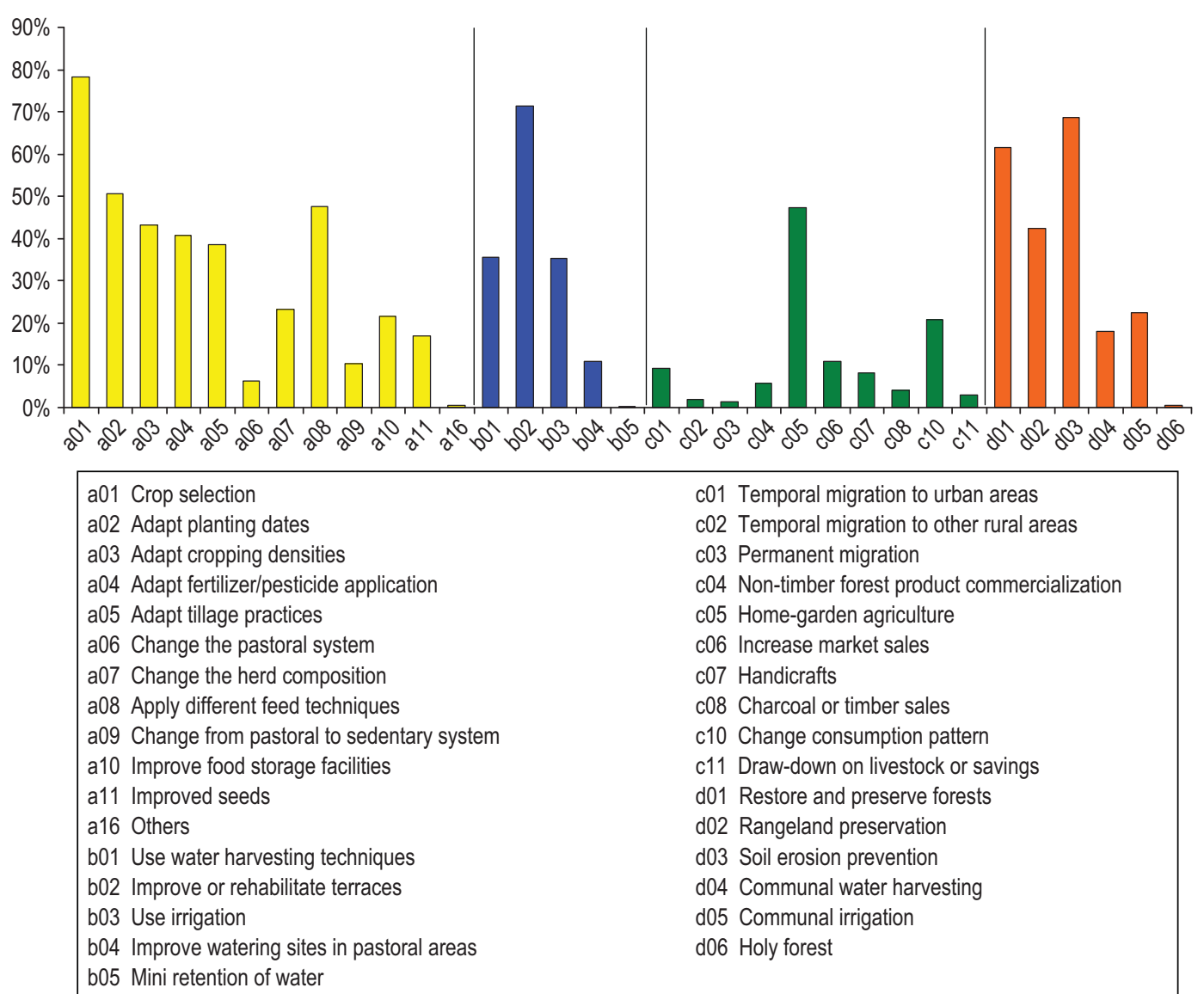

c01 Temporal migration to urban areas c02 Temporal migration to other rural areas c03 Permanent migration c04 Non-timber forest product commercialization c05 Home-garden agriculture c06 Increase market sales c07 Handicrafts c08 Charcoal or timber sales c10 Change consumption pattern c11 Draw-down on livestock or savings d01 Restore and preserve forests d02 Rangeland preservation d03 Soil erosion prevention d04 Communal water harvesting d05 Communal irrigation d06 Holy forest make the decisions more often than women. Decisions on handicrafts, consumption, and charcoal and timber sales are largely made by women. Women also have an important say regarding home-garden agriculture.

\section{Villages and Clusters Adopt Mixed Strategies}

Strategies adopted differ substantially among the villages (see Tables C.1 and C.2).

- In Gola and for the young agropastoralists (cluster 2), the top-5 strategies are individual strategies focusing on improved agricultural practices (crop selection, planting dates, cropping densities, fertilizer application, feed techniques). In their transformation process, they are still learning how to improve yields.

- In the pastoralist village Haro Kersa and for the low-educated pastoralists, communal strategies are often adopted, focusing on improved water management and water storage to reduce their sensitivity to climate variability. As they are dependent on communal grazing lands and communal watering points and only have limited individual strategies at their disposal, it is advisable to coordinate actions to improve their situation.

- Households in the midland and highland villages have a more mixed strategy of improved seed selection combined with soil erosion prevention-including terrace rehabilitation and reforestation for the highlands - and home-garden agriculture with the 


\section{BOX 2. EXPERIENCES WITH TEMPORARY MIGRATION}

At least a quarter of the participants in each of the midland and highland focus group discussions indicated that at least one of the household members migrated to other towns during the last year. Many said that quite a number of youngsters in the area travel about $400-500 \mathrm{~km}$ for salt mining work but also to the nearby towns of Kombolcha, Dessie, and Addis Ababa. Some women travel to countries like Dubai and Saudi Arabia. Many migrants send remittances back home. In a focus group discussion in Keteteya, the downside of the situation is expressed as follows:

"due to food shortage in the households, some girls are forced to drop out of school and travel to the nearby towns to look for work. Some of the girls ended up in prostitution and came back home with HIV/AIDS."

objective to reduce sensitivity to climate variability and improve coping capacity.

- Income diversification strategies like migration, non-timber forest products, market sales, handicrafts, and timber sales are not regularly chosen. Home-garden agriculture is the main income diversification strategy adopted.

- Reduction of expenses is for most households not a feasible option as their expenses already are low. For the better-off, large, landowning farmers, this is a more important strategy.

\section{Without an Improved Enabling Environment, Household Strategies may not Sustain}

The institutional stakeholders and experts interviewed made a distinction between strategies in which the households have a responsibility and those for which the government is responsible. On the one hand, the government has to invest in options with the objective to realize a better functioning social and market system (improved roads, electricity, telecommunication, markets for farm inputs, credit facilities, law courts, health care, and veterinary facilities). These options provide the enabling environment and the basic facilities needed for a well-functioning society. Most of these options require public investments but may partly be realized through food-for-work or money-for-work programs executed by (local) authorities and extension agencies. These investments also include improved meteorological information dissemination and disaster management plans, which provide households with the information needed to make deliberate choices. On the other hand,

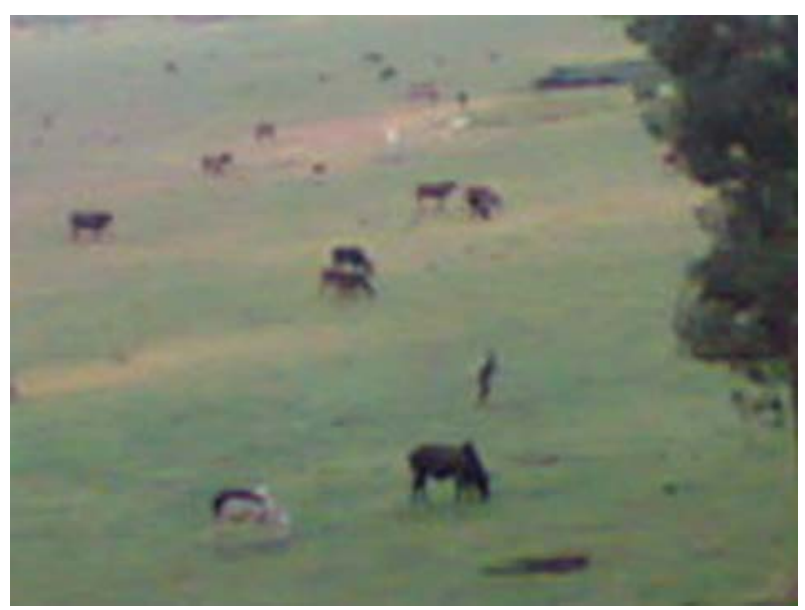

households also need support in terms of training, financial support. and techniques and inputs that give them the opportunity to improve their situation in a sustainable way and to diversify their income. These correspond to the individual or communal strategies the households themselves noted in the interviews.

\section{Strategies are Adopted Especially to Reduce Drought Hazards}

The households indicated that all strategies included in the questionnaire reduce the drought hazards they are facing. This is, of course, highest for the water management and agricultural techniques. For strategies related to migration, marketing, and income diversification activities, still more than 50 percent of the people adopting these strategies indicated that it reduces their drought hazards. 


\section{BOX 3. HIGH INTEREST RATES CHARGED BY MONEY LENDERS}

There are few interest-free lending activities (in cash and in kind) among the households in the area. However, most credit is obtained from local moneylenders who offer arrangements to exchange cash for crop harvest at about 500 percent interest. In a focus group discussion in Hardibo, it was mentioned that

"there are moneylenders in the area who provide farmers a credit of $\mathrm{Br} 1$ to be repaid in $1 \mathrm{Kg}$ grain (equivalent to $\mathrm{Br} 5-7$ ) during the harvest season. The arrangement is called Ye kitel."

Some better-off households may also be involved in buying crops from the farmers at a cheap price during the harvest season and selling it back to them at a very high price later during the slack period.

This shows that the households see income diversification sensitivity reduction as an important strategy to reduce hazards. Strategies reducing flood hazards include soil erosion prevention measures, reforestation, terracing, and rangeland management. People are aware of the effects of these strategies on surface runoff. Differences between villages and household types are small.

\section{Cost Estimates are Difficult to Interpret}

Table 6 presents information on the costs of the adaptation strategies. ${ }^{4}$ Interpreting the cost estimates is difficult. Many people did not know the costs of the strategies adopted, many strategies did not have direct costs (e.g. change consumption habits), or people are reluctant to disclose the costs. Some strategies involve one-time investments costs, whereas other strategies have annually recurring costs. Moreover, for some strategies it is not immediately clear which costs have to be made (e.g. adapt planting dates or adapt cropping densities). The analysis of the cost data found that it is difficult to give reliable quantitative cost estimates and to give full insight into why households make these costs. In the current study organization, asking for more detailed quantitative costing information was difficult. The costing framework and questionnaire already were very elaborate; to ask even more details on these costing elements would have been too time consuming. A follow-up study could put more emphasis on the

4 Only for the strategies for which more than 10 positive cost estimates were given, the averages have been determined. For the others, the estimates will be too unreliable and are therefore excluded from the analysis. quantitative side of the different elements of the costs and the type of institutional assistance households need. This may shed more light on the costs households commit to and on the question of whether they need assistance from outside institutions.

\section{The More Vulnerable Groups Invest Less} Money and Time than the Better-Off Groups

Taking into account the objections as raised above, some careful observations can be made on the costs and time invested in the adaptation strategies.

- The more vulnerable farm types ("small, poor farmers" and "average farmers") have lower average expenses than the better-off groups ("large, landowning farmers" and "asset-rich farmers"). They have fewer resources available to invest. The "young agropastoralists" report the highest expenses. They invest in the transformation of their farming practices, which most likely are financed by selling cattle.

- For seed selection, the lowland villages pay higher costs than the midland and highland villages (403 Birr for Haro Kersa, 326 Birr for Gola, compared to an average of 125 Birr for the midland and highland villages). The same observation follows if the clusters are compared. Reasons may be cultivation of more expensive crops in the lowlands, unfavorable market conditions in the lowlands because agriculture is less important, or farmers knowing these costs in more detail because they just recently started crop cultivation. The same applies 
TABLE 6. COST ESTIMATES OF THE ADAPTATION STRATEGIES (BIRR)

\begin{tabular}{|c|c|c|c|c|c|c|}
\hline & \multicolumn{3}{|c|}{ Average over all observations } & \multicolumn{3}{|c|}{ Average over positive observations } \\
\hline & \multirow[b]{2}{*}{ mean } & \multicolumn{2}{|c|}{ quartiles } & \multirow[b]{2}{*}{ mean } & \multicolumn{2}{|c|}{ quartiles } \\
\hline & & $25 \%$ & $75 \%$ & & $25 \%$ & $75 \%$ \\
\hline \multicolumn{7}{|l|}{ Agricultural techniques } \\
\hline Crop selection & 114 & 0 & 150 & 205 & 80 & 240 \\
\hline Adapt planting dates & 29 & 0 & 0 & 125 & 50 & 150 \\
\hline Adapt cropping densities & 53 & 0 & 16 & 202 & 50 & 320 \\
\hline $\begin{array}{l}\text { Adapt fertilizer/pesticide } \\
\text { application }\end{array}$ & 242 & 0 & 400 & 351 & 80 & 525 \\
\hline Adapt tillage practices & 20 & 0 & 0 & 152 & 60 & 175 \\
\hline Change the herd composition & 28 & 0 & 0 & 196 & 50 & 200 \\
\hline Apply different feed techniques & 213 & 0 & 250 & 483 & 140 & 600 \\
\hline Improve food storage facilities & 120 & 0 & 26 & 191 & 10 & 120 \\
\hline Improved seeds & 187 & 0 & 265 & 257 & 200 & 290 \\
\hline \multicolumn{7}{|l|}{ Water management techniques } \\
\hline Use water harvesting techniques & 61 & 0 & 0 & 303 & 158 & 450 \\
\hline Use irrigation & 215 & 0 & 204 & 485 & 78 & 405 \\
\hline \multicolumn{7}{|l|}{$\begin{array}{l}\text { Income diversification } \\
\text { techniques }\end{array}$} \\
\hline Home-garden agriculture & 28 & 0 & 0 & 146 & 50 & 175 \\
\hline \multicolumn{7}{|l|}{ Communal pooling techniques } \\
\hline Communal irrigation & 560 & 0 & 0 & 1607 & 100 & 300 \\
\hline
\end{tabular}

Notes: For the averages over the positive observations, the observations are excluded for which households indicated they had made costs but for which they reported a cost estimate of 0 Birr. See also Tables C.3 and C.4.

for the other individual farming strategies such as fertilizer/pesticide application, cropping density adaptation, and so on.

- For the majority of the water management, income diversification, and communal pooling strategies, respondents do not report any monetary costs. Many of these strategies do not directly cost money or are paid by extension agencies or other organizations.

- Households in Gola spend more than double the time on improving farming practices than the other villages. ${ }^{5}$ This again shows that households are still learning how to improve their farming practices. Households in Haro Kerso only report a time investment of 17 days per household for all adapta-

5 Aggregating the time spent on the different strategies asked for in the questionnaire, however, gives an unreliably high estimate for time spent on these strategies (more than 250 days). This probably shows problems with double-counting. tion strategies, much less than the average of 114 days for the entire sample.

- The better-off household types ("large, landowning farmers" and "asset-rich farmers") spend more time on their adaptation strategies than the "small, poor farmers" and the "average farmers." This is spent on communal soil erosion prevention and water management strategies. This is an indication that the better-off households have better access to institutional support than the worse-off households.

- Time spent on soil erosion prevention programs, terrace rehabilitation, and reforestation is on average 40 days per year for the midland and highland villages and 90 days for Gola. It can be expected that households are double-counting the time spent on the different soil erosion prevention strategies. Nevertheless, the communal pooling strategies to reduce soil erosion and improve water management 
do cost households a few weeks to a few months of labor per year.

- In Haro Kersa, in the "low-educated pastoralist" community, financial decisions are made by men. In the other villages, men make most financial decisions, but women are involved in about half of the financial decisions on adaptation strategies.

\section{INSTITUTIONAL ACCESS AND CLIMATE ADAPTATION}

\section{Households are in Contact with many Institutions, but not all are Relevant for Adaptation}

It is interesting to see whether particular types of institutions are more active in particular villages than in others, or whether particular clusters of households make use of the assistance from particular institution. From the analysis, it follows that almost all households are in touch with local authorities, extension agencies, village communities, and religious communities (see Table D.1). It is striking to see that NGOs are especially active in the lowland villages of Gola and Haro Kersa, whereas these households have fewer contacts with the local authorities and the village and religious communities in their village. This is related to the pastoral nature of these villages. Women's groups are present in Choresa, Birko Debele, and Hardibo and cooperatives especially in Choresa. In the other villages, about a third of the households are in contact with cooperatives. The contacts with these institutions, however, are in many cases not helpful for deciding on adaptation strategies (see Table D.2). Apparently, they operate in other fields than promoting strategies to reduce vulnerability of the households.

Alternatively, households may perceive their roles differently.

\section{Extension Agencies and Local Authorities Provide Most Assistance}

The analysis clearly shows that in all villages and for all clusters, the local authorities and extension agencies are the institutions from which the households receive the most assistance when they adopt adaptation strategies (see Figure 13 and Table D.3). On average, 97 percent of the households obtain assistance from extension agencies and 71 percent from the local authorities. For the extension agencies, differences between villages and between clusters are relatively small. It is striking to see that in Birko Debele in Kalu woreda only a few households indicate that they receive assistance from the local authorities (only 6 percent), even though the majority of the households have contacts with them. On the other hand, even though for the lowland villages many households indicate they didn't have contacts with the local authorities, those having contacts perceived it as being assistance for adopting particular adaptation strategies. Apparently, there are differences in the types of assistance local authorities provide and the usefulness of it.

\section{Extension Agencies Focus Especially on Agricultural and Communal Strategies}

Almost all households are in touch with extension agencies, but extension agencies provided assistance for only 73 percent of the strategies adopted (see Table D.3). Their role is smaller for strategies related to livestock raising, migration, income diversification methods (like handicrafts and non-timber forest production commercialization), marketing strategies, and other income diversification activities (see Table D.4). Their focus is more on agricultural and communal development. It seems that they put less emphasis on promoting other strategies or that households do not realize they can be helpful with those issues. Local

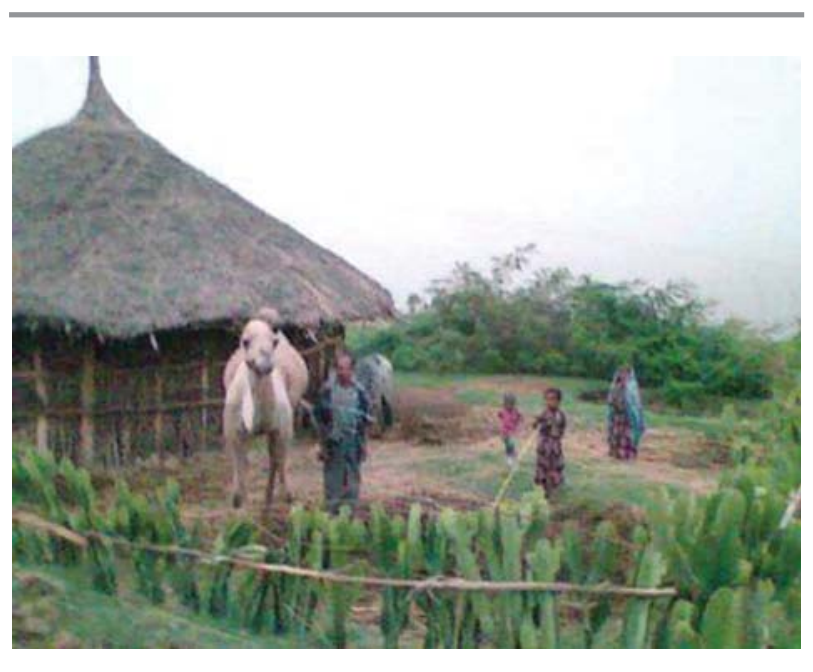


FIGURE 13. PERCENTAGE OF HOUSEHOLDS IN THE DIFFERENT VILLAGES AND FROM THE DIFFERENT CLUSTERS RECEIVING ASSISTANCE FROM ANY OF THE MAIN INSTITUTIONS

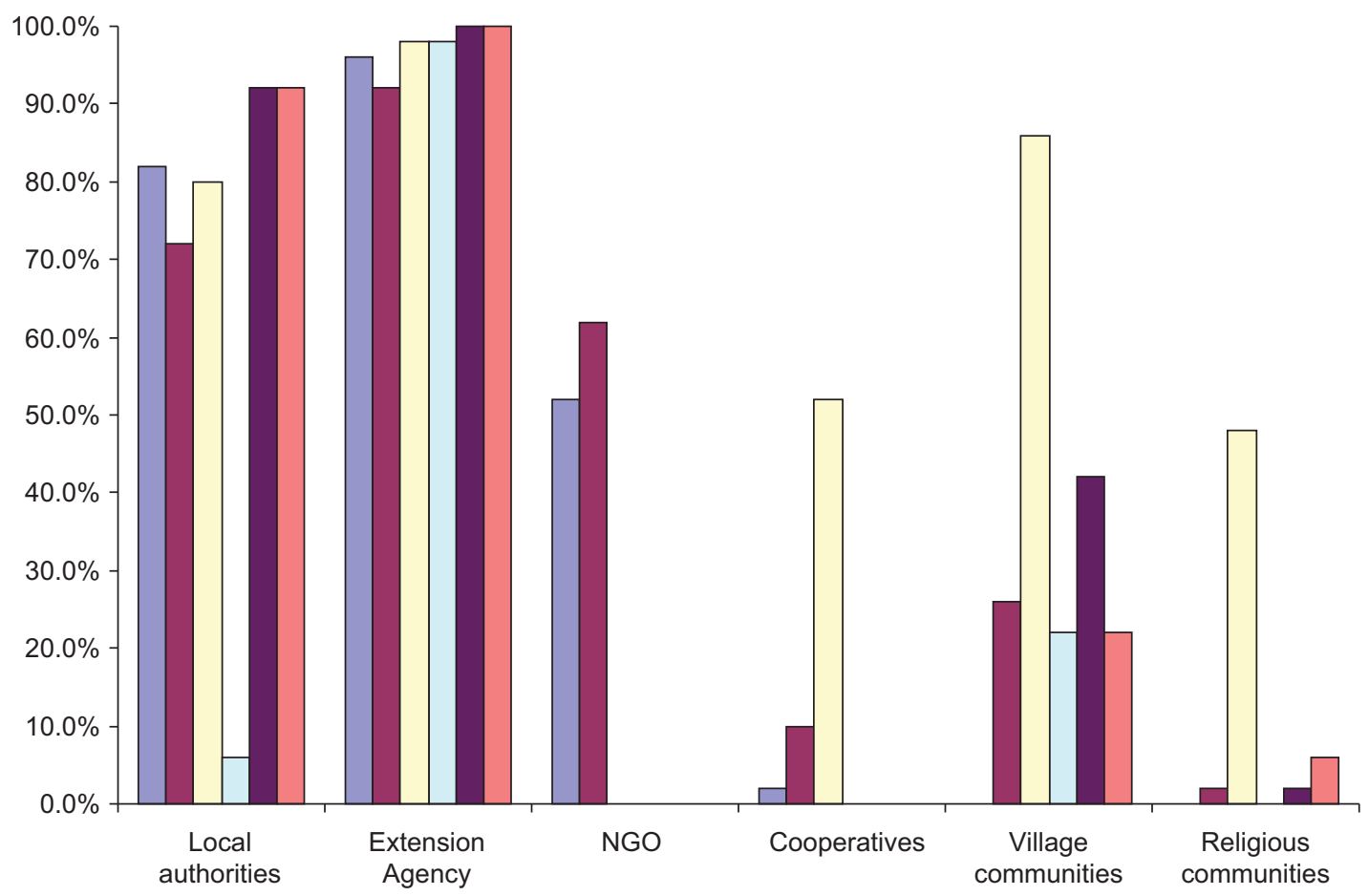

$\square$ Haro Kersa $\square$ Gola $\square$ Choresa $\square$ BirkoDebele $\square$ Ketetya $\square$ Hardibo

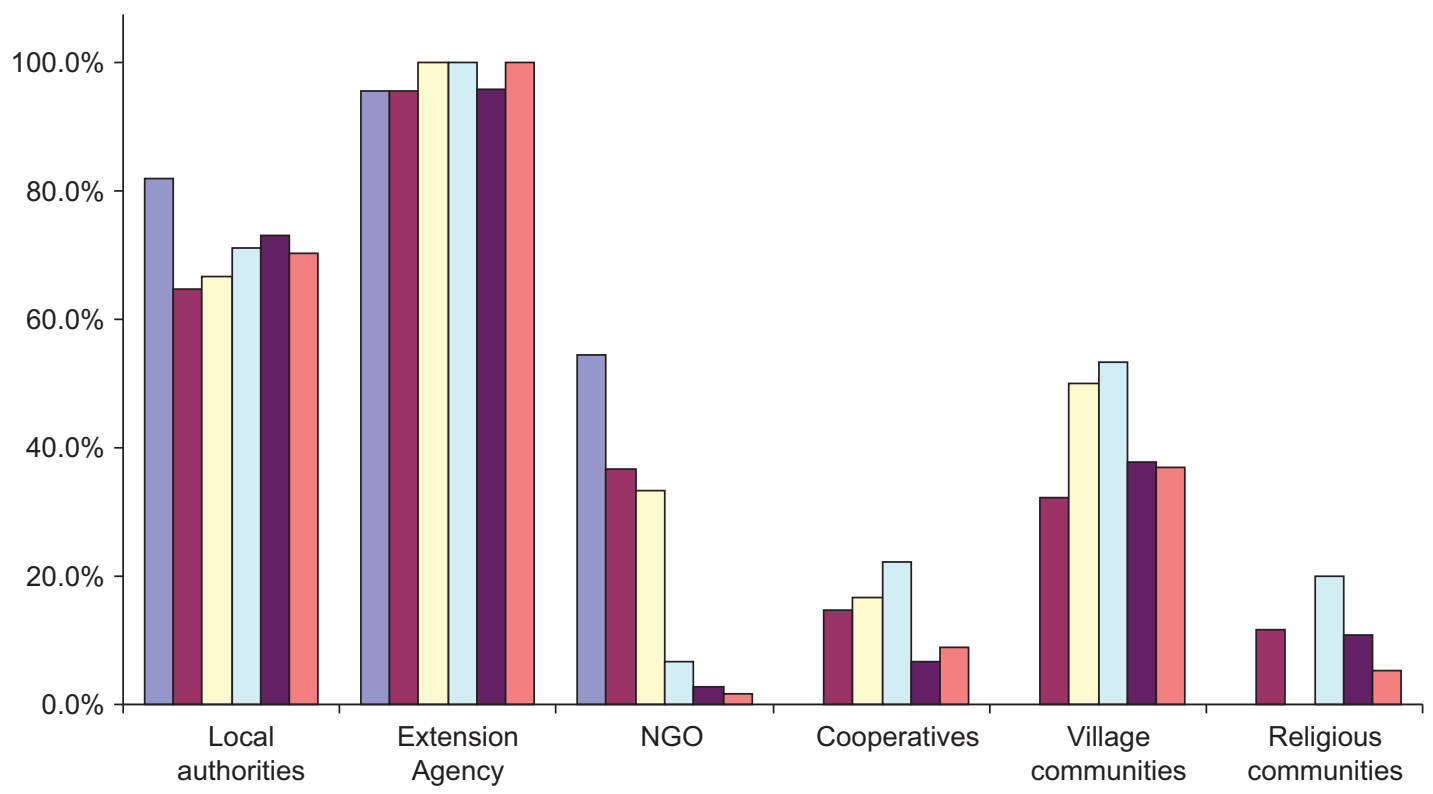

$\square$ low-educated pastoralists $\square$ young agro-pastoralists $\square$ large, landowning farmers

$\square$ asset rich farmers $\quad \square$ small, poor farmers $\quad \square$ average farmers 
authorities also focus on particular strategies. Next to the communal development and agricultural strategies, they assist households with income diversification strategies like home-garden agriculture, non-timber forest product commercialization, and charcoal sales.

\section{Village Community Serves Especially the Better-Off Household Types}

The village community is important in Choresa and Keteteya (respectively 86 percent and 42 percent of the households receive assistance from this institution; see Table D.5). These institutions ${ }^{6}$ play an important role in mobilizing households from the village and for spreading good practices over the village households. Moreover, it is especially the households from the somewhat betteroff, large, landowning farmers and asset-rich farmers (cluster 3 and 4) who say they use the village community more often (respectively 50 percent and 53 percent of the households, compared to an average of 34 percent). Again, this is an indication that especially the better-off farm types, who also adopt communal strategies more often, have the strongest position in the informal community institutions and they succeed in bringing their requirements forward. For the more marginalized groups, the community institutions are less accessible or these households have less information on the types of assistance the village community can offer. Institutional stakeholders in the villages, however, indicated that all households receive the same assistance. Despite that, membership in some institutions (even informal institutions) may be more difficult for marginalized groups if membership fees are required. The village community is especially important for the strategies that have to be implemented by a group of households, like reconstructing terraces, setting up communal irrigation systems, reforestation, rangeland preservation, and soil erosion

6 The village community includes institutions like Idir and Kire, which is an informal organization from whom members pay a fee and which is used for all kinds of social purposes, like looking after sick people, and conducting marriages and funerals. The Idir and Kire serve as a kind of social insurance. It has become a more formal institution as it has bylaws and rules. Jiggie and Debbo are informal and temporary arrangements between households to share labor in times when it is needed, like for weeding and harvesting. Finally, Iqub is an informal savings and loans group in which a small group of people share money, which alternately goes to one of the members. A difference with commercial microfinance is that no interest rate is charged. programs (see Table D.3 and D.4). Next to the communal strategies, village community institutions also assist with questions related to migration and with spreading good practices of home-garden agriculture and food storage over the village.

The Sample of Villages Contains only a Small Number of NGOs

In the midland and highland villages, households do not have regular contact with NGOs. For our sample, NGOs were active only in the lowland villages in Fentale (52 percent of the households in Haro Kersa and 62 percent in Gola receive assistance from NGOs; see Table D.2). ${ }^{7}$ In these regions, they especially assist with strategies related to pastoralism and livestock raising. In Fentale, NGOs also assist with improving agricultural production to make the households less dependent on one source of income.

\section{Cooperatives, Religious Communities, and} Women's Groups are Almost Absent

Cooperatives play a role only in Choresa and almost no role in the other villages. They are especially active in supplying fertilizers and pesticides and for the set-up and organization of irrigation. In Choresa, the religious community also is important. They assist with questions related to temporary or permanent migration. Women's groups, even though not many households have contacts with them (only six households), focus their activities especially on home-garden agriculture and non-timber forest product commercialization. These are among the strategies to diversify income. Finally, microfinance institutions, also reported by only a few households (nine households), assisted households in setting up non-timber forest product commercialization.

\section{Assistance Given is Especially in Terms of Training}

The assistance by institutions consists mainly of training, which accounted for 67 percent of all assistance (see Table D.5). This is positive as it improves household skills. On average, labor assistance accounted for

\footnotetext{
7 Note that in Ethiopia in some woreda extension agencies and local authorities have strong networks, whereas in others their presence is less well-developed. In these woredas, this gap is filled by NGOs.
} 
14 percent of total assistance by institutions. Large, landowning farmers (cluster 3) were an exception; only 4 percent of the assistance they received was in the form of labor. Inputs are provided in about 16 percent of all cases of assistance. These inputs are in terms of materials used for the communal development strategies like water harvesting and irrigation and in terms of fertilizers, pesticides, or improved seeds.

\section{Only a Few Households Report Receiving Food Aid}

According to the people interviewed, food aid is almost absent in their village, except for households from the low-educated pastoralists (cluster 1; Tables D.5 and D.6). They are among the most vulnerable households of our sample, lack income diversification opportunities, and do not grow much food themselves. This absence of food aid is in contrast with the observation that all village households have a food shortage during at least some periods of the year, and that many households in Ethiopia are dependent on food aid in some periods of the year. This may be less of a problem in Kalu, but it may also be true that households are reluctant to admit they received food aid. Moreover, the message that households don't have sufficient food refers to the problem that they don't have sufficient stocks of their preferred staple, but some of the less preferred staple crops remain in stock. Finally, food-for-work activities within the framework of the PSNP or PCDP projects may not be perceived as food aid.

\section{Cash is Provided by NGOs and Microfinance Institutions}

Inputs like fertilizers are especially provided by cooperatives. Table D.7 shows that cash is provided by NGOs and microfinance institutions. Apparently, the informal community institutions like Idir and Iqub are considered to be less important for obtaining cash as an input into adaptation strategies. Another reason may be that the cash requirement for the strategies may be beyond the capacity of the informal village institutions.

\section{Climate Hazards Affect Institutional Activities}

The institutional stakeholders indicated that extreme weather events affect their activities in the villages. Some of these effects are related to changed aid requests from the households (changing from help in terms of productive investments to help in terms of emergency relief). Other effects refer to reduced participation opportunities because households lack the means or shift their attention to emergency relief activities. The final effect refers to changes in the activities of the institutions themselves because of changing circumstances in their working conditions. In order to cope with the climate hazards, the institutional stakeholders employ the following adaptation strategies: (a) accommodating increased movement of members in search of employment, (b) identifying the most affected and reporting to the woreda administration, (c) calling off some of the activities, (d) providing some food aid and safety net assistance, (e) providing credit or buying inputs, (f) enhancing group accountability to ensure loan repayment, and $(\mathrm{g})$ increasing food aid.

\section{The Network of Extension Agencies is an Important Asset for Ethiopia}

The network of extension agencies, with an almost complete coverage of all households in the villages in which they are working, is an important asset for Ethiopia. It gives the authorities the means to reach households in a relatively easy manner. Moreover, the broad focus of the public safety net programs, which make investments both in the public (roads, irrigation canals) and in the private domain (assistance to households with their individual household strategies), is a promising strategy. It strengthens the enabling environment and it strengthens the capacity of households to improve their situation themselves.

Institutions Face Financial, Managerial, Infrastructural, Training, and Legal Constraints

The institutional stakeholders, however, point at a number of constraints they face in the implementation of their tasks. First, they face a number of managerial and financial constraints. For institutions to function properly, adequate resources and managerial skills are required and the different institutions should cooperate closely in order to target their assistance to the right places. National and regional authorities play an important role here in ensuring, organizing, and maintaining this coordinating task. Second, they need adequate infrastructure in terms of road networks and in terms of 
research and information dissemination networks. Adequate infrastructure provides the enabling environment for the institutions to properly perform their tasks. Third, realizing sustainable growth in the villages demands the continuous presence of the institutions in the regions so that they obtain trustworthy relationships with the households and have the opportunity for follow-up activities and to relieve the most pressing needs. As mentioned above, the widespread presence of extension agencies in Ethiopia, combined with longterm safety net programs financed by multiple donors, provides a good basis for this and reduces the risk that changing donor preferences result in short-term and small-scale initiatives. Realizing trustworthy relationships with farmers and raising awareness among the stakeholders, however, requires improved specific training from extension workers on sociological and psychological processes among farm households. Fourth, some institutions pointed at the restrictiveness of some of the government's policies and laws. On the one hand, these policies are in place to assure the effective output of institutions and enhance cooperation among institutions. On the other hand, they are sometimes seen as being restrictive or discouraging.

\section{Do Institutions Have to Give Direct Aid or Create an Enabling Environment?}

A number of the institutional stakeholders stressed their role in making available farm inputs at reasonable prices or even free of charge to start new farming practices. They see a strategy in which farms are directly subsidized or provided new inputs and new technologies as the best way to spread good practices. An alternative and maybe more sustainable strategy is to create an enabling environment in which private traders or businesses have the possibility to survive. This requires adequate infrastructure, telecommunications, and well-functioning financial and legal systems. If national, regional, and local authorities support these services, an environment can be created in which input supply and output purchase by private traders can be sustained.

\section{CALI Results Support the Strategies of Ethiopia's Development Programs}

One of the questions raised in the CALI project was geared to assessing the needs of institutions in the execution of their tasks. For this reason, the institutional stakeholder questionnaire included questions on budgetary needs of the institutions. The respondents, however, could not provide much insight into their spending or the need for additional funds. As both the institutional budgetary needs and the household costs of the adaptation strategies could not be estimated in a reliable way, it was not possible to estimate the financial means/ resources institutions would need to further promote climate change adaptation strategies. Looking at the adaptation strategies discussed above, it follows, however, that most of these strategies already fit within the existing institutional programs. The strategies are not totally new or unexpected, but many of them are already promoted or planned for implementation. Activities to diversify income, set up water management techniques, implement sustainable agriculture, improve education, and strengthen infrastructure have been promoted for a long time. The Ethiopian safety net programs, executed through the extension agencies, seem to already have a good overview of the strategies households adopt and the most pressing needs of the households. The insights obtained from the CALI study support the focus of these programs. For example, the study shows that the services offered by the programs cover an adequate range of adaptation strategies. However, the programs may need to better target the most vulnerable households who are most difficult to reach, like poor pastoralists and poor agricultural households. Furthermore, improved coordination among the various institutions could avoid "double" visits to specific geographical areas and thus improve the efficiency of provision of services by the institutions.

\section{COSTING ADAPTATION}

\section{Implementing Strategies Requires \\ Cooperation}

The surveys give evidence of the types of investments stakeholders have to make for implementing adaptation strategies. For many strategies, households are not, or only to a limited extent, capable of choosing and implementing them on their own. Households may lack the knowledge, the skills, the labor, or the money. Figure 14 gives an overview of the investments needed to choose and successfully implement a strategy. The figure shows the type of resources needed by households, community 


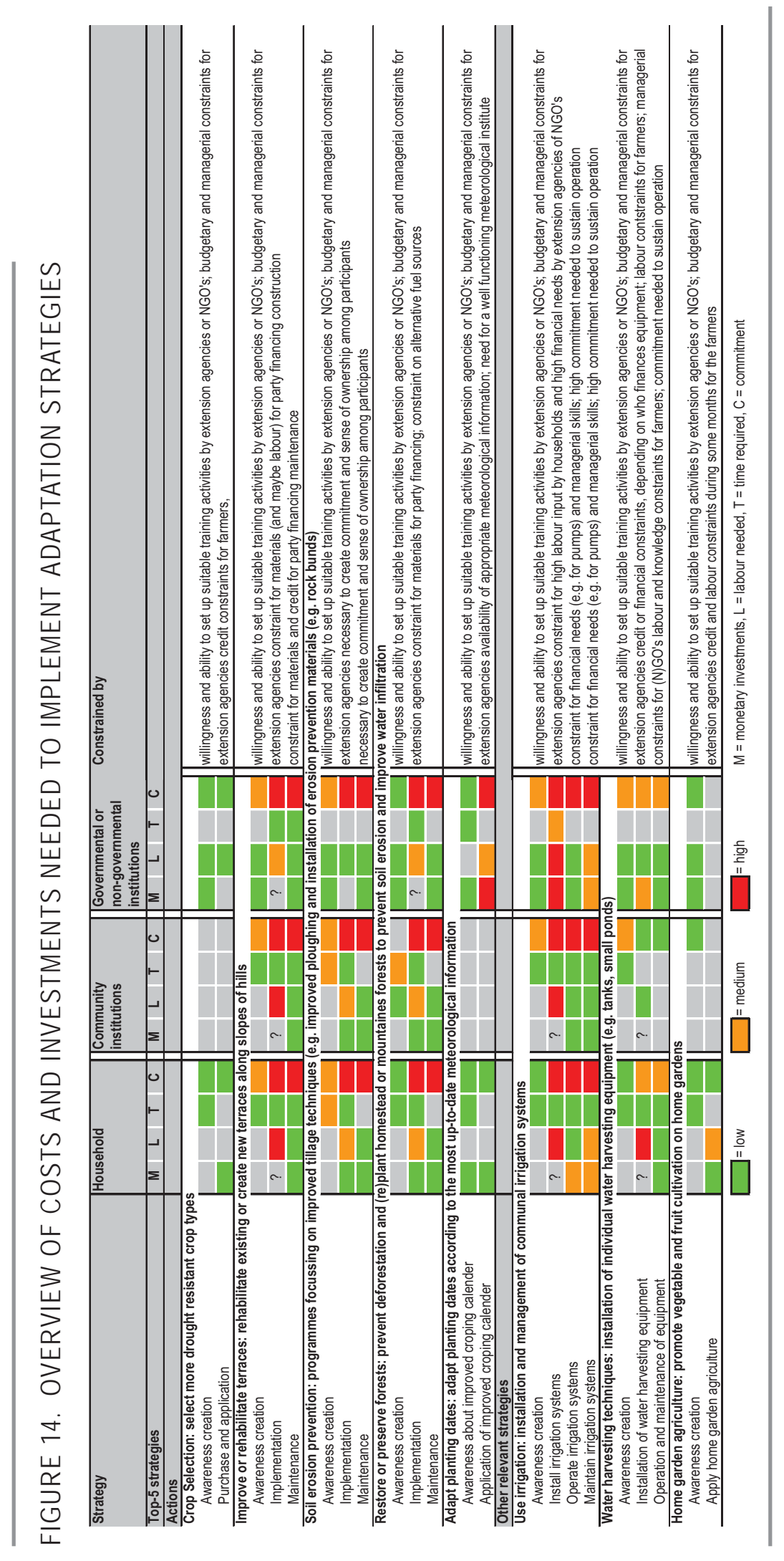


institutions, NGOs, and governmental institutions to implement a strategy.

A distinction is made between the following resources:

- $M=$ monetary needs

- $L=$ labor inputs required to actually carry out the tasks

- $T$ = time needed for training, negotiations, and social contacts

- $C=$ commitment needed which refers to the willingness to furnish the effort to successfully and, in case of communal action, jointly implement the strategies.

For each of the resources, Figure 14 indicates whether low, medium, or high investments are expected and what currently constrains the successful implementation of the strategy. Given the general lack of information about the costs of implementing adaptation strategies, the sensitivity to ask such information from households and the low response rate on these questions, it has not been possible to elicit reliable quantitative costing information. Reliable costing information from other sources is also almost nonexistent. Moreover, no distinction is made between assistance to be provided by governmental or nongovernmental institutions. In principle, the same type of assistance can be provided by governmental or nongovernmental institutions. It depends on the local context and the organizational and financial capacity of the institutions present whether governmental or nongovernmental institutional backup is preferable.

\section{Adoption of Low-Cost Strategies Depends on their Expected Benefits}

Figure 14 and the above discussion on adaptation strategies show that low-cost strategies for which households expect immediate gains are already chosen by many households. This is especially true for sensitivity reducing agricultural strategies (e.g. seed selection, change planting dates, change cropping densities). For these strategies, little institutional assistance is required. Training, however, may improve efficiency and institutions can play a role in mitigating some of the constraints, like malfunctioning markets, which constrain the purchase of inputs (see below).
There are several other promising low-cost strategieslike handicrafts, charcoal sales, or non-timber forest product commercialization - that are selected by only a few households. Home-garden agriculture also is a technique that could be selected by many more households and is expected to have high benefits both in nutritive value or as cash earnings. There may be several reasons why expected benefits turn out to be negative:

- markets for these goods may be too thin or malfunctioning

- inputs may be difficult to acquire if markets are missing

- households may lack the knowledge to implement the strategies

- for home-garden agriculture, households may lack seeds, irrigation/watering equipment, or storage techniques to make it a successful strategy

- home garden agriculture may not be adopted because of coinciding peak labor demands with other farm activities.

Alternatively, households may not perceive the focus on coping capacities as being useful in reducing their vulnerability even if net benefits are positive. For most people, agriculture is the main income source already for decades, without any major new income source (except perhaps for migration). It is not evident that people easily initiate new income earning activities, especially if there is not an enabling environment for this activity and if education levels are low. Only a few strategies to improve coping capacity are adopted. Again, an important role in the adoption of these strategies is apparent for both formal and informal institutions. They can provide training, raise awareness, and promote good practices.

\section{Adoption of High-Cost Strategies Requires a Cash Income or Institutional Assistance}

The more expensive individual adaptation strategieslike the use of water harvesting techniques, improved food storage facilities, and the use of individual irrigation (e.g. pumps) — are also constrained by knowledge and access to credit. Many of these strategies have positive expected net benefits, but face financing constraints and require higher skills. In Ethiopia, several of these more expensive strategies are adopted in consultation 
with the NGOs or governmental institutions present in the area.

\section{More Expensive Communal Strategies Face Financial and Managerial Constraints}

Implementation of the communal strategies requires coordination among the different households in order to avoid free rider behavior and share the costs and benefits in an equitable way. Expected net benefits of these strategies are in many cases positive, but they are constrained by financing and managerial skills. Such projects often have high costs, which cannot be raised by the participating households themselves and which can only be recovered in the longer run. For that reason, the involvement of NGOs or governmental institutions is often necessary. In Ethiopia, the integrated development projects like PSNP, PCDP, and Irrigation and Drainage Project partly fulfil this task. Moreover, informal community institutions play an important role in guaranteeing sufficient commitment among the participating households. The longer run investments (in terms of money and labor) to operate and maintain e.g. communal irrigation schemes require commitments among all participants. This also implies creating a sense of ownership among the participants to assure that the strategies can also be applied in the longer run. It is expected that more training and knowledge transfer about the requirements and pros and cons of the different strategies helps improve this sense of ownership and stimulates households to make their own choices. Finally, for the NGOs and governmental institutions implementing these communal strategies, their presence and involvement should be assured over a longer period as well. For this, it is important to have coordinated, longer term, and integral commitment from international donors.
Assistance from Formal and Informal Institutions may Relieve Adoption Constraints

From the above, three conclusions can be drawn. First, low cost, individual strategies, having low requirements for labor and skills, already are adopted by almost all household types. Second, adoption of some promising strategies may be constrained by financial constraints, labor constraints, or knowledge constraints. As discussed above, these strategies have several types of cost elements, each of which may constrain adoption. More wealthy household types, usually having more cash income, more assets, more cash crop cultivation and more diversified income sources, can adopt the more expensive strategies that reduce their sensitivity or increase their coping capacity. Larger households, with more productive household members, can adopt strategies that are more labor demanding. Higher educated households, having a larger share of household members who attended at least primary education, are better able to choose the strategies that best fit their livelihoods. Interference from formal and informal institutions may lessen some of these constraints. It requires, however, tailor-made strategies of the institutions, targeting carefully the different constraints to strategy adoption. Third, implementation of communal strategies requires back-up from formal and informal institutions. These strategies require awareness raising, commitment, technical expertise, financial support, and managerial back-up. Each of these cost elements may constrain the successful implementation of the communal adaptation strategies. Long-term commitment and integrated coordination by the international donor community may lessen some of these constraints. Some of the actions are specific for particular strategies; others are more general investments in public goods necessary to create an environment that is suitable for sustaining adaptation strategies. 


\section{CONCLUSIONS AND POLICY IMPLICATIONS}

The CALI project was intended to (1) identify the costs of adaptation through local institutions, and (2) investigate which institutions support households to adapt to climate variability, which efforts and costs have to be made for realizing the adaptation options, and how they facilitate adaptation to climate variability. This report presents the results of the household survey, focus group discussions, institutional stakeholder interviews, and expert judgments. The study formulated vulnerability profiles that were based on the exposure of households to climate variability, their sensitivity to the exposure, and their coping capacity. These profiles show that household vulnerability differs substantially between and within villages. Size and diversity of income and the ability to flexibly decide on alternative measures to mitigate the adverse climate effects-which depends on, for example, level of education and dependency ratio- have effects on the adaptation options households adopt and the type of institutional assistance they receive.

This section discusses the main conclusions from the data analysis. This study conducted surveys in six villages in two regions of Ethiopia. For that reason, the conclusions are not representative of the entire country, and generalizing the main results and policy recommendation for other regions with different agroclimatological and socioeconomic characteristics should be done with care. The main conclusions are presented below.

\section{Vulnerability to Climate Change}

- The lowland villages are most vulnerable, whereas the midland villages are in a somewhat better situation. In the lowland villages exposure is high and coping capacity low. In the midland villages, coping capacities are somewhat better and also exposure seems to be lower. In all regions, however, exposure is high due to rainfall variability and droughts. The dependence on one source of income is a threat to livelihoods in all regions.

- Though their cattle are valuable assets, pastoralists often are in a very vulnerable situation despite their apparent wealth. They depend on only a few income sources and have low levels of education. Similarly, households cultivating only small plots of land often have low education levels and only a few sources of income.

- Next to climate hazards such as droughts and rainfall variability, increasing food prices and other nonclimate-related hazards also threaten livelihood security. The focus of development strategies should not entirely change toward reducing climate hazards. Making development strategies climate-proof is important, but it is equally important to maintain a focus on sustainable development.

\section{Adaptation to Climate Change}

- To reduce sensitivity to climate variability, almost all farmers select drought-resistant seeds and adapt planting dates and cropping density. The variable start of the rainy season renders the choice when to 
sow more difficult. Improved rainfall information could help farmers make better choices.

- The presence of extension agencies is reflected in the importance of communal strategies adopted by the households. Many households invest money or time in communal irrigation and water management programs, communal soil fertility programs, communal reforestation, and so on. These strategies also focus on reducing sensitivity to climate variability. The required coordination and investments often cannot be borne by the households themselves, but require institutional assistance. As pointed out by Holden et al. (2006), the selection of communal strategies should be based on a bottomup approach in which the local community is involved in the identification, implementation, and maintenance of the project. Ideally, communal strategies should be based on collective action in which the community is the demanding party.

- Strategies to improve coping capacities are selected less often by households. Income diversification techniques like handicrafts, market trade, and trade of non-timber forest products are adopted by only a few households. Temporary migration also is not seen by many households as an appropriate adaptation strategy. One reason is that local markets are imperfect; that is, the market environment is not equally accessible for everybody in terms of physical and institutional access. In particular, infrastructure (roads and telecommunications) is missing or in bad condition, market conditions are bad, market information is missing, credit facilities are unfavorable to poor households, and legal support is often inaccessible to rural households. This results in high and variable food prices, usurious interest rates, and unbalanced market supply (high supply during periods of low demand and vice versa), which aggravates poverty. The safety net programs currently executed in Ethiopia partly deal with these problems.

- In many cases, both men and women decide about adoption of adaptation strategies. For financial decisions, like market sales or drawing down livestock or savings, and in pastoral areas, men have a larger say. On the other hand, women decide about handicrafts, consumption matters, and charcoal and timber sales. Women have an important say regarding home-garden agriculture. In promoting particular strategies, institutions should target the household members making the decisions.

- Estimates of average costs and time needed to implement the strategies are difficult to interpret. For some of the individual strategies, costs are small but have significant labor implications (for example, for adapting planting dates and cropping densities). It can be concluded, however, that more vulnerable households spend less money on adaptation than the better-off groups. For communal strategies, households usually only invest time; inputs usually are financed by institutions.

\section{Institutional Access}

- Households are in contact with many institutions. For adaptation to climate variability, however, extension agencies and local authorities provide the most assistance. Extension agencies reach almost all households in the areas where they operate. In the areas not covered by them, NGOs are active. Even though many households indicate that they are in contact with cooperatives, religious communities, and women's groups, households do not view these institutions as providing help for climate change adaptation.

- Extension agencies focus their assistance on agricultural and communal strategies. Their role is smaller for strategies related to livestock, migration, smallscale income diversification activities, and trade. This gap is partly filled by NGOs, cooperatives and (informal) village community institutions.

- The better-off households seem to receive more assistance from (informal) village community institutions than the marginalized households. This is an indication that the better-off households, who also adopt communal strategies more often, are more effective in bringing their interests forward. Even though institutional stakeholders indicate that no distinction is made between household types, marginalized groups may not be able to access community institutions if membership fees are required.

- Assistance received by households, both for individual farming and for communal strategies, is especially in terms of training. This is positive as it 
improves household skills. Input is provided for individual farm strategies like adopting improved seeds and fertilizer application and for communal strategies that require investments like reforestation, irrigation schemes, terrace construction, and soil erosion measures (like rock bunds).

- It is striking to observe that only a few households indicate they received food, even though almost all households face food shortages during some periods of the year. Households may not perceive food-forwork as food aid or may be reluctant to admit they received food aid.

- Climate hazards affect institutional activities because aid requests may shift from development to relief projects or because households lose the means and time to invest in adaptation strategies or participate in communal activities. This exemplifies the importance of correctly targeting the institutional assistance to those activities that mitigate the hazards households face.

- Institutions indicate that they face financial, managerial, infrastructural, training, and legal constraints. The coordinating role played by the Ethiopian authorities may constrain small-scale, locally operating institutions. Coordination by national or regional authorities, however, is important to assure that the right assistance is targeted to the right places.

- The institutional stakeholder interviews did not provide insight into the financial constraints faced by institutions. For this, a more in-depth study is necessary that analyzes the financial flows of the institutions and the investments they make in particular strategies.

\section{POLICY RECOMMENDATIONS}

As discussed above, the CALI study provides a number of interesting observations on household vulnerability to climate variability. Moreover, observations on the adaptation options households have adopted in the past to become less sensitive to climate variability show they are aware of the main hazards and are able to select a number of very relevant strategies. The institutional analysis showed that their choice is supported by the network of extension agencies and other (informal) institutions. Based on the above analysis, the following conclusions can be drawn.

\section{More Emphasis Should be Given to Activities to Improve Coping Capacity}

The results show that most adopted strategies focus on reducing sensitivity to the exposure to climate change. The individual farming strategies and the communal strategies on water management and soil erosion are intended to make households less dependent on rainfall. The expected result is a more secure flow of income from agricultural production and livestock. Less attention is paid to activities to improve coping capacity such as income diversification techniques that are correlated less to agricultural output, like handicrafts, commerce, non-timber forest products, or charcoal/timber sales. Home-garden agriculture also deserves more attention as it not only provides more diverse meal composition, but also gives households additional cash resources if the vegetables are sold on the market. As home-garden agriculture usually depends on small-scale irrigation, it is less susceptible to rainfall variability. As discussed below, one of the constraints to successful development of such income diversification techniques is the malfunctioning market environment.

\section{Education and Training Provide People with the Skills to Make Balanced Decisions}

Next to income diversification, the capacity of households to cope with climate change can improve if they have the skills and opportunities to make balanced decisions themselves. Education and training are necessary to obtain these skills. The results show that the younger generation receives more education than their parents. Moreover, the difference in education received between boys and girls seems to disappear. Next to that, assistance received from institutions is in most cases in terms of training. Even though it is difficult to judge the quality of this training, it is a positive sign that apparently substantial investments are made in improving the skills of rural households. This gives future generations a better starting position. Differences between villages and between households, however, are substantial. Children from the vulnerable pastoralist households in Haro Kersa and from the more marginalized households receive less education than those from the other households. As a result, they have scant prospects for future improvements in their level of vulnerability. In targeting activities, it is important to realize that those who need 
it the most are the most difficult to reach. Special attention should be given to those who are difficult to reach, like the poor, illiterate, and subsistence farmers.

Policies Should Have an Integral Approach and not Focus on Climate Adaptation Only

The study found that households perceive climate variability (less rainfall during the rainy season, prolonged periods of drought and increased temperatures) as being an important hazard. The hazards faced, however, are not always caused by global warming. Soil erosion, overgrazing, deforestation, and lack of organic fertilizer use are equally important causes for reduced yields and reduced water storage in the soil. Flood problems in Gola, even though they cause many problems, are related less to climate variability but more to effects of soil degradation and the protection measures taken by the nearby sugar estate. In addition, high food prices and human, animal, and crop diseases are considered to be important and threatening for livelihoods in rural areas. This shows that focusing development policies on climate variability alone will not solve the problems of rural households. Development policies should follow an integral approach in which the major limiting factors are identified and appropriate bottom-up strategies are designed with the objective to create an environment in which development can be sustained. Dealing with only one element of vulnerability will not yield satisfactory results.

\section{Target Assistance at the Household Members Who Make the Decisions}

The results show that particular strategies are adopted by men, but for other strategies women make the decisions. For example, small-scale income diversification strategies are the responsibility of women. In order to ensure that these strategies are adopted, institutions should carefully target their assistance to those making the decisions.

\section{Successful Development Requires a Stable Enabling Market Environment}

One of the reasons why income diversification initiatives often do not endure is that the basic facilities needed for markets to function properly are missing.
This requires, among other things, improved roads, telecommunications, market information, availability of farm inputs, credit facilities, legal services, and veterinary facilities. Most of these options require public investments but may partly be realized through foodfor-work or cash-for-work programs executed by (local) authorities and extension agencies. As shown by Holden et al. (2006), it is important that the selection of communal strategies be based on a bottom-up approach in which the local community is involved in all stages of the project in order to ensure the durability of the investments. Benin and Pender (2006) show that a better functioning market environment makes collective action more beneficial and effective. This is a sign that once an enabling market environment is created, communal strategies focusing on collectively maintaining the natural resource base (soil, forest, and water resources) are more likely to emerge and endure. Needed public investments also include improved market and meteorological information dissemination and disaster management plans in order to provide the households with the information needed to make deliberate choices. Institutional stakeholders were particularly cognizant of malfunctioning markets. The importance of the hazard of high food prices and the problem of high price fluctuations during the year shows that farmers also see the problem of missing markets. These problems, however, cannot be solved by them, but require investments from the authorities.

Targeting of Interventions is Essential in Freeing Marginalized Groups from the Poverty Trap

The results showed that marginalized households adopted less communal strategies and were less involved in the assistance provided by (informal) community institutions in the village. Results do not show that extension agencies focus more on marginalized groups. In targeting aid, it is important that marginalized groups receive special attention. As marginalized groups already are in a more vulnerable situation and have lower capabilities of improving the situation themselves, it is important that they are explicitly considered in development policies. Bottom-up strategies proposed by communities themselves should be adequately reviewed, as they may not involve the more marginal households. 
Do Institutions Have to Give Direct Aid or Create an Enabling Environment?

Because of market problems, some institutions in Ethiopia take over the role of private traders and provide farm inputs at reasonable prices or even for free to start up new farming practices. According to them, good practices are spread in the best possible way if farms are directly subsidized or receive new inputs and new technologies for free. However, subsidies often result in suboptimal use of (agricultural) inputs. An alternative and maybe more sustainable strategy may be to create an environment in which private traders or businesses have the possibility to survive. As argued above, this requires adequate infrastructure, telecommunications, and wellfunctioning financial and legal systems. If national, regional, and local authorities provide these services, an environment is created in which input supply and output purchase by private traders can be sustained.

\section{CALI Results Support the Strategies of the Ethiopian Safety Net Programs}

Looking at the reasons why rural households are in a vulnerable situation, it follows that this is only partly caused by climate variability. Even if exposure to climate change is high, households having a high coping capacity or adopting strategies that reduce their sensitivity to climate change may not be vulnerable. For Ethiopia, refocusing development policies toward climate change adaptation is not necessary. As explained above, making development strategies climate-proof is important, but the main focus should be on removing the factors limiting sustainable development. This helps create an environment in which investments can be sustained, markets function properly and households have the opportunity to take initiatives to improve their own lives. In this respect, the situation in Ethiopia, as illustrated by our research, is positive. Many of the adaptation strategies adopted by the survey households focus on removing some of these limiting factors. These strategies already fit within the existing institutional programs or are planned for implementation. Activities to diversify income, set up water management techniques, implement sustainable agriculture, improve education, and strengthen infrastructure have been promoted for a long time by many governmental and development agencies. The Ethiopian safety net programs, executed through the extension agencies, already seem to have a good overview of the strategies households adopt and the most pressing needs of households. The insights obtained from the CALI study support these programs. The CALI results show that development agencies, working jointly with the households, should select a set of strategies that are climate proof, reduce sensitivity to climate change, and increase coping capacity. These strategies should target the most vulnerable households and enable the creation of an institutional and market environment in which such initiatives can endure. 


\section{REFERENCES}

Admassie, A., B. Adenew, and A. Tadege. 2008. Perceptions of stakeholders on climate change in Ethiopia. Washington, DC: IFPRI.

Benin, S., and J. Pender. 2006. "Collective action in community management of grazing lands: the case of the highlands of northern Ethiopia." Environment and Development Economics 11: 127-149.

CSA (Central Statistical Authority). 2004. The Federal Democratic Republic of Ethiopia Statistical Abstract for 2003. Addis Ababa: CSA.

Deressa, T., R. Hassan, C. Ringler, T. Alemu, and M. Yesuf. 2008. Analyzing the determinants of Farmers' choice of adaptation methods and perception of climate change in the Nile Basin of Ethiopia. Washington, DC: IFPRI.

Deressa, T., R. Hassan, and C. Ringler. 2008. Measuring Ethiopian Farmers' vulnerability to climate change across regional states. Washington, DC: IFPRI.

Holden, S., C.B. Barrett, and F. Hagos. 2006. "Food-forwork for poverty reduction and the promotion of sustainable land use: can it work?" Environment and Development 11: 15-38.

IFPRI. 2006. Reflections from the Development Community. IFPRI Forum. Washington, DC: IFPRI.
Kassam, A.H., H.T. van Velthuizen, P.H. Sloane, G.W. Fischer, and M.M. Shah. 1991. Agro-Ecological Land Resources Assessment For Agricultural Development Planning. A Case Study of Kenya. World Soil Resources Reports,71/5. Rome: FAO.

Kok, M.T.J,. and J. Jäger, eds. 2009. "Vulnerability of people and the environment - challenges and opportunities." Background report for chapter 7 of the Fourth Global Environment Outlook (GEO-4). Bilthoven, the Netherlands: PBL, UNEP.

LIU/DMFSS. 2008. "Livelihood Baseline Data, Ethiopia."

NCCCF and Oxfam America. 2009. Proceedings of the National Climate Change Conference. Addis Ababa, Ethiopia.

NMA (National Meteorology Agency). 2001. "Initial Communication of Ethiopia to the United Nations Framework on Climate Change (UNFCCC)." Addis Ababa, Ethiopia: NMA.

NMA (National Meteorology Agency). 2007. Climate Change National Adaptation Program of Action (NAPA) of Ethiopia. Addis Ababa, Ethiopia: NMA.

Ruijs, A. and M. de Bel. 2009. "CALI Inception Report.” Paper prepared by Royal Haskoning, LEI, under the authority of The World Bank. The Netherlands. 
SC-UK/DPPA. 2008. "Livelihoods and vulnerabilities: an Understanding of Livelihoods in Somali Regional State, Ethiopia."

SC-UK/DPPFSB/DPPA. 2008. "Livelihoods and vulnerabilities: an Understanding of Livelihoods in Afar Regional State, Ethiopia."
UNEP. 2002. Global Mercury Assessment. Geneva: United Nations Environment Programme. 


\section{APPENDIX 1. METHODOLOGY AND RESEARCH FRAMEWORK}

\section{A1.A. METHODOLOGY AND COSTING FRAMEWORK}

In order to reach the objectives of the study, the study sets out to answer the following research questions:

- Which adaptation strategies have been adopted in the past?

- For which hazards have these strategies been adopted and to what extent are the adaptations related to climate variability hazards rather than other hazards?

- Which inputs in terms of cash, materials, information, or labor were required in order to adapt to the changed circumstances?

- Which household and livelihood characteristics explain why certain households adopt particular strategies?

- Which formal or informal institutions are most relevant for assisting or stimulating households to adopt certain strategies?

The study is conducted in Ethiopia with a reasonable representation of major agroecological regions. Both primary and secondary data are collected for the analysis. The primary data is collected through a household questionnaire, focus group discussions, and institutional stakeholder interviews. The household questionnaires aim at obtaining information on (1) household composition, (2) demographic characteristics, (3) resource endowments, (4) perceived climate hazards, (5) adaptation strategies, (6) institutional contacts, and (7) costs associated with the strategies. The focus group discussion aims at obtaining hands-on and detailed information on (1) concepts, perceptions, ideas of a group on perceived climate-related hazards and their effect on livelihoods of the different social groups; (2) the adaptation strategies; (3) the type of institutional support obtained to deal with climate-related hazards; and (4) the costs associated with the adaptation strategies. Institutional stakeholder interviews focus on (1) the types of services provided by the various institutions, (2) their role in assisting households with adaptation, (3) their linkages with authorities, and (4) the costs used for performing their tasks as well as identifying their constraints.

The household data is analyzed to explore whether clusters of households, livelihood, or vulnerability profiles can be distinguished in order to see the linkages between adaptations and clusters. Furthermore, a costing framework was set up (see below) to identify important cost elements of the different adaptation strategies. The use of a combination of household questionnaire, focus group discussions, and institutional stakeholder/expert interviews helps to increase the reliability of data through triangulation.

Moreover, data on some of the questions involving community activities have been verified in focus group discussions. Finally, the results have been cross-checked with experts working in related areas. We are aware of the limitation on the number of research villages for representation and wider generalization. However, the issue of representation cannot be addressed by just adding the number of woredas 


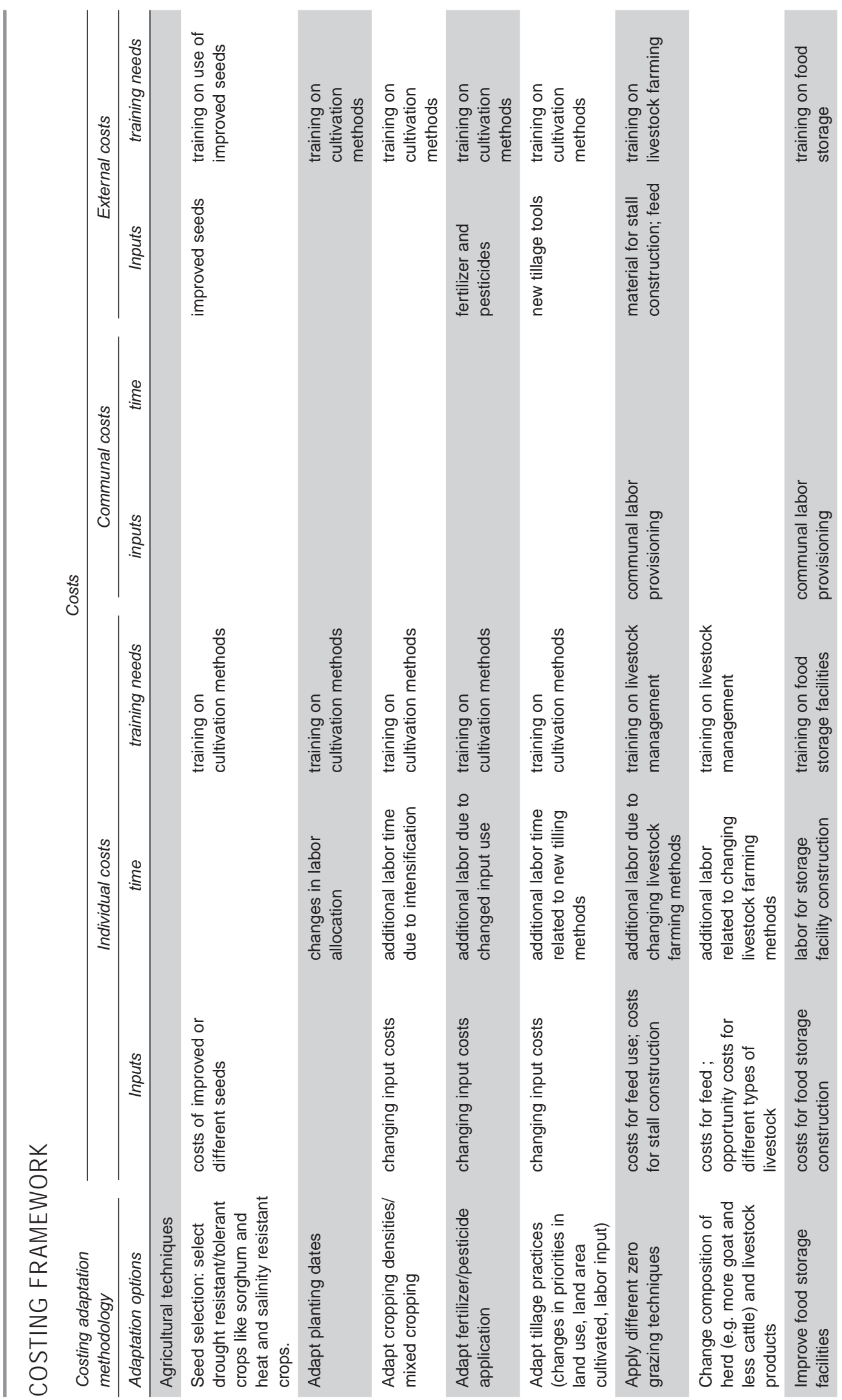




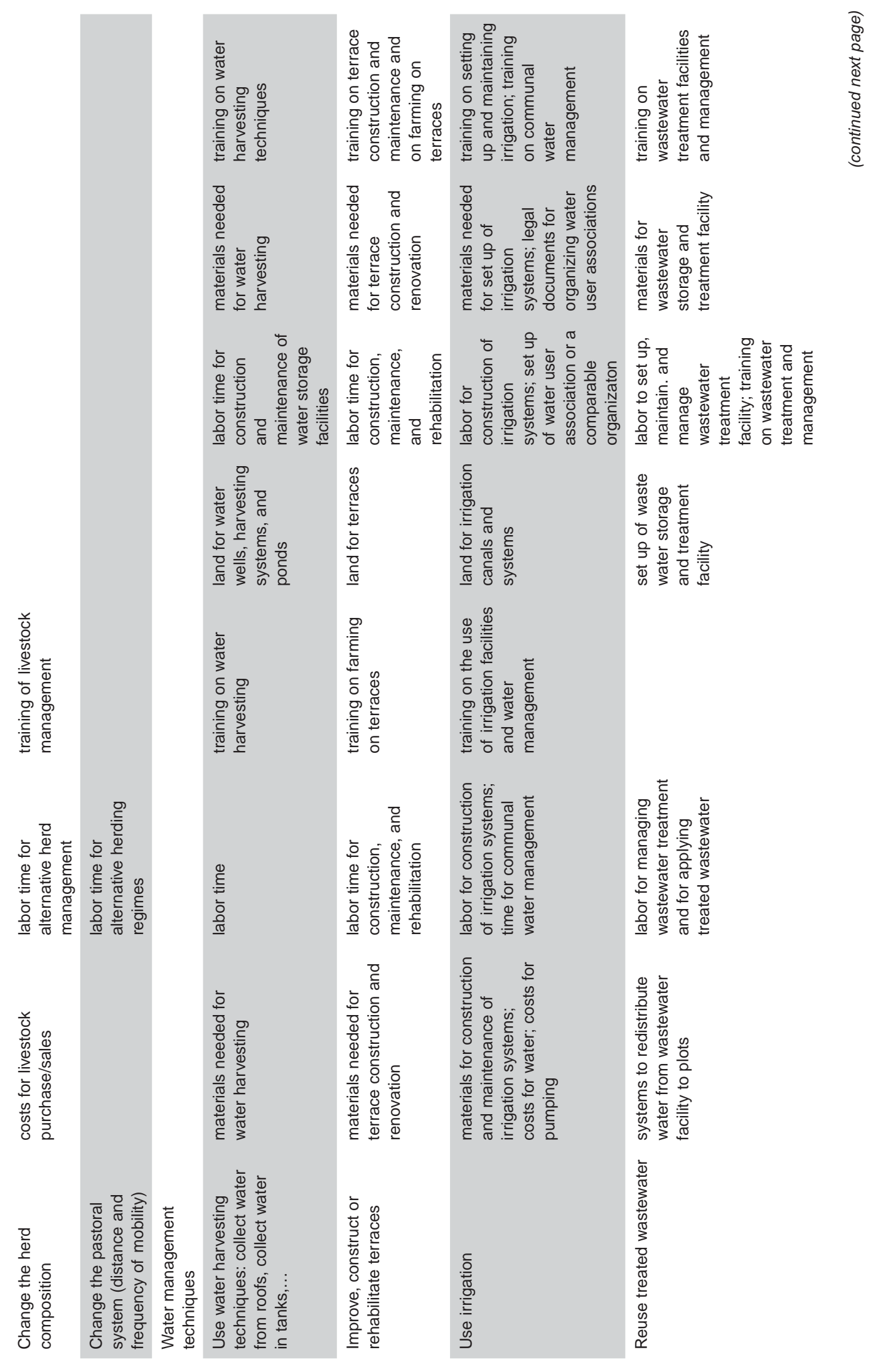




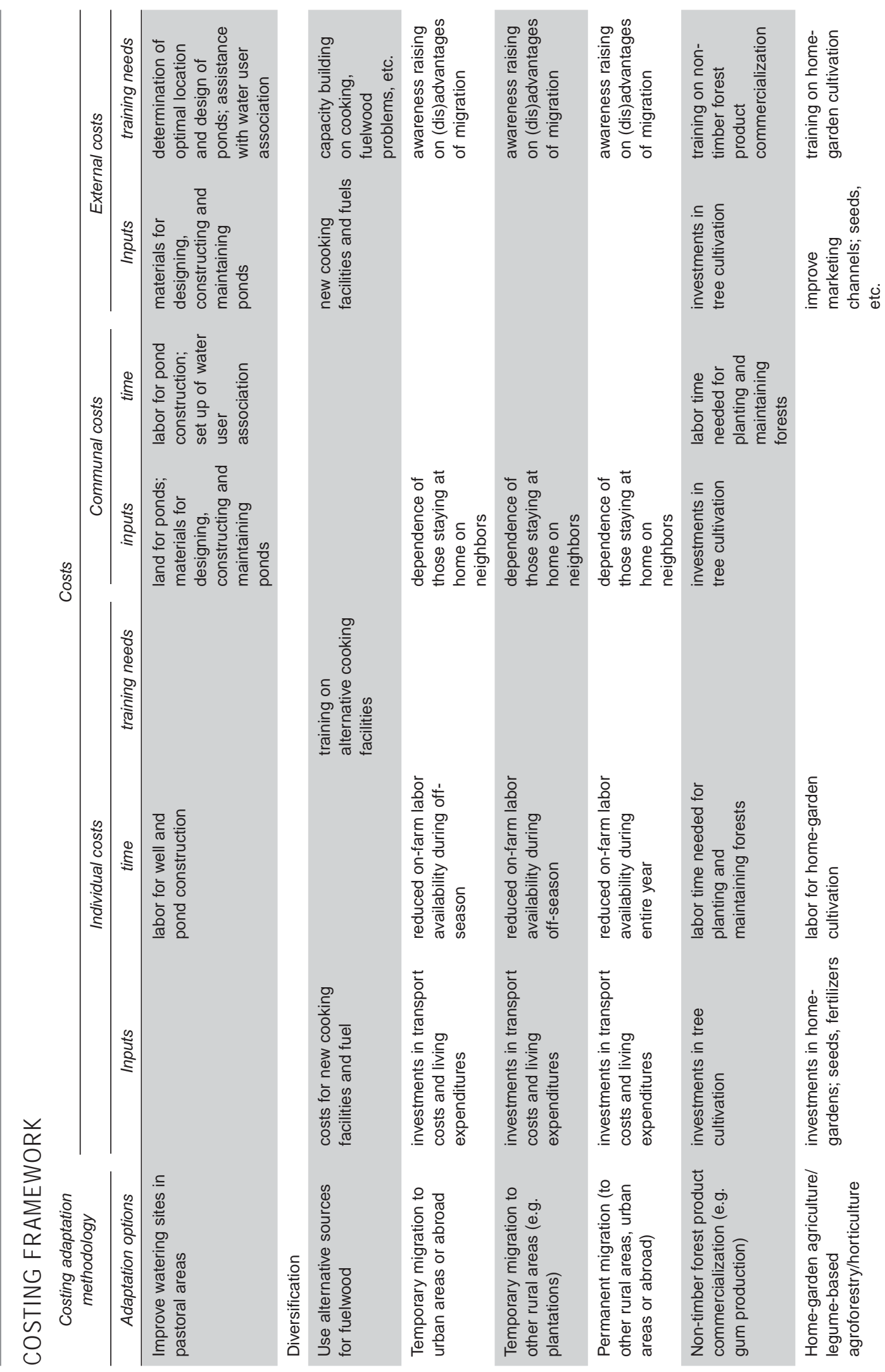




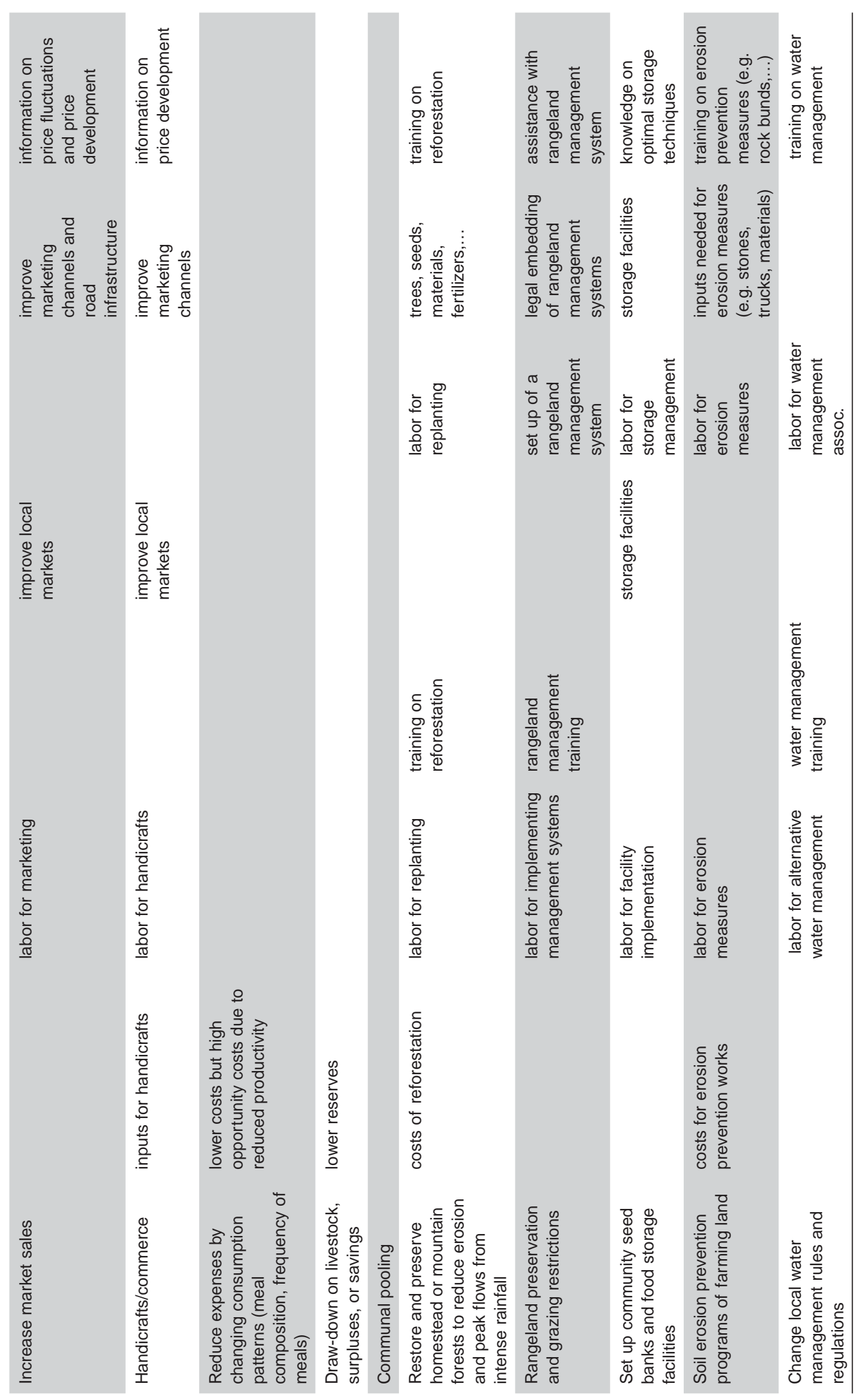


by one or the number of villages within the two woredas. It only reduces the errors. One implication of this is that the study represents a case study of the selected woredas, and we should be cautious about the interpretation of the results coming out of the study.

The questionnaire has been pre-tested to judge if it is comprehensible to the average respondent.

\section{A1.B. HOUSEHOLD QUESTIONNAIRE}

\section{Rationale of the Questionnaire}

Compared to the household questionnaire as presented in the inception report, the questionnaire as used in the villages contains a number of changes. The changes were made in response to comments received during the three launching workshops, lessons learned from visits to the three project countries, observations from the members of the project team, and lessons learned during the pilot interviews.

The objective of the household questionnaire is to learn about the following issues (in order of importance):

- Which adaptation strategies do rural households adopt? Which climate-related hazards explain why households choose these strategies?

- What are the costs the households have to make when they adopt a particular strategy?

- Which institutions are most helpful to assist the households adopting particular adaptation strategies?

- Are there differences in the adaptation strategies adopted by particular household types or wealth classes; which livelihood characteristics best explain which strategies are adopted?

In order to reach these objectives, information will be collected on four issues:

1. Factors explaining livelihood type and wealth class: this contains information on e.g. primary activity (e.g. farming type), household characteristics (size of household, level of education, ...), assets owned, land cultivated, crops cultivated, livestock owned, and access to financial resources.
2. Information on perceptions regarding climaterelated hazards.

3. Information on the adaptation strategies adopted and the costs made to apply the strategies in terms of money, time and in-kind inputs.

4. Information on the institutions with whom households have contacts.

Compared to the household questionnaire in the inception report, the order of some questions has changed, questions 2 till 6 have changed and some of the costing elements asked for and the way they are asked for has changed. The main reason for simplifying and shortening the questions 2 till 6 is that for the purpose of this study, it is not necessary to obtain detailed information on individual household member characteristics and household activities. For example, it is not necessary to know:

- for each household member how many years of education they have;

- what is the exact relation between land cultivated, yields and sales;

- the exact number of each possible type of livestock owned and the exact sales of animals;

- the exact catch and sales of fish.

In these questions we ask for information in such a level of detail that it allows us to define different types of households and livelihoods and to be able to analyze which characteristics explain the choice of a particular strategy. More detailed information on the above issues is interesting and relevant for farming systems studies or household analyses. For the purpose of our study, however, this information is not necessary and it distracts us from the main objective. Moreover, much of the information that is not asked for (e.g. on the amount harvested and the number of animals owned) is sensitive information for which it can be wondered whether reliable answers will be given. Furthermore, in the questionnaire, a number of additional questions are raised in order to obtain gender specific information on adaptation. Below, the questions are discussed one by one.

1. The first question is necessary in order to obtain general information about the respondent and the type of household the respondent is representing. An important determinant of the adaptation 
strategies adopted will be the main activity of the household. For that reason, the respondent is asked to rank using a participatory approach (using cards indicating the possible occupations, if possible using pictures) the importance of the different activities for their household. For small households, it is possible that they are only involved in one or two activities. Larger households and especially extended families are probably involved in multiple activities. Here, it is also asked whether the activity is performed especially by the men or women in the household, in order to learn more about the gender issues.

2. In the second question, we ask for information about household composition and household characteristics. The way this question is asked may differ per country. In principle, it is preferable and easier for the interviewer to ask each individual member about their age, years of education and relation to the household head. However, for example for Mali, it may be preferable to ask for more aggregate information for two reasons. First, in Mali extended families may have a too large number of household members, making this question too time consuming. The country teams have the choice to ask one of the two questions, as long as all household within one country receive the same question. The question also contains a sub-question on migration. This is for double-checking the adoption of the adaptation strategy to permanently or temporarily migrate.

3. The third question elicits information about land and crops cultivated. In the draft version of the questionnaire, we also asked for information about the amount harvested and the amount sold. Moreover, it was proposed by some people to add questions about the date since when particular crops are cultivated and on whether cultivation of particular crop has increased or decreased. This last question would give information about the effect of changing climate characteristics on crops cultivated. We decided not to add this question as it is already part of question 8. Moreover, it is difficult for respondents to indicate how much of each crop was harvested and how much was sold. Moreover, this level of detail is not necessary. In order to know more about household type and wealth class, it is sufficient to know how much land is cultivated with the different types of crops and whether or not they sold part of their harvest on the market. The size of the land cultivated with particular crops tells us which type of farming system we are dealing with (small-middle-large farm, subsistence-mixed-cash crop oriented farm). The yes-no question on sales tells us whether households take part in the money economy. We also ask information about ownership status of land to see whether land ownership has an effect on the adaptation strategies adopted. For countries for which it is sure that the entire household budget is managed by the men, this question can be deleted.

4. The fourth question only applies for households owning livestock. Livestock is an important savings source for many households. For pastoralists, it is their primary source of income. Different from the draft version, we do not ask for detailed information on the amount of animals owned and sold for a large number of possible types of animals. The main reason for this is that people are usually not willing to give exact insights in the number of animals owned and sold. Moreover, in order to learn more about the wealth class of the household, it is sufficient to have information in a more aggregate manner. For that reason, we ask for information per livestock category: breeding cattle, dairy cattle, traction animals (oxen, mule, horse), small ruminants (goats/sheep) and poultry. Moreover, we ask about the number of animals currently owned and the number owned 12 months ago. This gives information on changes in wealth class. This information is also meant to double check some of the questions related to the adaptation options, to indicate whether wealth has increased or decreased and to indicate whether households are participating in the money economy.

5. The fifth question only applies for households engaged in fishing activities. We ask which types of fish are caught and whether they sold fresh or produced fish. Like in the previous question, we do not ask for the amount of fish caught because it is too difficult to answer such a question.

6. The sixth question deals with asset ownership. The types of assets owned are an important determinant of wealth class. The more or more luxury assets owned, the wealthier the household will be. It is expected that wealth class partly explains the types of adaptation strategies adopted. In the 
analysis, we distinguish four types of assets: basic necessary assets (especially equipment), basic nonessential assets (like radio, jewellery, bicycle/ moped,...), luxury assets (like a cell phone, gas/ petrol stove, refrigerator), and top-level assets (including a television, car, and house built of bricks). For the basic necessary and non-essential assets, also the number of assets owned is asked for. For the other types of assets it is asked when they are purchased in order to learn more about changes in wealth class.

7. The seventh question deals with the hazards households experience and their perceptions on the importance of these hazards. First, it is asked which climate-related hazards they have experienced in the past and when they experienced them. In a narrative manner, the respondent is asked in what period the hazard was experienced and whether they can recall any major climate-related events that have taken place in the last 30 years and that have caused substantial changes in livelihoods. Based on that, it is attempted to link it to a particular year. Next to that, it is asked whether the households have any specific difficult periods throughout the year in order to learn more about the vulnerability of the household. It is also asked to what extent these hazards affected their activities and who is affected the most. Thirdly, it is asked which hazards are considered most threatening and whether they have changed. Using a participatory approach (by ordering cards with possible hazards) it is elicited how households perceive the importance of climate and non-climate-related hazards. Here, it is also asked whether the hazards especially affect men or women, in order to learn more about gender differences in hazard perception.

8. In Question 8 more information is elicited about the types of institutions households have contacts with. Moreover, it is attempted to link the reason for contacting a particular institution with the hazards they are facing (as asked for in question 7). This learns us whether particular institutions have a certain focus on particular climate hazards. If they are not related to any climate hazard, this is also indicated.

9. Question 8 is one of the most important questions of the questionnaire. Compared to the draft version, we have slightly changed the order and types of questions. We first ask for the types of adaptation options they have adopted, whether they are adopted by the men or women in the household, and why (which hazard is reduced). Secondly, for those options adopted, we ask for detailed information about the costs. We distinguish between monetary costs, time input and in-kind input that were not purchased. In the draft questionnaire, a participatory approach was proposed to ask for the monetary costs. The rationale for this was that it was thought to be difficult to memorize the costs made for a particular option. We decided to change this approach based on discussions with several people. For households who are only partially integrated in the monetary economy, it can be expected that if they actually have to spent money for adopting a strategy, they know the amount. Next, for the time and money spent on the strategy, it is asked who has to make the expenses: men-women, individual-communal-external. This gives information on the gender perspective of adaptation and the importance of communal and external aid to adopt particular strategies. For the in-kind inputs, it is asked what type and how much of each input is used. In the data analysis phase, it will be attempted to monetarize these inputs in order to learn more about the implicit costs of the options. Thirdly, it is also asked what type of benefit is envisaged if an option is chosen. We distinguish between earning additional cash income, reducing risk and increasing non-cash income. Fourthly, it is asked whether the household received help from institutions. This question is important in order to be better able to target assistance to institutions. It shows which entry points are important and what type of help the institutions need.

In the first village in which the questionnaire is used, it is evaluated whether the questionnaire works as expected. If some questions are too difficult or are misinterpreted, they will be reformulated. It is attempted to keep these reformulations as small as possible, such that only the formulation changes but not the rationale and its position with the questionnaire.

\section{NOTES ON HOW TO CONDUCT THE QUESTIONNAIRE}

These notes give tips about how to ask for some of the questions when conducting the questionnaire. 


\section{Question 1:}

- Not all questions have to be asked to the respondent. Village name and code, household code and sex of the respondent can be filled in without asking it to the respondent.

- i. Rank occupations of the household in order of importance: Use the cards as given at the end of the questionnaire and ask the respondent to lay them down in such a way that the most important occupation of the household is put on the left side and the least important occupation on the right side. Activities not performed can be put on a separate pile. Once the options are ranked, ask whether the activities are especially performed by men or by women. An alternative way of ranking is to give the respondent 15 stones and ask them the put stones on the cards indicating how important they are. The interviewer has to write down the number of stones put on each card. Make sure that for all villages within one country the same approach is adopted.

\section{Question 2:}

First, the country team has to choose whether option 1 or option 2 is chosen. In case of option 1 aggregate information will be asked for on household composition. In option 2, questions will have to be asked for per household member.

- a. within each cell, fill in the number of men or women within a certain age class. Ask the respondent how many boys/girls under the age of 15 life in the household, how many men/women in between 15 and 30 live in the household, etc. Permanently migrated people must not be included. Temporarily migrated members should only be included if they live in the household at the time of the interview.

- b. first ask whether household members have temporarily migrated to another village, city or abroad in the last 12 months; secondly ask for the age of the migrated household members. In the cells, fill in the number of people of a certain age class who have temporarily migrated.

- c. first ask whether household members have permanently migrated from the village. If people have migrated, then ask the age and sex of the people migrated. In the cells, fill in the number of people of a certain age class of have permanently migrated.

- d. ask how many boys/girls/men/women have had education in one of the indicated classes. In the cells, fill in the number of household members who were in school for a particular number of years.

\section{Question 3:}

- a. first ask which crops the household cultivated in the last 12 months. Fill in the names of the crops in column a. When the questionnaires are finished, the interviewer has to fill in the crop codes in the first column of the table.

- b. Ask for each crop how much land was cultivated with that crop. In the cells, fill in the amount of land cultivated in the last 12 months. Make sure that for all households within a village the same unit of measurement is used.

- c. ask for each crop whether the household sold a part of its stock on the market in the last 12 months. Tick yes or no. If a crop is sold, ask whether the earnings from the sales are managed by the men or the women. If the household budget is managed by both equally, tick both $\mathrm{M}$ and $\mathrm{W}$. If it is sure that the entire budget is managed by the men (e.g. in Yemen), this question can be deleted.

- d. ask for how much land the household has ownership rights or permanent or long-term use rights. Use the same unit of measurement as in question b.

- e. ask how much land was rented or sharecropped in. Land sharecropped in is land cultivated by the household that is owned by another household.

\section{Question 4:}

- a. First ask whether the household owns livestock. If the answer is no, look around to see whether indeed there are no signs that not even poultry is owned. If the household indeed does not own any livestock, move to question 5 .

- b. for the types of livestock indicated in the first column of the table, ask whether the number of animals owned is in one of the classes indicated. Tick the cell indicating the number of animals they own. Check whether the answer given is plausible. If a large number of animals are observed close to the dwelling, ask more questions about who owns these 
animals. The distinction made between cattle and dairy cattle refers to livestock owned especially for purpose of meat or reproduction or for the purpose of milk production and sales.

- c. similarly to question $4 \mathrm{~b}$, ask how much livestock was owned 12 months ago.

\section{Question 5:}

- a. first ask whether the household engages in fishing activities. Tick the correct answer. Secondly, if they engage in fishing activities, ask whether they do it individually or as a member of a fishing group. If the answer to the first question is no, move to question 6.

- b. indicate the type of fish people catch. When the questionnaire is finished, the interviewer has to fill in the fish codes in the first column of the table.

- c. ask whether the household sells any freshly caught fish during the last 12 months. Tick the correct answer.

- d. ask whether the household has sold any processed fish. Processed fish is cleaned, smoked or dried. Tick the correct answer.

\section{Question 6:}

- in the table a list is given of possible assets households can own. For the first list of assets it has to be asked whether they own these assets. Tick yes or no. If they own them, ask for the number of the asset they own.

- For the second list of assets, it has to be asked whether they own the asset. Tick yes or no. If they own the asset, ask when they purchased the asset.

\section{Question 7:}

- a. For the five hazards indicated in the first table of question 7, ask whether people experienced in their lifetime periods of more than one year that can be characterized as

1. being more unfavourable than normal years with lower amounts of rainfall than normal during the rainy season, leading to droughts, and which they remember as being distinctly different from other periods;
2. being more unfavourable than normal years with more irregular rainfall, e.g. because it was dry for a long time after the first rains or because the first rains started later or because there were too long periods without rain during the farming season, leading to droughts and reduced yields;

3. being more unfavourable than normal years because it had periods of excessive rainfall due to which fields flooded;

4. being more unfavourable than normal years because it knew excessive showers leading to damage to crops, livestock or property (e.g. destroyed roofs);

5. being unfavourable than normal years with higher than average temperatures which combined with long periods without rainfall resulted in scorched crops.

- b. If they experienced one of the hazard described above, ask when the period took place. If they don't know the year ask for events that have taken place in that period that can be traced back to a year(s).

- c. Ask whether people can recall whether there are any periods in the past 30 years, that can be characterized by major droughts, major floods or major shifts in rainfall pattern and that have caused substantial changes in the way people make a living.

- d. Ask people to describe in their own words the major weather related hazard they are facing in their daily activities. Is it related to the amount of rainfall, the variability (spread of showers over the rainy period), the temperature,....

- e. Ask the respondent whether in the last 12 months they had a period in which they experienced problems to sufficiently feed all household members. Also ask the months in which they experience these problems.

- $f$. for the hazards for which the respondent indicated that they have experienced it, ask how it affected 1. crop production (were yields less??) - 2. area cultivated (did they cultivate less fields??) - 3. livestock owned (did animals die or did they sell animals??) 4. fish landed (did it affect catch) - 5. assets owned (were assets sold to get cash??) - 6. cash income (did they own less cash??)

- g. ask whether the effect had a larger effect on the men or the women of the household, or whether there is no difference. 
- h. For the 10 hazards given in the table (and on cards) ask the respondent to order the cards in such a way that the most important hazard is put on the left side and the least important on the right side. Hazards that are not at all deemed to be important can be put on a separate pile and scored 0 .

- i. ask the respondent whether the hazards indicated in the table have become more or less threatening than in the past. Compared to the past, do they affect production, income and consumption more than in the past?

\section{Question 8:}

- a. Ask with which organizations listed in the table the household holds contacts with

- b. If they have contacts with the organizations, ask how often they have contacts with the organizations.

- c. If they have contacts with the organizations, ask for how long they are in contact with the organization.

- d. The interviewer has to check whether the moment since when they are in touch with an organization is related to any of the climate events as listed in question 7.

- e. ask whether the assistance given by the organizations is useful to reduce the weather related hazards as discussed in question 7 .

\section{Question 9:}

- This question is the most important question of the questionnaire. It is important to get a full overview of the strategies people have adopted to reduce the effects of the different hazards asked for in the previous question.

- $\mathrm{a} / \mathrm{b}$. For the different strategies listed ask whether people have made these changes in their activities in order to reduce their dependence on weather. If they adopted a strategy ask whether the decision to adopt the strategy was made by one of the men or women in the household. Moreover, in that case ask which of the hazards listed in question 7 was the main reason for changing their activities. If none of these hazards was the reason, give the score 6 .

- c. fill in the strategies asked for in question a were adopted to reduce any of the climate-related hazards.
- d. in this question, we have to ask which investments had to be made for adopting the strategy. This refers to cash expenditures that had to be made, time needed to make the change and in-kind inputs that were needed. Moreover, it is asked whether the time spent or cash expenditures made are done by men, by women, by the community or by external organizations.

1. ask whether in first year after adopting the strategy, adoption cost them more time compared to their normal activities and how much time (days).

- For agricultural activities, this may be clear: do the new activities cost more time than the usual practice;

- for water management techniques, setting up and maintaining the systems asks for time;

- for diversification techniques relating to migration, people migrating probably have to spent time on preparing their trip and it takes time before they start earning a living (ask for how much time it takes to find work); for diversification techniques relating to new activities, it takes time make handicrafts, collect timber or produce charcoal.

- For communal pooling, the activities indicated take time to build.

2. Also ask who did the work: 1 . men from the household, 2. women from the household, 3. men jointly with other men from the community, 4. women jointly with other women from the community, 5 people from other organizations.

3. Ask whether people had to make cash expenditures to start the activity.

- For agricultural activities, cash expenditures refer to seeds, equipment, inputs, building materials and other cash expenditures

- For water management techniques, cash expenditures refer to investments in water collection systems, inputs, equipment, materials, etc.

- For diversification techniques related to migration, cash expenditures refer to travel costs and money needed to cover the first period in which people don't earn an income yet. For techniques referring to other activities, cash expenditures refer to equipment and materials needed to start these activities. 
- For communal pooling techniques, cash expenditures refer to expenditures on inputs and equipment that have to be made by the household.

4. If people had to make cash expenditures, how much money did it cost them in the first year after they adopted the strategy.

5. Like for question d.3, ask who had to make the expenditures

6. Ask the type of in-kind input they needed and how much. This has to be filled in in a separate table. In-kind inputs may include equipment or materials that are available in the household or in the village. It refers to all inputs except for the inputs they purchased and labor input.
- e. Ask which benefits they obtained from adopting the strategy;

1. did they earn more cash income,

2. did they have less risk to lose production or animals; did they have less risk on income or food shortages; did they have less risk to water shortages?

3. did their non-cash income increase (higher production, more livestock)

- f. ask whether they were assisted, advised, trained or supported by organizations or institutions working in the village.

- g. if they were assisted by any organization, ask what type of input they received: training, labor, inputs, cash or food. 


\section{Village and household characteristics}

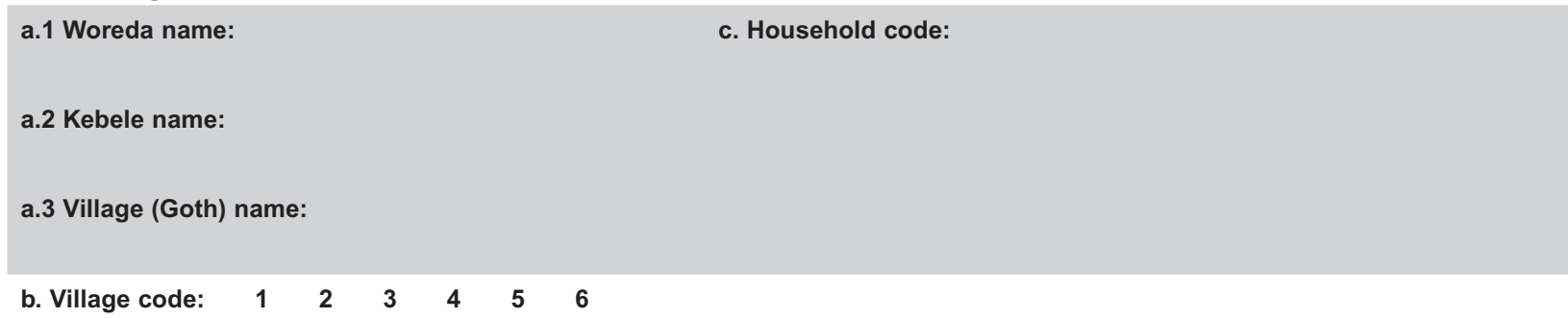
d. Respondent name:
e. Sex of respondent:
$\square$ Male
Female

\section{f. Relation of respondent to household head}
1. Household head
2. Wife of household head
3. Other

g. Number of years the family of the household members is living in the village:

h. Number of years, household occupies this residence:

\section{i. 1 Rank occupations of the household in order of importance}

$(1=$ most important, $\ldots, 8$ = least important; 0 = no source of income for any of the household members;

* use cards indicating the possible activities and ask the respondent to order them from most important to least important, with a separate pile for activities that are not performed;

* alternatively, they can indicate the importance of each activity by allocating stones over the seven items, for which they allocate more stones to the more important activities)

i.2 Indicate whether the activity is especially performed by men or women; if there's no difference, tick both answers.

\begin{tabular}{|c|c|c|c|}
\hline \multirow{2}{*}{\multicolumn{2}{|c|}{$\begin{array}{l}\text { (i.1) } \\
\text { Main activities of the household }\end{array}$}} & \multicolumn{2}{|c|}{$\begin{array}{c}\text { (i.2) } \\
\text { Performed by men or women }\end{array}$} \\
\hline & & Men & Women \\
\hline \multicolumn{4}{|c|}{ Crop farming } \\
\hline \multicolumn{4}{|c|}{ Animal husbandry } \\
\hline \multicolumn{4}{|c|}{ Fisheries } \\
\hline \multicolumn{4}{|c|}{ Day labor within agriculture } \\
\hline \multicolumn{4}{|c|}{ Off-farm labor (non-agricultural) } \\
\hline \multicolumn{4}{|c|}{ Trade and commerce } \\
\hline \multicolumn{4}{|c|}{ Civil servant } \\
\hline Other: & & & \\
\hline
\end{tabular}




\section{Household composition and household characteristics}

This question deals with the household members who are currently living within the household and those who migrated for less than 12 months.

a. What is the sex of the household members? Tick male or female.

b. What is the age of the household members?

c. Did the household member migrate for a period of less than 12 months during the last year? Tick yes or no.

d. How many years of education did the household member receive?

\begin{tabular}{|c|c|c|c|c|c|c|}
\hline \multirow{2}{*}{$\begin{array}{c}\text { Household } \\
\text { member }\end{array}$} & \multicolumn{2}{|c|}{ Sex } & \multirow{2}{*}{$\begin{array}{c}\text { Age } \\
\text { (years) }\end{array}$} & \multicolumn{2}{|c|}{$\begin{array}{c}\text { Temporarily } \\
\text { migrated }\end{array}$} & \multirow[b]{2}{*}{ Years of education } \\
\hline & Male & Female & & Yes & No & \\
\hline \multicolumn{7}{|l|}{1} \\
\hline \multicolumn{7}{|l|}{2} \\
\hline \multicolumn{7}{|l|}{3} \\
\hline \multicolumn{7}{|l|}{4} \\
\hline \multicolumn{7}{|l|}{5} \\
\hline \multicolumn{7}{|l|}{6} \\
\hline \multicolumn{7}{|l|}{7} \\
\hline \multicolumn{7}{|l|}{8} \\
\hline \multicolumn{7}{|l|}{9} \\
\hline \multicolumn{7}{|l|}{10} \\
\hline \multicolumn{7}{|l|}{11} \\
\hline \multicolumn{7}{|l|}{12} \\
\hline \multicolumn{7}{|l|}{13} \\
\hline \multicolumn{7}{|l|}{14} \\
\hline 15 & & & & & & \\
\hline
\end{tabular}

a. Are there any household members who belong to the household but who have migrated permanently? Note that these do not refer to household members who left the household to start their own household somewhere else. It refers e.g. to husbands or wives who have migrated permanently with the objective to send cash to the village.

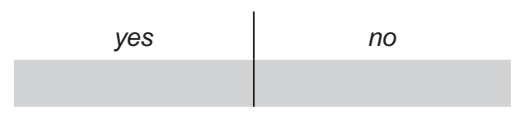

If the answer was yes: ask which people migrated permanently? 


\section{Crops cultivated last year}

a. What are the crops you cultivated during the last 12 month (tick if the crop is grown)

b. How much land have you cultivated with each of these crops?

c. From which crops harvested during the last 12 months did you sell a part? (tick 'yes' or 'no'). If crops are sold, ask whether the money earned is managed by the men or women. If the household budget is managed equally by the men and women, tick both cells 'men' and 'women'.

\begin{tabular}{|c|c|c|c|c|c|c|c|}
\hline \multirow[b]{2}{*}{ Crop code } & \multirow{2}{*}{$\begin{array}{l}\text { (a) } \\
\text { Crops cultivated during the last } 12 \\
\text { months }\end{array}$} & \multicolumn{2}{|c|}{$\begin{array}{l}\text { (b) } \\
\text { Land cultivated }\end{array}$} & \multicolumn{2}{|c|}{$\begin{array}{l}\text { (c.1) } \\
\text { Sold }\end{array}$} & \multicolumn{2}{|c|}{$\begin{array}{c}(c .2) \\
\text { Income managed by whom? }\end{array}$} \\
\hline & & Amount & Unit & Yes & No & Men & Women \\
\hline \multicolumn{8}{|l|}{1} \\
\hline \multicolumn{8}{|l|}{2} \\
\hline \multicolumn{8}{|l|}{3} \\
\hline \multicolumn{8}{|l|}{4} \\
\hline \multicolumn{8}{|l|}{5} \\
\hline \multicolumn{8}{|l|}{6} \\
\hline \multicolumn{8}{|l|}{7} \\
\hline \multicolumn{8}{|l|}{8} \\
\hline \multicolumn{8}{|l|}{9} \\
\hline \multicolumn{8}{|l|}{10} \\
\hline \multicolumn{8}{|l|}{11} \\
\hline \multicolumn{8}{|l|}{12} \\
\hline \multicolumn{8}{|l|}{13} \\
\hline \multicolumn{8}{|l|}{14} \\
\hline \multicolumn{8}{|l|}{15} \\
\hline \multicolumn{8}{|l|}{16} \\
\hline \multicolumn{8}{|l|}{17} \\
\hline \multicolumn{8}{|l|}{18} \\
\hline \multicolumn{8}{|l|}{19} \\
\hline 20 & & & & & & & \\
\hline
\end{tabular}

d. How much land do you own or have permanent or long-term use right for? (unit)

\section{Livestock}

a. Does the household own livestock or animals?

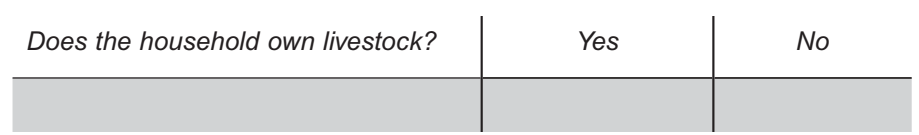

\section{Continue with question $4 \mathrm{~b}$ only if the household owns livestock!}


b. How much livestock does the household currently own? (mark the category indicating the number of livestock owned)

\begin{tabular}{|c|c|c|c|c|}
\hline \multirow[b]{2}{*}{ Livestock } & \multicolumn{4}{|c|}{$\begin{array}{l}\text { (b) } \\
\text { How much livestock does the household } \\
\text { currently own? }\end{array}$} \\
\hline & $1-2$ & $3-5$ & $6-10$ & $\begin{array}{c}\text { More than } \\
10\end{array}$ \\
\hline \multicolumn{5}{|l|}{ 1. Beef cattle } \\
\hline \multicolumn{5}{|l|}{ 2. Dairy cattle } \\
\hline \multicolumn{5}{|l|}{ 3. Camels } \\
\hline \multicolumn{5}{|l|}{ 4. Traction livestock (e.g. mule, horse, oxen) } \\
\hline \multicolumn{5}{|l|}{ 5. Goats / sheep } \\
\hline 6. Poultry & & & & \\
\hline
\end{tabular}

\section{Fisheries}

a. Does the household engage in fishing activities?

\begin{tabular}{l|l|l}
\multirow{2}{*}{ Does the household engage in fishing activities? } & Yes & No \\
\cline { 3 - 4 } & & \\
\hline & & \\
\hline \multirow{2}{*}{ Is the household a member of a fishing group? } & Yes & No \\
\cline { 2 - 3 } & & \\
\hline
\end{tabular}

\section{Continue with question $\mathbf{5 b}-\mathrm{d}$ only if the household engages in fishing activities!}

b. Which type of fish do you catch?

c. Did you sell any fresh fish during the last 12 months?

d. Did you process (clean, dry or smoke) and sell any fish during the last 12 months?

\begin{tabular}{|c|c|c|c|c|c|}
\hline \multirow[b]{2}{*}{ Fish code } & \multirow{2}{*}{$\begin{array}{l}\text { (b) } \\
\text { Fish species }\end{array}$} & \multicolumn{2}{|c|}{$\begin{array}{l}\text { (c) } \\
\text { Sold }\end{array}$} & \multicolumn{2}{|c|}{$\begin{array}{c}(d) \\
\text { Process and sell }\end{array}$} \\
\hline & & Yes & No & Yes & No \\
\hline & & & & & \\
\hline & & & & & \\
\hline & & & & & \\
\hline & & & & & \\
\hline & & & & & \\
\hline & & & & & \\
\hline & & & & & \\
\hline & & & & & \\
\hline & & & & & \\
\hline & & & & & \\
\hline
\end{tabular}




\section{Major assets owned}

a. Which of the listed assets does the household own?

b. If you own these assets, how many do you own?

c. If you own these assets, how many years ago did you purchase them?

\begin{tabular}{|c|c|c|c|}
\hline \multirow[b]{2}{*}{ Item } & \multicolumn{2}{|c|}{$\begin{array}{c}\text { (a) } \\
\text { Assets owned }\end{array}$} & \multirow{2}{*}{$\begin{array}{c}\text { If (a) is yes: } \\
\text { (b) } \\
\text { Number of assets owned }\end{array}$} \\
\hline & yes & no & \\
\hline \multicolumn{4}{|l|}{ Plough } \\
\hline \multicolumn{4}{|l|}{ Hoe } \\
\hline \multicolumn{4}{|l|}{ Axe } \\
\hline \multicolumn{4}{|l|}{ Sickle } \\
\hline \multicolumn{4}{|l|}{ Shovel } \\
\hline \multicolumn{4}{|c|}{ Fishing equipment } \\
\hline \multicolumn{4}{|l|}{ Jewellery } \\
\hline \multicolumn{4}{|l|}{ Cart } \\
\hline \multicolumn{4}{|l|}{ Improved stove } \\
\hline \multicolumn{4}{|l|}{ Radio } \\
\hline \multicolumn{4}{|l|}{ Bicycle/moped } \\
\hline \multicolumn{4}{|c|}{ Iron roofed house } \\
\hline \multicolumn{4}{|l|}{ Kitchen house } \\
\hline Item & & & $\begin{array}{c}\text { If (a) is yes: } \\
\text { (c) } \\
\text { When purchased? }\end{array}$ \\
\hline \multicolumn{4}{|l|}{ Gas/petrol stove } \\
\hline \multicolumn{4}{|l|}{ Refrigerator } \\
\hline \multicolumn{4}{|c|}{ Stable for livestock } \\
\hline \multicolumn{4}{|l|}{ Cellphone } \\
\hline \multicolumn{4}{|l|}{ Television } \\
\hline \multicolumn{4}{|l|}{ Boat } \\
\hline \multicolumn{4}{|c|}{ House built of bricks } \\
\hline \multicolumn{4}{|l|}{ Car } \\
\hline \multicolumn{4}{|l|}{ Bank account } \\
\hline \multicolumn{4}{|l|}{ Other............. } \\
\hline Other............ & & & \\
\hline
\end{tabular}

\section{Importance of hazards endangering livelihood}

a. Have you experienced in your lifetime periods which are characterized by more or less favourable rainfall or temperature? (Tick yes or no)

b. If you experienced the hazard, can you indicate when this has taken place or do you know of important events that have taken place during those periods? (present the year(s) or describe the event in such a way that the year can be determined by us)

c. For those climate related hazards that you have experienced, to what extent did you experience effects in your activities?

d. Which household members are affected more by the hazard; the men (m), the women (w) or no difference between them (tick both)? 


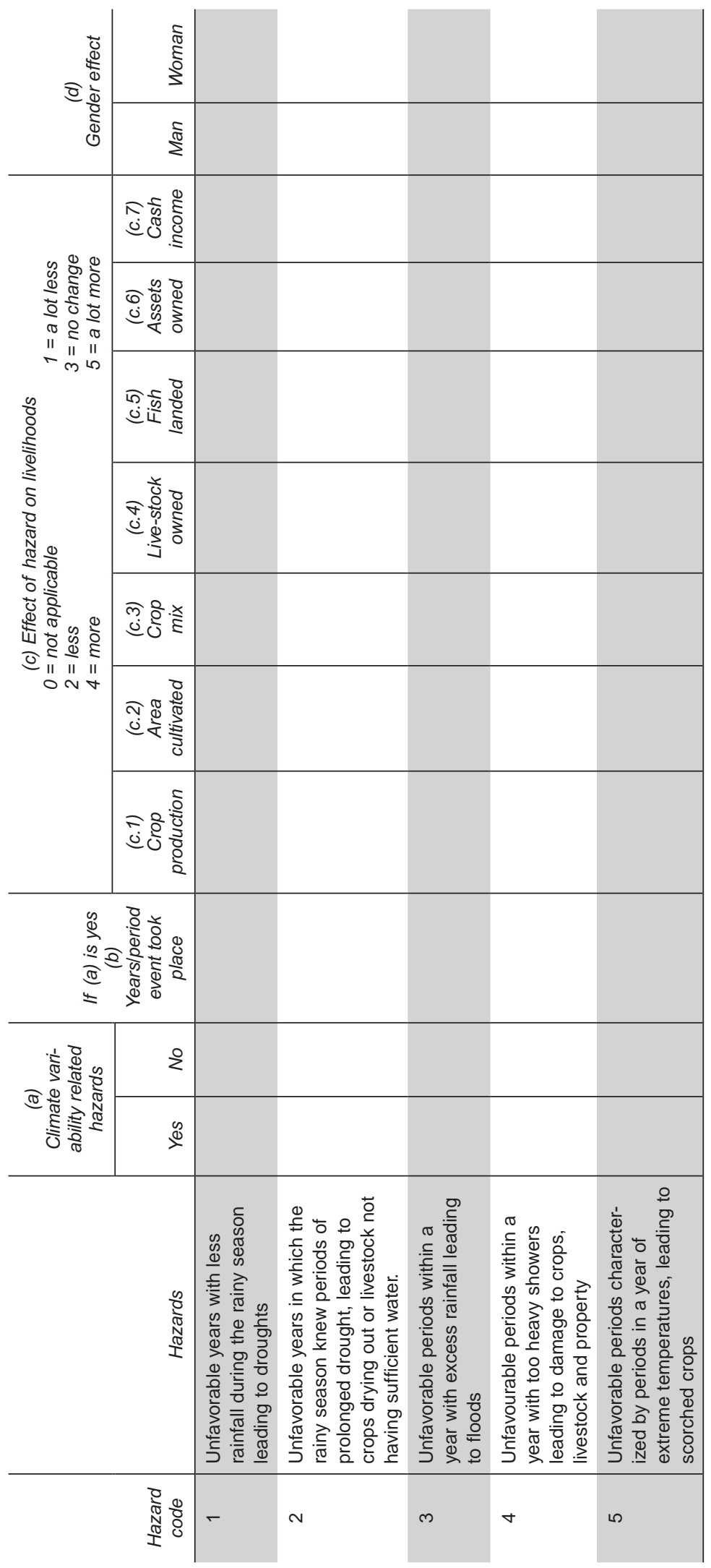


e. Do you recall any major periods of drought or flood in the past 30 years that have substantially changed the lives of many people in the area and which have caused large changes in the way people till their land or earn a living?

Note to interviewers: check to what extent this corresponds with the hazards given in question 7 a.

f. Describe in your own words the major climate related hazards you are facing in your daily activities.

Note to interviewers: check to what extent this corresponds with the hazards given in question $7 a$.

g. In the last 12 months, were there any periods in which the household experienced difficulties to sufficiently feed all household members? If there were such periods, which months were difficult?

g.1 Experience any difficult periods last year?

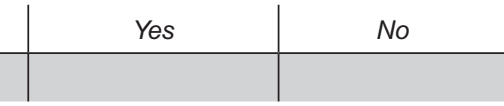

g.2 Which months were difficult?

\begin{tabular}{c|c|c|c|c|c|c|c|c|c|c|c}
\hline jan & feb & march & april & May & june & july & aug & sept & oct & nov & dec \\
\hline & & & & & & & & & & & \\
\end{tabular}

h. Rank the hazards given below from $1=$ the least important to $10=$ the most important and use cards describing the hazards

i. If you compare the situation in the last five years with the period before. Have the hazards become more threatening in the last 5 years?

\begin{tabular}{|c|c|c|c|}
\hline \multirow[b]{2}{*}{ Hazards } & \multirow{2}{*}{$\begin{array}{l}(h) \\
\text { Hazard ranking }\end{array}$} & \multicolumn{2}{|c|}{$\begin{array}{c}\text { (i) More or less threatening than in the } \\
\text { past? }\end{array}$} \\
\hline & & Yes & No \\
\hline \multicolumn{4}{|c|}{ Drought due to less rainfall during the rainy season } \\
\hline \multicolumn{4}{|c|}{ Drought due to periods of drought during the rainy season } \\
\hline \multicolumn{4}{|c|}{ Floods due to excessive rainfall } \\
\hline \multicolumn{4}{|c|}{ Damage due to excessively heavy showers } \\
\hline \multicolumn{4}{|c|}{ Changed average and extreme temperatures } \\
\hline \multicolumn{4}{|l|}{ Human diseases } \\
\hline \multicolumn{4}{|c|}{ Animal or crop pests and diseases } \\
\hline \multicolumn{4}{|c|}{ Decreasing soil fertility } \\
\hline \multicolumn{4}{|c|}{ Problems with input purchase or output sales } \\
\hline \multicolumn{4}{|l|}{ High food prices } \\
\hline Other: ............ & & & \\
\hline
\end{tabular}




\section{Institutions}

a. With which organizations or groups does your household have contact?

b. If you have been in contact with an organization, how often do you have contacts?

c. If you have been in contact with the organization, since when have you been contacting the specific institution? (Is it possible to link the date since when households are in contact with an institution with the data since when a hazard is experienced as discussed in question $7 \mathrm{a}$

d. If you have been in contact with the organization, has the help or assistance obtained been helpful to prepare your household for hazards which are a danger for your household?

\begin{tabular}{|c|c|c|c|c|c|c|c|}
\hline \multirow{2}{*}{$\begin{array}{l}\text { Organization } \\
\text { Hazards }\end{array}$} & \multicolumn{2}{|c|}{$\begin{array}{c}\text { (a) } \\
\text { In contact }\end{array}$} & \multirow[t]{2}{*}{$\begin{array}{c}\text { (b) } \\
\text { Frequency of contacts with } \\
\text { institutions } \\
\begin{array}{c}1 \text { = never; } 2 \text { = occasionally; } \\
3=\text { during the growing sea- } \\
\text { son; } 4 \text { = a few times per } \\
\text { year; } \\
5=\text { a few times per month; } \\
6=\text { every week }\end{array}\end{array}$} & \multirow[t]{2}{*}{$\begin{array}{c}(c) \\
\text { Have been in contact } \\
\text { since } \\
1 \text { = this year; } \\
2=\text { last year; } \\
3=\text { five years ago; } \\
4=\text { ten years ago; } \\
5=\text { more than } 10 \\
\text { years ago }\end{array}$} & \multirow[t]{2}{*}{$\begin{array}{c}(d) \\
\text { Link to hazards in question } 7 \\
\begin{array}{c}1=\text { less rainfall; } \\
2=\text { dry spells during rainy } \\
\text { season; } \\
3=\text { floods; } \\
4=\text { heavy showers; } \\
5=\text { extreme temperatures; } \\
6=\text { other }\end{array}\end{array}$} & \multicolumn{2}{|c|}{$\begin{array}{c}\text { (e) } \\
\text { Helpful for } \\
\text { adaptation }\end{array}$} \\
\hline & Yes & No & & & & Yes & No \\
\hline \multicolumn{8}{|l|}{ 1. Local authorities } \\
\hline \multicolumn{8}{|l|}{ 2. Extension agents } \\
\hline \multicolumn{8}{|l|}{ 3. NGOs } \\
\hline \multicolumn{8}{|l|}{$\begin{array}{l}\text { 4. Cooperatives and } \\
\text { self-help groups }\end{array}$} \\
\hline $\begin{array}{l}\text { 5. MFIs and financial } \\
\text { self-help groups }\end{array}$ & & & & & & & \\
\hline
\end{tabular}

\begin{tabular}{|c|c|c|c|c|c|c|c|}
\hline \multirow{2}{*}{$\begin{array}{c}\text { Organization } \\
\text { Hazards }\end{array}$} & \multicolumn{2}{|c|}{$\begin{array}{c}\text { (a) } \\
\text { In contact }\end{array}$} & \multirow[t]{2}{*}{$\begin{array}{c}\text { (b) } \\
\text { Frequency of contacts with } \\
\text { institutions } \\
1 \text { = never; } \\
2=\text { occasionally; } \\
\text { during the growing } \\
\text { season; } \\
4=\text { a few times per year; } \\
5=\text { a few times per month; } \\
6=\text { every week }\end{array}$} & \multirow[t]{2}{*}{$\begin{array}{c}(c) \\
\text { Have been in contact } \\
\text { since } \\
1=\text { this year; } \\
2=\text { last year; } \\
3=\text { five years ago; } \\
4=\text { ten years ago; } \\
5=\text { more than } \\
10 \text { years ago }\end{array}$} & \multirow[t]{2}{*}{$\begin{array}{l}\text { (d) } \\
\text { Link to hazards in question } 7 \\
\begin{array}{c}1 \text { = less rainfall; } \\
2=\text { dry spells during rainy } \\
\text { season; } \\
3 \text { = floods; } \\
4 \text { = heavy showers; } \\
5=\text { extreme temperatures; } \\
6=\text { other }\end{array}\end{array}$} & \multicolumn{2}{|c|}{$\begin{array}{c}(e) \\
\text { Helpful for } \\
\text { adaptation }\end{array}$} \\
\hline & Yes & No & & & & Yes & No \\
\hline \multicolumn{8}{|l|}{ 1.Religious groups } \\
\hline \multicolumn{8}{|l|}{ 7. Women's groups } \\
\hline \multicolumn{8}{|l|}{ 8. Other.......... } \\
\hline \multicolumn{8}{|l|}{ 9. Other.......... } \\
\hline \multicolumn{8}{|l|}{ 10. Other } \\
\hline 11. Other & & & & & & & \\
\hline
\end{tabular}




\section{Major hazards and strategies of the household to cope with hazards}

a. Do you apply the adaptation options given below in order to adapt to the hazards given in the previous question? Who decided about the strategy change; one of the men or women of the household?

b. If the adaptation strategy is adopted, the impact of which of the hazards is reduced?

\begin{tabular}{|c|c|c|c|c|c|c|c|c|c|c|}
\hline \multirow[b]{2}{*}{ Strategy type } & \multicolumn{4}{|c|}{ (a) Strategy adopted } & \multicolumn{6}{|c|}{ (b) The impact of which hazards are reduced? Impact of: } \\
\hline & Yes & No & Men & Women & $\begin{array}{l}1=\text { less } \\
\text { rainfall }\end{array}$ & $\begin{array}{c}2=\text { dry spells } \\
\text { during rainy } \\
\text { season }\end{array}$ & $3=$ floods & $\begin{array}{l}4=\text { heavy } \\
\text { showers }\end{array}$ & $\begin{array}{l}5=\text { extreme } \\
\text { temperatures }\end{array}$ & $6=$ other \\
\hline \multicolumn{11}{|c|}{ A. AGRICULTURAL TECHNIQUES } \\
\hline \multicolumn{11}{|l|}{ A1. Crop selection } \\
\hline \multicolumn{11}{|l|}{ A2. Adapt planting dates } \\
\hline \multicolumn{11}{|l|}{$\begin{array}{l}\text { A3. Adapt cropping } \\
\text { densities }\end{array}$} \\
\hline \multicolumn{11}{|l|}{$\begin{array}{l}\text { A4. Adapt fertilizer/pesti- } \\
\text { cide application }\end{array}$} \\
\hline \multicolumn{11}{|l|}{$\begin{array}{l}\text { A5. Adapt tillage } \\
\text { practices }\end{array}$} \\
\hline \multicolumn{11}{|l|}{$\begin{array}{l}\text { A6. Change the pastoral } \\
\text { system (distance and } \\
\text { frequency of mobility) }\end{array}$} \\
\hline \multicolumn{11}{|l|}{$\begin{array}{l}\text { A7. Change the herd } \\
\text { composition }\end{array}$} \\
\hline \multicolumn{11}{|l|}{$\begin{array}{l}\text { A8. Apply different feed } \\
\text { techniques, like e.g. zero } \\
\text { grazing }\end{array}$} \\
\hline \multicolumn{11}{|l|}{$\begin{array}{l}\text { A9. Change from pasto- } \\
\text { ral to sedentary agricul- } \\
\text { tural system }\end{array}$} \\
\hline \multicolumn{11}{|l|}{$\begin{array}{l}\text { A10. Improve food stor- } \\
\text { age facilities }\end{array}$} \\
\hline A11. Other ....... & & & & & & & & & & \\
\hline
\end{tabular}

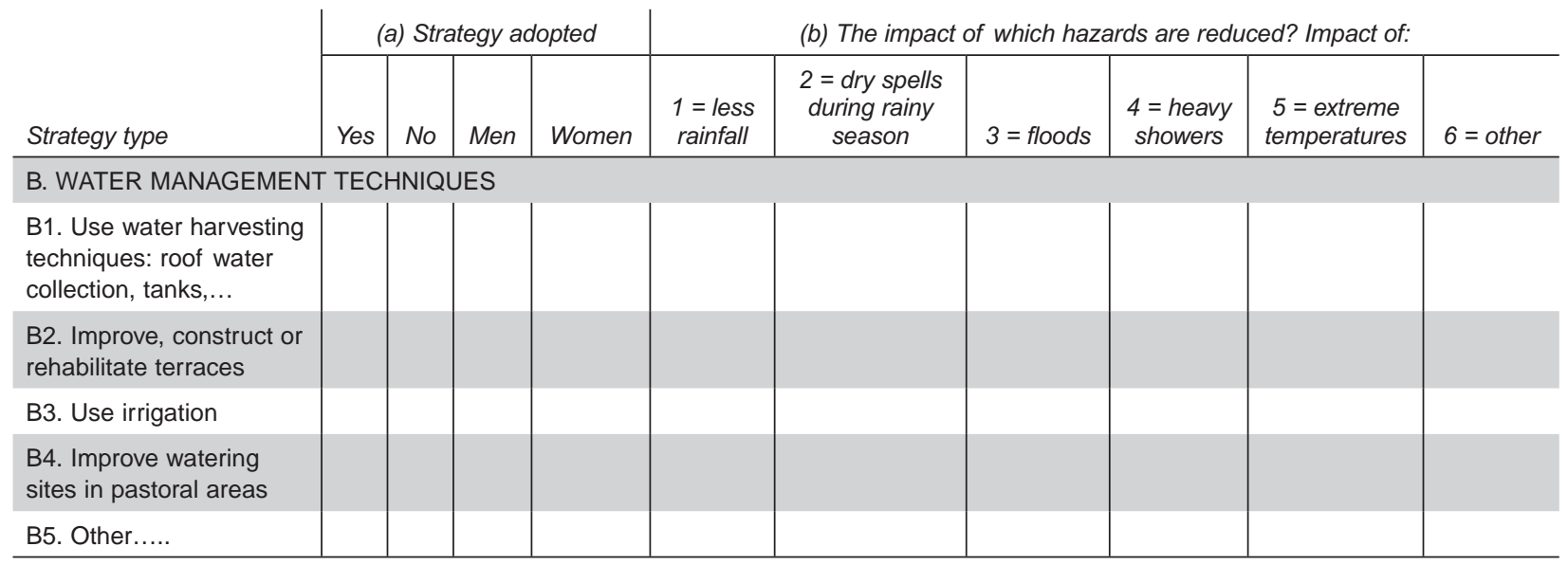




\begin{tabular}{|c|c|c|c|c|c|c|c|c|c|c|}
\hline \multirow[b]{2}{*}{ Strategy type } & \multicolumn{4}{|c|}{ (a) Strategy adopted } & \multicolumn{6}{|c|}{ (b) The impact of which hazards are reduced? Impact of: } \\
\hline & Yes & No & Men & Women & $\begin{array}{l}1=\text { less } \\
\text { rainfall }\end{array}$ & $\begin{array}{l}2=\text { dry spells } \\
\text { during rainy } \\
\text { season }\end{array}$ & $3=$ floods & $\begin{array}{l}4=\text { heavy } \\
\text { showers }\end{array}$ & $\begin{array}{c}5=\text { extreme } \\
\text { temperatures }\end{array}$ & $6=$ other \\
\hline \multicolumn{11}{|l|}{ C. DIVERSIFICATION } \\
\hline \multicolumn{11}{|l|}{$\begin{array}{l}\text { C1. Temporal migration to } \\
\text { urban areas or abroad }\end{array}$} \\
\hline \multicolumn{11}{|l|}{$\begin{array}{l}\text { C2. Temporal migration } \\
\text { to other rural areas (e.g. } \\
\text { plantations) }\end{array}$} \\
\hline \multicolumn{11}{|l|}{$\begin{array}{l}\text { C3. Permanent migration } \\
\text { (to other rural areas, } \\
\text { urban areas or abroad) }\end{array}$} \\
\hline \multicolumn{11}{|l|}{$\begin{array}{l}\text { C4. Non-timber forest } \\
\text { product commercialisa- } \\
\text { tion }\end{array}$} \\
\hline \multicolumn{11}{|l|}{$\begin{array}{l}\text { C5. Home-garden agri- } \\
\text { culture }\end{array}$} \\
\hline \multicolumn{11}{|l|}{$\begin{array}{l}\text { C6. Increase market } \\
\text { sales }\end{array}$} \\
\hline \multicolumn{11}{|l|}{ C7. Handicrafts } \\
\hline \multicolumn{11}{|l|}{$\begin{array}{l}\text { C8. Charcoal or timber } \\
\text { sales }\end{array}$} \\
\hline \multicolumn{11}{|l|}{ C9. Start fisheries } \\
\hline \multicolumn{11}{|l|}{$\begin{array}{l}\text { C10. Reduce expenses } \\
\text { by changing consumption } \\
\text { (type and number of } \\
\text { meals) }\end{array}$} \\
\hline \multicolumn{11}{|l|}{$\begin{array}{l}\text { C11. Draw down on live- } \\
\text { stock, surpluses or sav- } \\
\text { ings }\end{array}$} \\
\hline C12. Other & & & & & & & & & & \\
\hline
\end{tabular}

\begin{tabular}{|c|c|c|c|c|c|c|c|c|c|c|}
\hline \multirow[b]{2}{*}{ Strategy type } & \multicolumn{4}{|c|}{ (a) Strategy adopted } & \multicolumn{6}{|c|}{ (b) The impact of which hazards are reduced? Impact of: } \\
\hline & Yes & No & Men & Women & $\begin{array}{l}1=\text { less } \\
\text { rainfall }\end{array}$ & $\begin{array}{l}2=\text { dry spells } \\
\text { during rainy } \\
\text { season }\end{array}$ & $3=$ floods & $\begin{array}{l}4=\text { heavy } \\
\text { showers }\end{array}$ & $\begin{array}{c}5=\text { extreme } \\
\text { temperatures }\end{array}$ & $6=$ other \\
\hline \multicolumn{11}{|c|}{ D. COMMUNAL POOLING } \\
\hline \multicolumn{11}{|l|}{$\begin{array}{l}\text { D1. Restore and pre- } \\
\text { serve homestead or } \\
\text { mountain forests to } \\
\text { reduce erosion }\end{array}$} \\
\hline \multicolumn{11}{|c|}{$\begin{array}{l}\text { D2. Rangeland preserva- } \\
\text { tion and grazing restric- } \\
\text { tions }\end{array}$} \\
\hline \multicolumn{11}{|c|}{$\begin{array}{l}\text { D3. Soil erosion preven- } \\
\text { tion programmes (e.g. } \\
\text { community terracing) }\end{array}$} \\
\hline \multicolumn{11}{|l|}{$\begin{array}{l}\text { D4. Communal water } \\
\text { harvesting, tanks }\end{array}$} \\
\hline \multicolumn{11}{|c|}{ D5. Communal irrigation } \\
\hline \multicolumn{11}{|l|}{ D6. Other: ........... } \\
\hline D7. Other: ........... & & & & & & & & & & \\
\hline
\end{tabular}


c. Do you apply the adaptation options given below (separate listing of A1-D7) in order to adapt to the hazards given in the previous question?

d. Which additional inputs did you need for this strategy?

1. How much additional time did you allocate to the activity in the first year after which you adopted the strategy?

2. If additional time has been allocated to the task, who had to spend these hours on the activity?

3. Did the strategy cost you a certain amount of additional money in the first year after you adopted it?

4. If the strategy cost you additional money, for how many birrs/real/FCFA did you purchase inputs or materials in the first year after which you adopted the strategy?

5. If the strategy cost you additional money, who had to make these costs?

6. What type of additional in-kind inputs did you need and how much, which you didn't have to purchase in the first year after which you adopted the strategy? (e.g. equipment, manure, seeds, other inputs) $\rightarrow$ see table below to fill it in

e. What are the additional benefits obtained from adopting the strategy?

f. Which institutions provided help in terms of training, inputs and assistance relevant for the hazards mentioned under (b)?

g. What kind of inputs did you obtain from these institutions?

\begin{tabular}{|c|c|c|c|}
\hline A. AGRICULTURAL TECHNIQUES & $\begin{array}{l}\text { B. WATER MANAGEMENT } \\
\text { TECHNIQUES }\end{array}$ & C. DIVERSIFICATION & D. COMMUNAL POOLING \\
\hline A1. Crop selection & $\begin{array}{l}\text { B1. Use water harvesting techniques: } \\
\text { roof water collection, tanks,... }\end{array}$ & $\begin{array}{l}\text { C1.Temporal migration } \\
\text { to urban areas or } \\
\text { abroad }\end{array}$ & $\begin{array}{l}\text { D1. Restore and preserve } \\
\text { homestead or mountain forests } \\
\text { to reduce erosion }\end{array}$ \\
\hline A2. Adapt planting dates & $\begin{array}{l}\text { B2. Improve, construct or rehabilitate } \\
\text { terraces }\end{array}$ & $\begin{array}{l}\text { C2. Temporal migration } \\
\text { to other rural areas }\end{array}$ & $\begin{array}{l}\text { D2. Rangeland preservation, } \\
\text { grazing restrictions }\end{array}$ \\
\hline A3. Adapt cropping densities & B3. Use irrigation & $\begin{array}{l}\text { C3. Permanent } \\
\text { migration (to other rural } \\
\text { areas, urban areas or } \\
\text { abroad) }\end{array}$ & $\begin{array}{l}\text { D3. Soil erosion prevention } \\
\text { programmes (e.g. community } \\
\text { terracing) }\end{array}$ \\
\hline $\begin{array}{l}\text { A4. Adapt fertilizer/pesticide } \\
\text { application }\end{array}$ & $\begin{array}{l}\text { B4. Improve watering sites in pastoral } \\
\text { areas }\end{array}$ & $\begin{array}{l}\text { C4. Non-timber forest } \\
\text { product } \\
\text { commercialisation }\end{array}$ & $\begin{array}{l}\text { D4. Communal water } \\
\text { harvesting, tanks }\end{array}$ \\
\hline A5. Adapt tillage practices & B5. Other..... & $\begin{array}{l}\text { C5. Home-garden } \\
\text { agriculture }\end{array}$ & D5. Communal irrigation \\
\hline $\begin{array}{l}\text { A6. Change the pastoral system } \\
\text { (distance and frequency of } \\
\text { mobility) }\end{array}$ & & $\begin{array}{l}\text { C6. Increase market } \\
\text { sales }\end{array}$ & D6. Other: ........... \\
\hline A7. Change the herd composition & & C7. Handicrafts & D7. Other: .......... \\
\hline $\begin{array}{l}\text { A8. Apply different feed } \\
\text { techniques }\end{array}$ & & $\begin{array}{l}\text { C8. Charcoal or timber } \\
\text { sales }\end{array}$ & \\
\hline $\begin{array}{l}\text { A9. Change from pastoral to } \\
\text { sedentary agricultural system }\end{array}$ & & C9. Start fisheries & \\
\hline $\begin{array}{l}\text { A10. Improve food storage } \\
\text { facilities }\end{array}$ & & $\begin{array}{l}\text { C10. Reduce expenses } \\
\text { changing consumption }\end{array}$ & \\
\hline \multirow[t]{2}{*}{ A11. Other ...... } & & $\begin{array}{l}\text { C11. Draw down on } \\
\text { livestock, or surpluses }\end{array}$ & \\
\hline & & C12. Other & \\
\hline
\end{tabular}




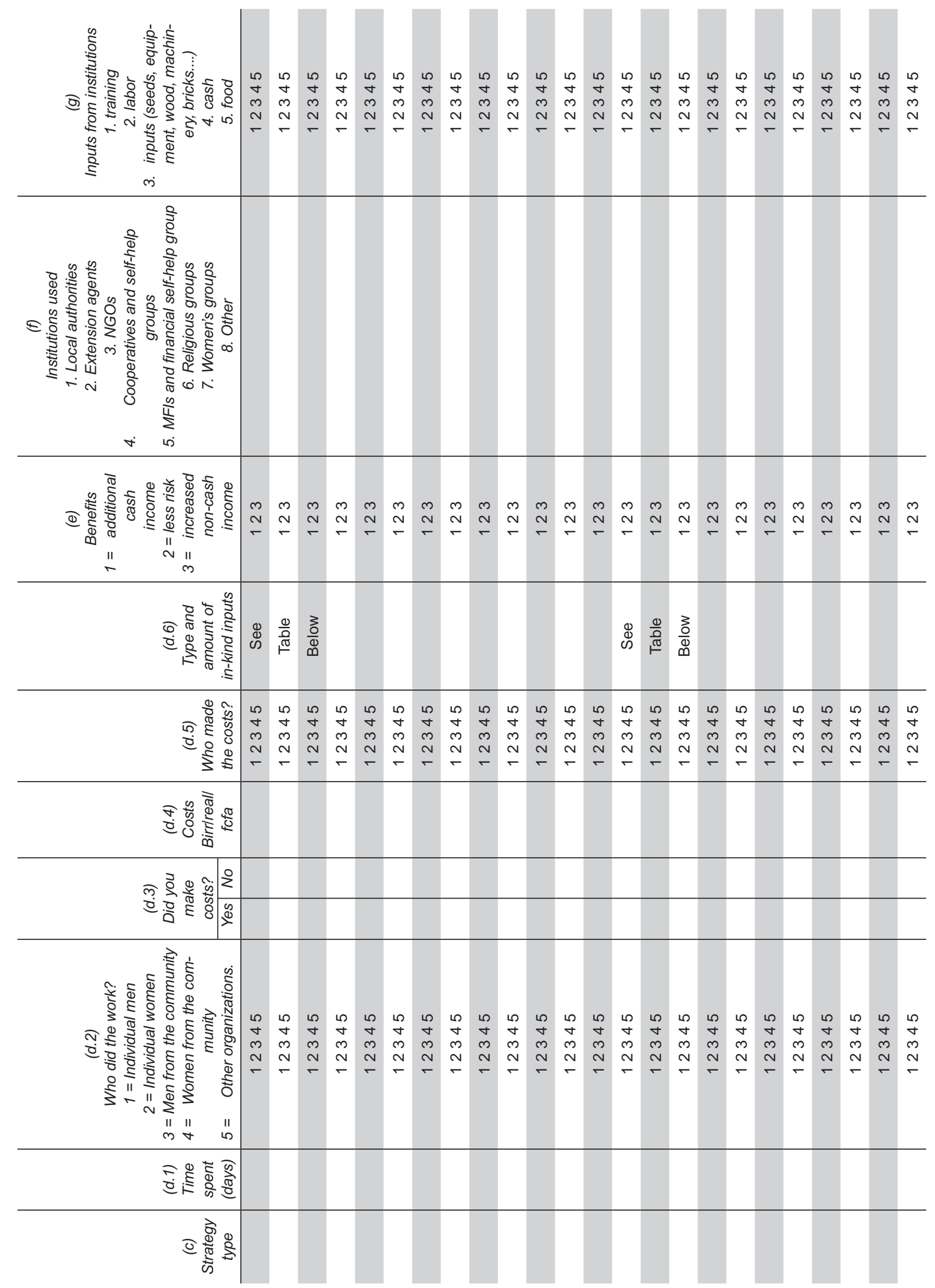


ILLUSTRATIVE PHOTOS

PHOTO 1: CROP FARMING

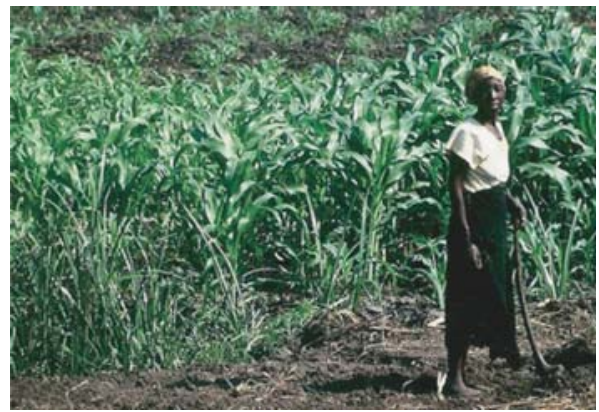

PHOTO 3: HIRED LABOR

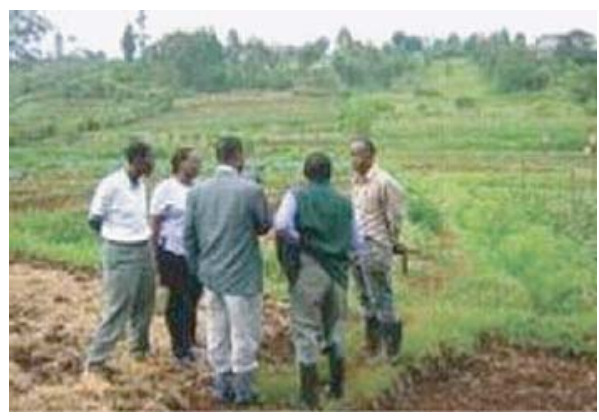

PHOTO 5: HANDICRAFTS

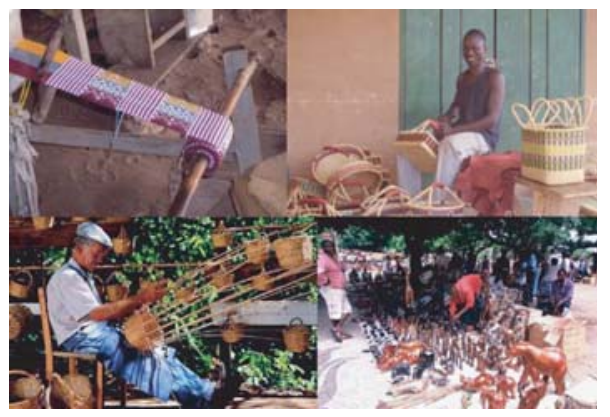

PHOTO 2: LIVESTOCK RAISING

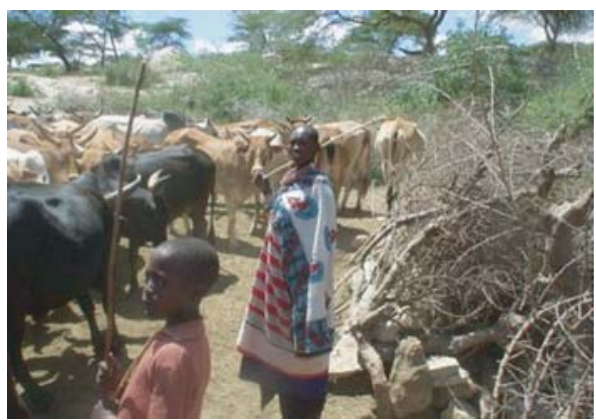

PHOTO 4: FISHERIES

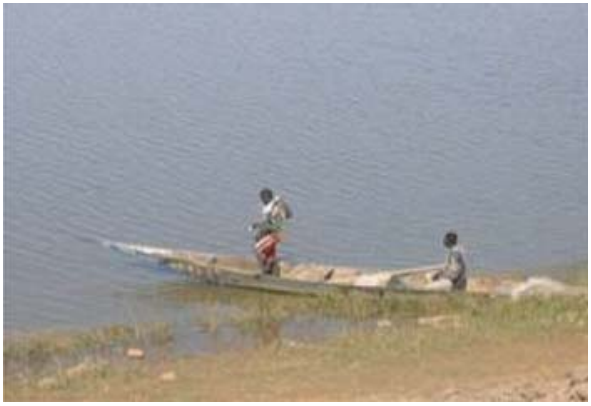

PHOTO 6: TRADE AND COMMERCE

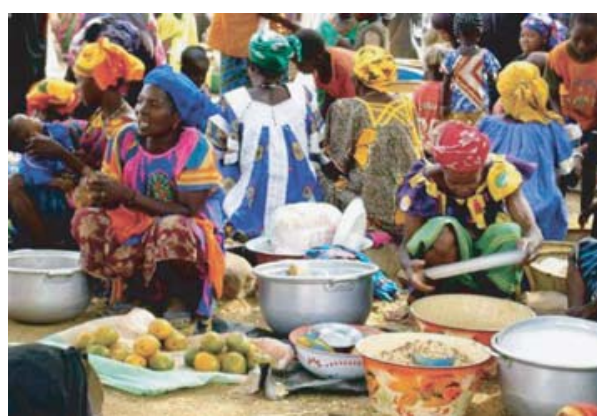


PHOTO 7: CIVIL SERVANT

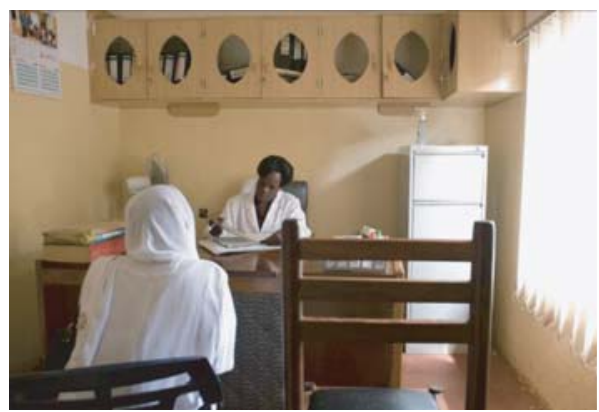

PHOTO 9: DROUGHT DUE TO LESS RAINFALL DURING RAINY SEASON

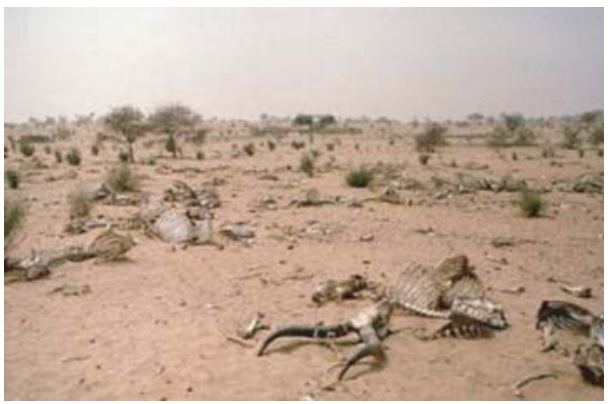

PHOTO 11: PROLONGED PERIODS OF DROUGHT DURING RAINY SEASON

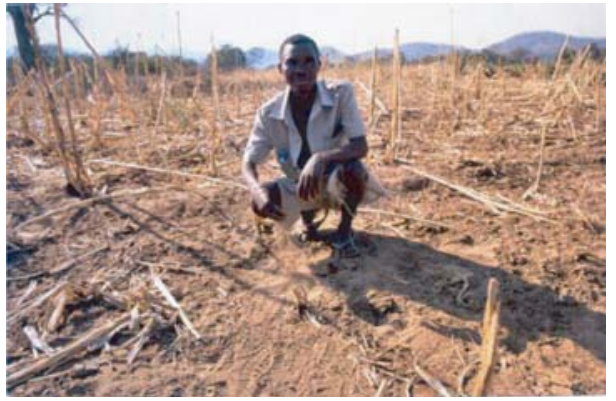

PHOTO 8: OTHER

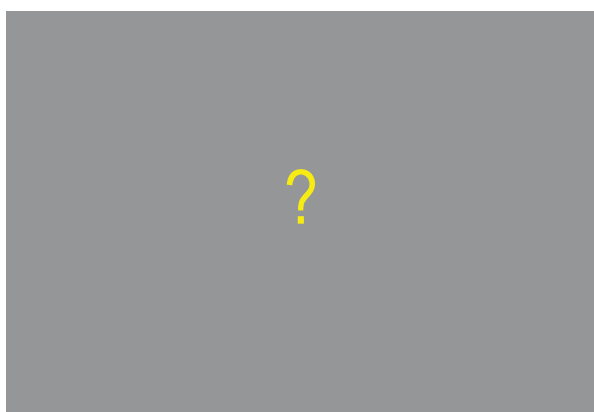

PHOTO 10: HUMAN DISEASE

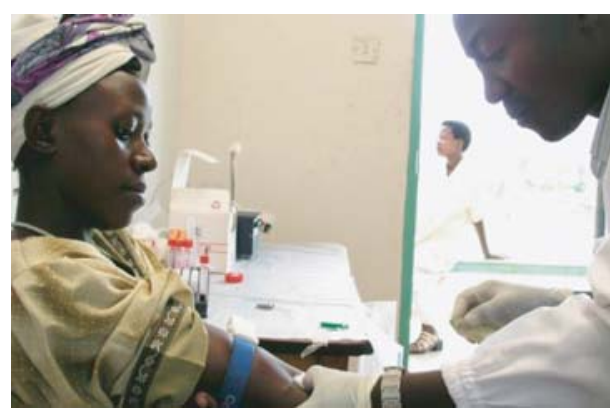

PHOTO 12: ANIMAL OR CROP PESTS AND DISEASES

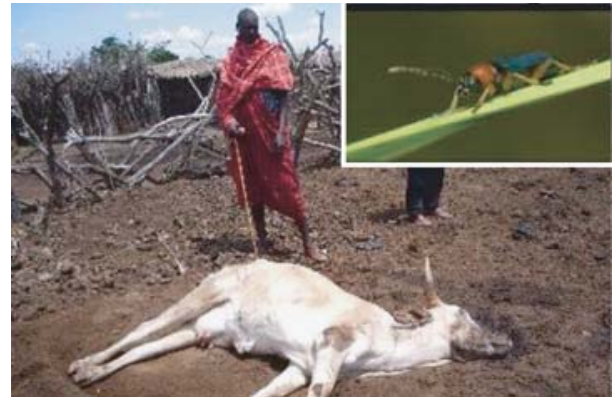


PHOTO 13: FLOODS DUE TO EXCESSIVE RAINFALL

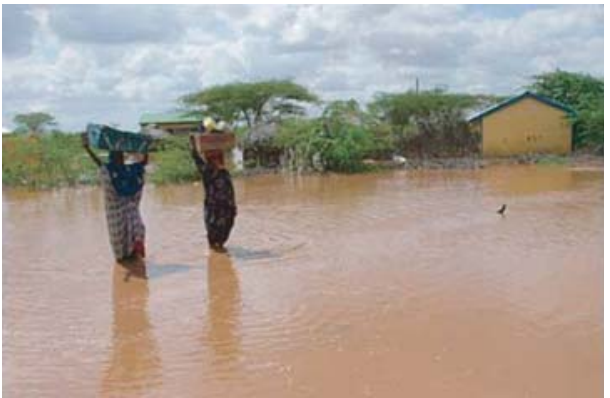

PHOTO 15: DAMAGE DUE TO EXCESSIVELY HEAVY SHOWERS

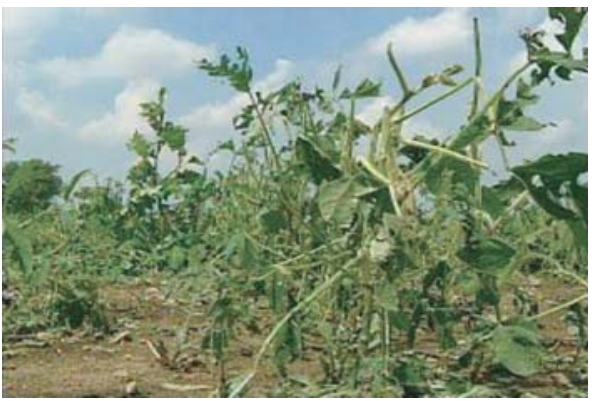

PHOTO 17: EXTREME TEMPERATURES LEADING TO E.G. SCORCHED CROPS

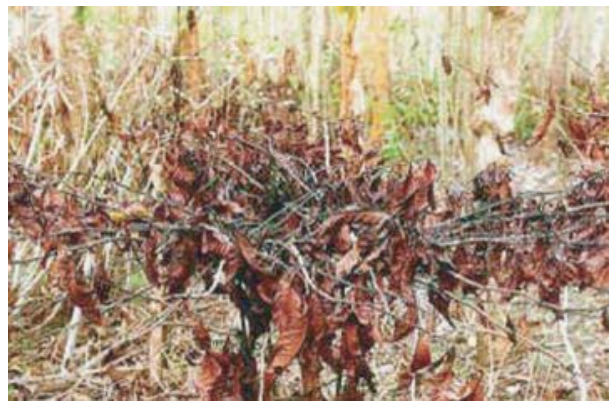

PHOTO 14: DECREASING SOIL FERTILITY

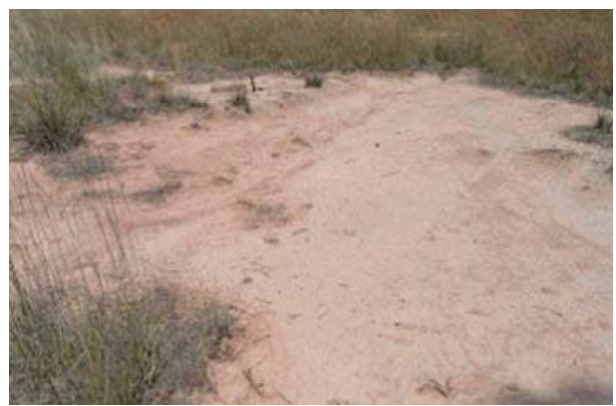

PHOTO 16: PROBLEMS WITH INPUT PURCHASE OROUTPUT SALES

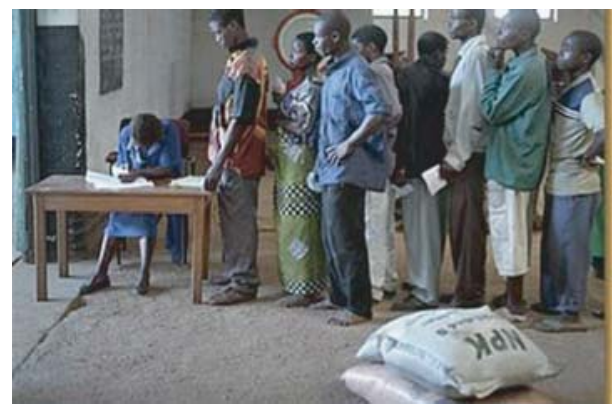

PHOTO 18: HIGH FOOD PRICES

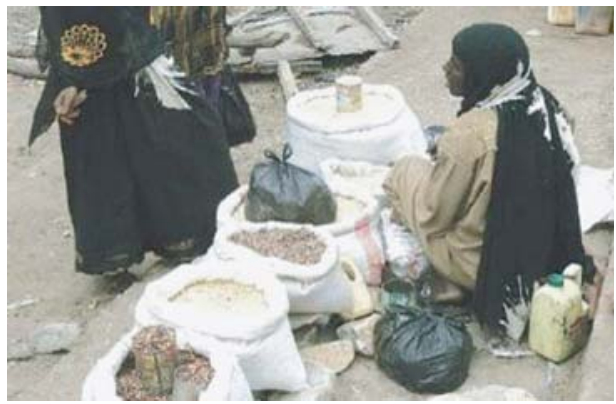


A1.C. INSTITUTIONAL STAKEHOLDER QUESTIONNAIRE

PART 1: General questions for all institutional stakeholders

0. Administrative

\begin{tabular}{l|l} 
& \multicolumn{1}{c}{ Answer } \\
\cline { 2 - 2 } Village name & \\
Region & \\
\hline Date of interview & \\
\hline
\end{tabular}

1. General statistics of respondent.

\begin{tabular}{l|c} 
& \multicolumn{1}{|c}{ Answer } \\
\cline { 2 - 2 } $\begin{array}{l}\text { 1a. What is your main activity/position/profession in the village } \\
\text { (please describe)? }\end{array}$ & years \\
1b. How long have you held this position? & years \\
1c. Age & \\
\hline 1d. Education (number of years) &
\end{tabular}

2. Livelihoods in villages continuously change because of many outside changes. Improvement of livelihoods is threatened by many different hazards

a. Rank the hazards given below from the least important (1) to most important (10) ${ }^{1}$

b. To what extent have the hazards become more or less threatening for the village compared to the past?

\begin{tabular}{|c|c|c|}
\hline Hazards & $\begin{array}{l}\text { (a) } \\
\text { Hazard ranking }\end{array}$ & $\begin{array}{c}\text { (b) } \\
\text { More or less threatening } \\
\text { than in the past? }\end{array}$ \\
\hline \multicolumn{3}{|l|}{ Drought } \\
\hline \multicolumn{3}{|c|}{ Rainfall variability (delayed start or early end of rainy season) } \\
\hline \multicolumn{3}{|l|}{ Floods } \\
\hline \multicolumn{3}{|l|}{ Changed average and extreme temperatures } \\
\hline \multicolumn{3}{|l|}{ Human diseases } \\
\hline \multicolumn{3}{|l|}{$\begin{array}{l}\text { Animal or crop pests and } \\
\text { diseases }\end{array}$} \\
\hline \multicolumn{3}{|l|}{ Decreasing soil fertility } \\
\hline \multicolumn{3}{|l|}{ Problems with input purchase or output sales } \\
\hline \multicolumn{3}{|l|}{ High food prices } \\
\hline \multicolumn{3}{|l|}{ Other: ............ } \\
\hline & $\uparrow$ & $\uparrow$ \\
\hline & $\begin{array}{c}1=\text { least important } \\
\quad \ldots . \\
10=\text { most important }\end{array}$ & $\begin{array}{c}1=\text { lot less } \\
2=\text { less } \\
3=\text { same } \\
4=\text { more } \\
5=\text { lot more. }\end{array}$ \\
\hline
\end{tabular}

1 See note at the end of the questionnaire. 
3. a. What kinds of organizations are present in your village?

b. Which of these organizations deals with assisting the population to adapt to changing weather characteristics?

c. How important are these organisations for helping the population to adapt to changing weather characteristics in terms of how good they help the population and how many people they reach?

\begin{tabular}{|c|c|c|c|}
\hline Services & Present? & $\begin{array}{l}\text { If present, deals } \\
\text { with adaptation strategies }\end{array}$ & $\begin{array}{c}\text { Importance of institution? } \\
\begin{array}{c}1=\text { not at all important } \\
5=\text { very important }\end{array}\end{array}$ \\
\hline Extension agents & yes - no & yes - no & $1-2-3-4-5$ \\
\hline $\begin{array}{l}\text { International donors and development } \\
\text { organizations }\end{array}$ & yes - no & yes - no & $1-2-3-4-5$ \\
\hline Non-governmental organizations & yes - no & yes - no & $1-2-3-4-5$ \\
\hline National authorities & yes - no & yes - no & $1-2-3-4-5$ \\
\hline Regional authorities (regional administration) & yes - no & yes - no & $1-2-3-4-5$ \\
\hline Local authorities (local administration) & yes - no & yes - no & $1-2-3-4-5$ \\
\hline Cooperatives & yes - no & yes - no & $1-2-3-4-5$ \\
\hline Schools & yes - no & yes - no & $1-2-3-4-5$ \\
\hline Banks & yes - no & yes - no & $1-2-3-4-5$ \\
\hline Village communities & yes - no & yes - no & $1-2-3-4-5$ \\
\hline Religious communities & yes - no & yes - no & $1-2-3-4-5$ \\
\hline Women's groups & yes - no & yes - no & $1-2-3-4-5$ \\
\hline Micro-financing groups & yes - no & yes - no & $1-2-3-4-5$ \\
\hline Self-help groups & yes - no & yes - no & $1-2-3-4-5$ \\
\hline Unions & yes - no & yes - no & $1-2-3-4-5$ \\
\hline Other: ............ & yes - no & yes - no & $1-2-3-4-5$ \\
\hline Other: ............. & yes - no & yes - no & $1-2-3-4-5$ \\
\hline
\end{tabular}

4. Discussion question: (type of service needed)

- Which organization(s) are in your opinion most helpful or best to help the population adapting to the risks of weather variability?

- What type of assistance do households need in order to adapt to the risks of weather variability? Training, knowledge, inputs, financial aid, communal projects on e.g. irrigation, soil erosion prevention or water harvesting, ...?

- What kind of problems hamper to your opinion the activities of the organizations who are assisting the population to adapt to changing weather variability.

- What kind of external assistance or help do organizations who are working in this field need in order to improve their results? Financial help, knowledge/training, inputs/material, back-up from governmental or international organizations, .....?

\section{PART 2: Questions only for stakeholders representing an institution/organization.}

5. General questions on organization

- Name of organization

- Geographical area served by the institution (villages/areas)

- Number of full-time staff employed by the institution

- Number of part-time staff employed by the institution

- Gender of the staff: \% female. 
- Estimation of average age of staff (years)

- Number of years institution is in operation (years).

6. Type of institution

- What is the goal/objective of the institutions?

- What type of service does your institutions provide? What are the activities of the institution?

- What is the benefit that members get from joining/participating in your institution?

7. Membership/clients of institution

- Who can become member or receive services?

- What are the criteria for becoming a member or for receiving services (Is this dependent on social standing, on economic standing or on geographic area?)

- Are there any restrictions on becoming member or receiving services?

- Are there any limitations for membership or services (i.e. only a certain number of years that members can receive service)

- Does the institution provide the same type of service to all members? (Is the service dependent on social group or level of need?)

\section{Funding}

- Where do the institutions get funding from?

- For formal institutions: What is the annual budget of your organization? How is the budget allocated over personnel expenses and activities initiated?

- For formal and informal institutions: Assume that your institution has a budget of 100 'tokens'. If you would allocate this budget over the services you provide, how would you allocate it? Moreover, if this budget would have to be allocated over different types of members or different groups within the community, how would you allocate it?

\section{Climate impacts}

- Has there been an extreme weather event that has impacted the type of service you provide or the demand for the type of service you are providing?

- Was the service still applicable or effective during the weather event?

- What strategies were employed to adapt to the change in conditions?

- During extreme weather events in the past, were there different forms of distribution (either physical route or social connections) of the services?

- Were the same number of people served? Were there more people seeking assistance? Fewer people seeking assistance?

- What role do you see organizations playing in implementing or promoting adaptation strategies? Capacity building? Funding?

\section{What government policies support institutions?}

- What government policies are restrictive to institutions?

- Do supportive or restrictive government policies play a role in determining whether you work with institutions in the country? 


\section{A1.D. FOCUS GROUP DISCUSSION}

Within each village, one focus group discussion is organized. The focus group discussion is a qualitative method with the objective to obtain hands-on and detailed information on concepts, perceptions and ideas of a group. The results from the discussion complement results and insights obtained from the household questionnaires, institutional stakeholder interviews and expert interviews. The main objectives of these group discussions are:

- to obtain more insights into the perceptions on the main (climate) hazards communities and households are facing;

- to obtain more information about the changes in hazards and adaptation options;

- to obtain more information about the reasons for adoption or non-adoption of the different adaptation options;

- to obtain more information about the advantages/disadvantages/bottlenecks/strong points/weak points of the different adaptation options;

- to obtain more information about the institutions facilitating the adoption of certain adaptation options;

- to obtain more information about the bottlenecks preventing institutions to give useful help;

- to obtain more information about differences in strategy adoption between socioeconomic groups with the community

In the focus group discussions, a group of 15 to 20 people from the village is invited and with the help of a facilitator are stimulated to talk freely and spontaneously about the issues mentioned above. A 'recorder' keeps a record of the discussion as well as the emotional reactions and important aspects of the group interaction. An assessment of the emotional tone of the meeting and the group process enables us to judge the validity of the information collected.

The length of each of the discussions takes approximately two hours. In Ethiopia, mixed groups of men and women are invited. The groups contain different age classes and have to contain as well people who experienced the droughts in the 1970s. Moreover, people from different wealth classes are included in order to get a good representation of the composition of the community. The list of people invited is set up jointly with the local authorities and representatives from the projects active in the villages.

Using images and pictures from different hazards, climate risks and adaptation options, the following discussion questions are brought forward:

- Which climate or rainfall related hazards do you face in your daily life?

- For drought hazards: to what extent has the start of the rainy season and the amount of rain fallen during the rainy season varied over the last decades? Do you adapt farming strategies if you have experienced drought problems over the past years? Are there differences in crops grown, tillage techniques, planting dates, activities performed, equipment used,...? Did you change the composition of your livestock owned, livestock management, ...?

- For flood hazards: to what extent has the amount of rainfall or the intensity with which it rains changed over the last decades? Do you change farming and livelihood strategies if you have experienced regular flooding problems over the past years? Are there differences in crops grown, tillage techniques, planting dates, activities performed, equipment used,....? Did you change the composition of your livestock owned, livestock management, ...?

- How much do these changes cost you in terms in resources used, labor requirements, etc.? 
- Which organizations, authorities or people are most helpful to learn more about how to prepare for these hazards? How can these organizations perform there tasks better?

- To what extent are choices dependent on ethnicity, wealth class, gender?

Depending on the direction in which the discussion is going, questions are phrased in a certain way or emphasis is put on particular topics. It is attempted to cover all the above questions during the discussion. During the discussion, the recorder pays particular attention to whether representatives from different socioeconomic groups answer the questions differently, whether they have different perceptions, use different adaptation options or are dependent on different institutions. 


\section{APPENDIX 2. DATA ANALYSIS}

\section{A2.A. DESCRIPTIVE ANALYSIS OF THE HOUSEHOLDS}

\section{TABLE A.1. MAIN DEMOGRAPHIC CHARACTERISTICS OF THE STUDY SITES}

\begin{tabular}{|c|c|c|c|c|c|c|}
\hline & Village & $\begin{array}{c}\text { Average household } \\
\text { size }\end{array}$ & $\begin{array}{l}\% \text { male } \\
\text { members }\end{array}$ & $\begin{array}{c}\% \text { female headed } \\
\text { households }\end{array}$ & Dependency ratio ${ }^{1}$ & Average age \\
\hline 1 & Haro Kersa & 8.0 & 53 & 6 & 1.1 & 21.5 \\
\hline 2 & Gola & 6.3 & 53 & 14 & 2.0 & 15.7 \\
\hline 3 & Choresa & 6.1 & 50 & 16 & 1.1 & 23.9 \\
\hline 4 & BirkoDebele & 5.8 & 54 & 20 & 1.3 & 22.8 \\
\hline 5 & Keteteya & 4.9 & 52 & 10 & 0.7 & 24.9 \\
\hline \multirow[t]{2}{*}{6} & Hardibo & 4.9 & 57 & 16 & 0.9 & 25.5 \\
\hline & Average & 6.0 & 53 & 14 & 1.2 & 22.1 \\
\hline
\end{tabular}

Notes: 1 . Dependency ratio $=$ (number of children under the age of 16 plus elderly people above 60) $/$ (number of adults in between 16 and 60 years) 2. See also Table A.1b 
TABLE A.2. DIFFERENCES IN EDUCATION AND MIGRATION

\begin{tabular}{|c|c|c|c|c|c|c|c|c|}
\hline & \multirow[b]{3}{*}{ Village } & \multicolumn{4}{|c|}{ Average years of education } & \multicolumn{3}{|c|}{ Migration } \\
\hline & & \multicolumn{2}{|c|}{$5-15$ years } & \multicolumn{2}{|c|}{ Adults } & \multirow{2}{*}{$\begin{array}{l}\% \text { of households with } \\
\text { temporarily migrated member }\end{array}$} & \multicolumn{2}{|c|}{$\begin{array}{l}\text { Average age of } \\
\text { migration }\end{array}$} \\
\hline & & Boys & girls & male & Female & & men & women \\
\hline 1 & Haro Kersa & 0.4 & 0.6 & 1.3 & 0.7 & 0 & n.a. & n.a. \\
\hline 2 & Gola & 3.0 & 2.4 & 2.7 & 1.3 & 2 & 13 & n.a. \\
\hline 3 & Choresa & 3.5 & 2.8 & 4.3 & 3.3 & 16 & 17 & 18 \\
\hline 4 & BirkoDebele & 1.5 & 2.7 & 1.7 & 1.9 & 8 & 30 & 26 \\
\hline 5 & Keteteya & 2.8 & 3.5 & 2.8 & 2.2 & 6 & 32 & 29 \\
\hline \multirow[t]{2}{*}{6} & Hardibo & 3.5 & 3.7 & 4.7 & 2.3 & 6 & 20 & 15 \\
\hline & Average & 2.5 & 2.3 & 2.8 & 1.9 & 6 & 25 & 24 \\
\hline
\end{tabular}

Notes: See also Table A.2b.

TABLE A.3. MAIN ACTIVITIES OF HOUSEHOLDS IN THE STUDY SITES

\begin{tabular}{|c|c|c|c|c|c|c|c|c|c|c|c|c|c|}
\hline & \multirow[b]{3}{*}{ Village } & \multicolumn{12}{|c|}{$\%$ of household for whom the activity is the $1^{\text {st }}, 2^{\text {nd }}$ or $3^{d}$ important activity } \\
\hline & & \multicolumn{3}{|c|}{ Agriculture } & \multicolumn{3}{|c|}{ Livestock raising } & \multicolumn{3}{|c|}{ Off-farm labor } & \multicolumn{3}{|c|}{ Trade/commerce } \\
\hline & & $1^{\text {st }}$ & $2^{\text {nd }}$ & $3^{d}$ & $1^{s t}$ & $2^{\text {nd }}$ & $3^{d}$ & $1^{\text {st }}$ & $2^{\text {nd }}$ & $3^{d}$ & $1^{\text {st }}$ & $2^{\text {nd }}$ & $3^{d}$ \\
\hline 1 & Haro Kersa & 6 & 82 & 2 & 94 & 6 & 0 & 0 & 0 & 0 & 0 & 0 & 0 \\
\hline 2 & Gola & 100 & 0 & 0 & 0 & 100 & 0 & 0 & 0 & 0 & 6 & 0 & 4 \\
\hline 3 & Choresa & 96 & 0 & 2 & 0 & 90 & 10 & 2 & 10 & 30 & 2 & 0 & 4 \\
\hline 4 & BirkoDebele & 92 & 6 & 2 & 4 & 78 & 12 & 0 & 10 & 22 & 0 & 0 & 2 \\
\hline 5 & Keteteya & 100 & 0 & 0 & 0 & 60 & 22 & 0 & 20 & 4 & 0 & 6 & 12 \\
\hline \multirow[t]{4}{*}{6} & Hardibo & 98 & 2 & 0 & 0 & 76 & 12 & 0 & 6 & 12 & 0 & 4 & 6 \\
\hline & total & 82 & 15 & 1 & 16 & 68 & 9 & 0 & 8 & 11 & 1 & 2 & 5 \\
\hline & & \multicolumn{12}{|c|}{ Work is especially done by } \\
\hline & & Male & & Female & Male & & Female & Male & & Female & Male & & Female \\
\hline 1 & Haro Kersa & 100 & & 4 & 100 & & 16 & 0 & & 0 & 0 & & 0 \\
\hline 2 & Gola & 90 & & 62 & 72 & & 82 & 100 & & 0 & 40 & & 20 \\
\hline 3 & Choresa & 92 & & 84 & 88 & & 94 & 67 & & 43 & 67 & & 0 \\
\hline 4 & Keteteya & 96 & & 74 & 93 & & 81 & 85 & & 38 & 78 & & 22 \\
\hline 5 & BirkoDebele & 92 & & 82 & 89 & & 81 & 53 & & 65 & 100 & & 33 \\
\hline \multirow[t]{2}{*}{6} & Hardibo & 88 & & 64 & 89 & & 51 & 73 & & 27 & 86 & & 29 \\
\hline & total & 93 & & 63 & 88 & & 67 & 69 & & 43 & 74 & & 22 \\
\hline
\end{tabular}


TABLE A.4. MAIN TYPES OF CROPS GROWN

\begin{tabular}{|c|c|c|c|c|c|c|c|c|c|c|c|}
\hline & \multirow[b]{2}{*}{ Village } & \multirow{2}{*}{$\begin{array}{c}\text { average } \\
\text { area per } \\
\text { household } \\
\text { (ha) }\end{array}$} & \multicolumn{9}{|c|}{ Average acreage planted with (ha) } \\
\hline & & & $\begin{array}{l}\text { Grain } \\
\text { (ha) }\end{array}$ & $\begin{array}{l}\text { Legumes } \\
\text { (ha) }\end{array}$ & $\begin{array}{l}\text { Potatoes } \\
\text { (ha) }\end{array}$ & $\begin{array}{l}\text { Vegetables } \\
\text { (ha) }\end{array}$ & $\begin{array}{l}\text { Cash } \\
\text { crop } \\
\text { (ha) }\end{array}$ & $\begin{array}{l}\text { Oil } \\
\text { crop } \\
\text { (ha) }\end{array}$ & $\begin{array}{l}\text { Rest } \\
\text { (ha) }\end{array}$ & $\begin{array}{c}\text { Fruit } \\
\text { trees } \\
\text { (no.) }\end{array}$ & $\begin{array}{l}\text { Other } \\
\text { trees } \\
\text { (no.) }\end{array}$ \\
\hline 1 & Haro Kersa & 1.00 & 0.68 & 0.16 & 0.00 & 0.00 & 0.00 & 0.17 & 0.00 & 0.00 & 0.00 \\
\hline 2 & Gola & 1.28 & 0.71 & 0.00 & 0.00 & 0.55 & 0.00 & 0.00 & 0.02 & 0.64 & 0.00 \\
\hline 3 & Choresa & 1.40 & 1.11 & 0.04 & 0.12 & 0.09 & 0.00 & 0.00 & 0.03 & 6.64 & 6.92 \\
\hline 4 & BirkoDebele & 1.24 & 1.05 & 0.05 & 0.12 & 0.01 & 0.01 & 0.00 & 0.01 & 2.52 & 10.10 \\
\hline 5 & Keteteya & 0.69 & 0.42 & 0.06 & 0.00 & 0.03 & 0.17 & 0.01 & 0.01 & 0.52 & 11.30 \\
\hline \multirow[t]{4}{*}{6} & Hardibo & 0.60 & 0.41 & 0.04 & 0.03 & 0.00 & 0.09 & 0.01 & 0.02 & 0.60 & 24.75 \\
\hline & total & 1.03 & 0.73 & 0.06 & 0.05 & 0.11 & 0.05 & 0.03 & 0.01 & 1.82 & 8.84 \\
\hline & & \multirow{2}{*}{$\begin{array}{c}\text { average } \\
\text { number of } \\
\text { trees (no.) }\end{array}$} & \multicolumn{9}{|c|}{$\%$ of households cultivating } \\
\hline & & & grain & legumes & potatoes & vegetables & $\begin{array}{l}\text { Cash } \\
\text { crop }\end{array}$ & fruit & trees & $\begin{array}{c}\text { Oil } \\
\text { crops }\end{array}$ & rest \\
\hline 1 & Haro Kersa & 0.00 & 60 & 28 & 0 & 0 & 0 & 0 & 0 & 40 & 0 \\
\hline 2 & Gola & 0.64 & 96 & 0 & 0 & 76 & 0 & 2 & 0 & 0 & 10 \\
\hline 3 & Choresa & 13.56 & 96 & 16 & 2 & 50 & 16 & 44 & 52 & 0 & 22 \\
\hline 4 & BirkoDebele & 12.62 & 100 & 14 & 2 & 4 & 22 & 20 & 44 & 2 & 4 \\
\hline 5 & Keteteya & 11.82 & 98 & 32 & 0 & 20 & 96 & 20 & 38 & 4 & 6 \\
\hline \multirow[t]{4}{*}{6} & Hardibo & 25.35 & 100 & 32 & 26 & 4 & 96 & 16 & 96 & 4 & 12 \\
\hline & total & 10.66 & 92 & 20 & 5 & 26 & 38 & 17 & 38 & 8 & 9 \\
\hline & & $\%$ of & \multicolumn{9}{|c|}{$\%$ of producing households who sold any of their } \\
\hline & & $\begin{array}{l}\text { households } \\
\text { who sold }\end{array}$ & grain & legumes & potatoes & vegetables & $\begin{array}{l}\text { Cash } \\
\text { crop }\end{array}$ & fruit & trees & $\begin{array}{l}\text { Oil } \\
\text { crops }\end{array}$ & rest \\
\hline 1 & Haro Kersa & 28 & 3 & 14 & n.a. & n.a. & n.a. & n.a. & n.a. & 65 & n.a. \\
\hline 2 & Gola & 74 & 8 & n.a. & n.a. & 95 & n.a. & 100 & n.a. & n.a. & 80 \\
\hline 3 & Choresa & 82 & 44 & 38 & 100 & 96 & 25 & 27 & 31 & n.a. & 9 \\
\hline 4 & BirkoDebele & 78 & 68 & 71 & 100 & 50 & 9 & 30 & 5 & 100 & 0 \\
\hline 5 & Keteteya & 98 & 49 & 69 & n.a. & 70 & 90 & 40 & 42 & 0 & 67 \\
\hline \multirow[t]{2}{*}{6} & Hardibo & 98 & 46 & 50 & 100 & 100 & 96 & 38 & 56 & 50 & 50 \\
\hline & total & 76 & 39 & 48 & 100 & 91 & 80 & 33 & 38 & 60 & 37 \\
\hline
\end{tabular}

Note: In the questionnaires some observations on cash crops (coffee and qat), fruit trees and other trees were in hectares, others were in number of trees. In order to put all crop types under the same unit, numbers of coffee and qat plants were transformed into hectares using a conversion factor of 1 plant per $2 \mathrm{~m}^{2}=0.0002 \mathrm{ha}$. For fruit trees and other trees, the observations per hectare were transformed into estimates of number of trees using a conversion factor of 1 tree per 0.015625 ha or 64 trees per hectare. This factor was derived from the survey data. 
TABLE A.4B. DETAILS ON AREA CULTIVATED AND LAND OWNED

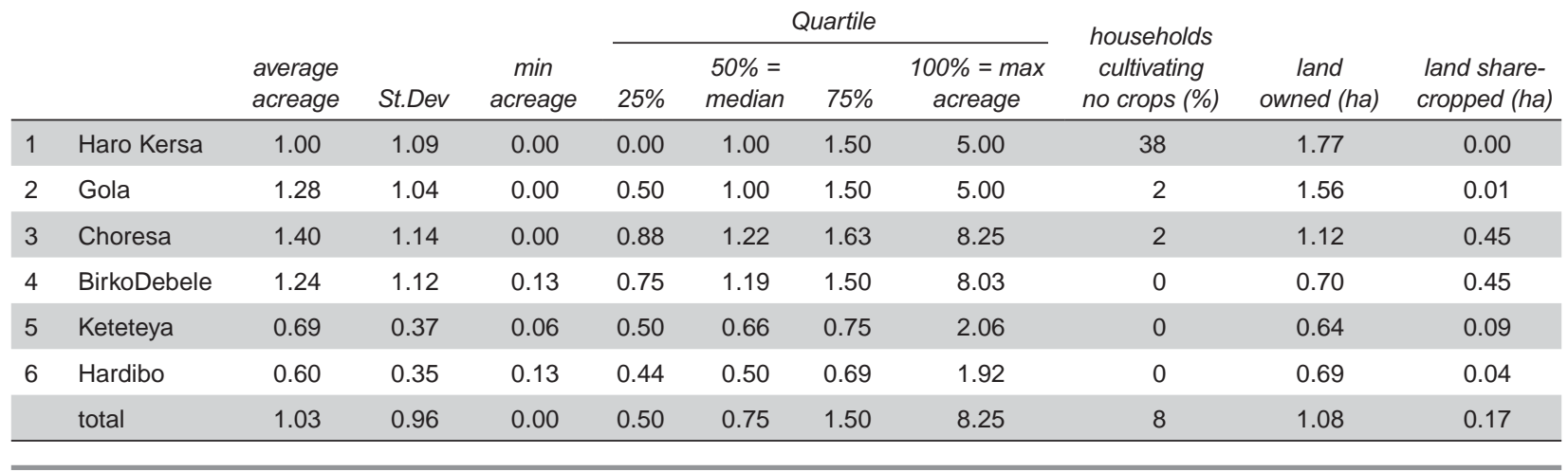

\section{TABLE A.5. LIVESTOCK OWNERSHIP}

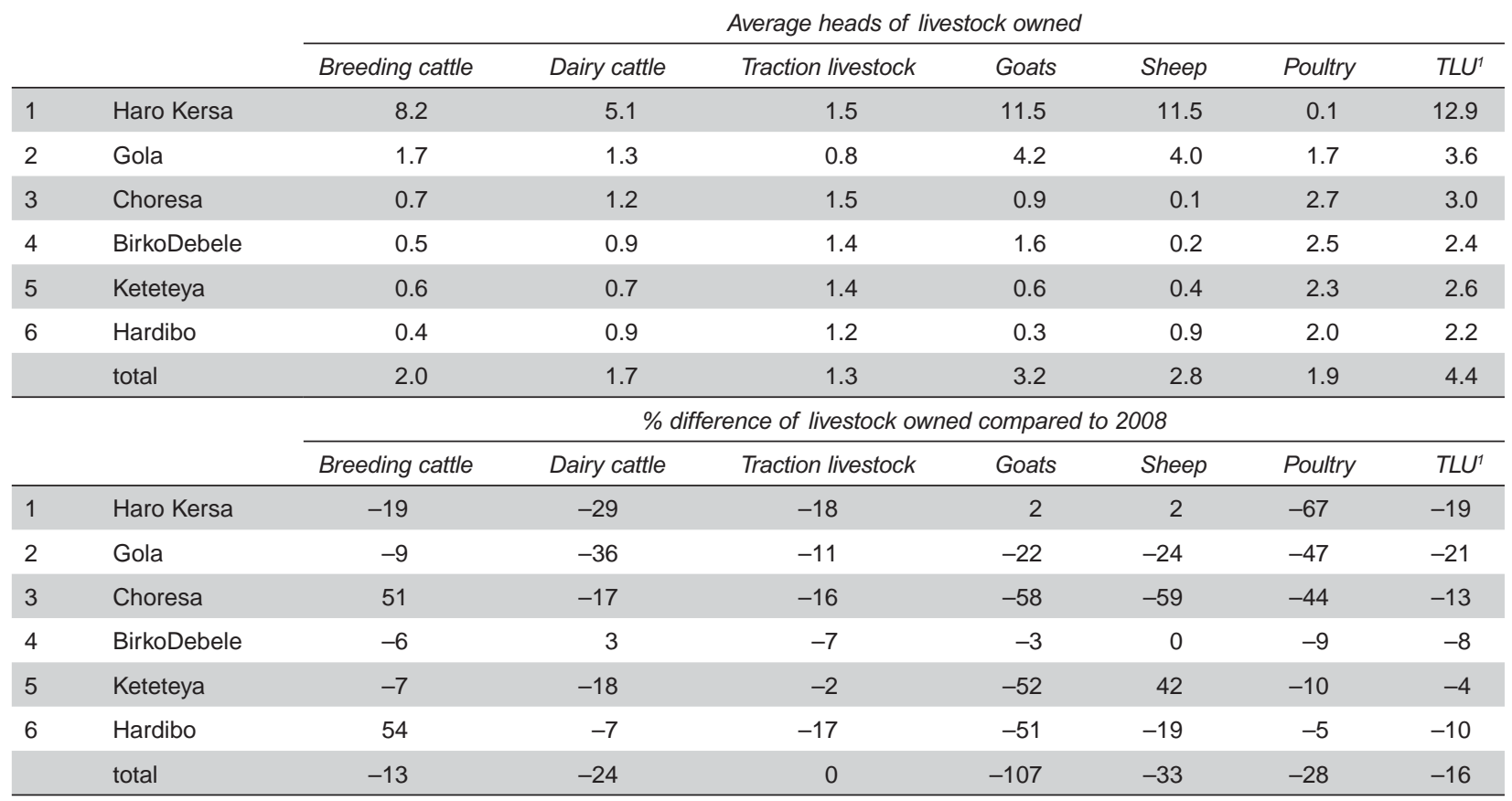

Notes: 1. TLU = tropical livestock units. TLU conversion factors: Cattle in herd: 0.7, Cows: 1.0, Sheep: 0.1, Goat: 0.08, Poultry: 0.01 (see Kassam et al., 1991 ). 
TABLE A.6. ASSET OWNERSHIP

\begin{tabular}{|c|c|c|c|c|c|c|c|c|}
\hline & \multirow[b]{2}{*}{ Village } & \multirow[b]{2}{*}{ Mean $^{1}$} & \multirow[b]{2}{*}{ St.Dev. } & \multirow[b]{2}{*}{ Minimum } & \multicolumn{4}{|c|}{ Quartiles } \\
\hline & & & & & $25 \%$ & $50 \%$ median & $75 \%$ & $100 \%$ maximum \\
\hline 1 & Haro Kersa & 10 & 7.7 & 1 & 5 & 7 & 12 & 30 \\
\hline 2 & Gola & 13 & 8.2 & 2 & 7 & 11 & 18 & 41 \\
\hline 3 & Choresa & 33 & 22.0 & 3 & 15 & 25 & 46 & 95 \\
\hline 4 & BirkoDebele & 23 & 22.3 & 1 & 9 & 14 & 31 & 87 \\
\hline 5 & Keteteya & 29 & 28.9 & 3 & 9 & 14 & 53 & 87 \\
\hline \multirow[t]{2}{*}{6} & Hardibo & 18 & 19.1 & 0 & 8 & 11 & 20 & 105 \\
\hline & Total & 21 & 21.2 & 0 & 8 & 13 & 24 & 105 \\
\hline
\end{tabular}

Notes: 1. Four types of assets were distinguished, which were weighted from 1 to 4 to calculate a household specific asset ownership indicator. The four types of assets were: 1) basic farming equipment including a plow, hoe, axe, sickle, shovel and fishing equipment; 2) basic assets including jewellery, cart, improved stove, radio and bicycle; 3) more luxury assets including iron roofed house, separate kitchen house, gas or petrol stove, refrigerator, stable for livestock and mobile phone; and 4) tv, boat, house built of cement and car. 


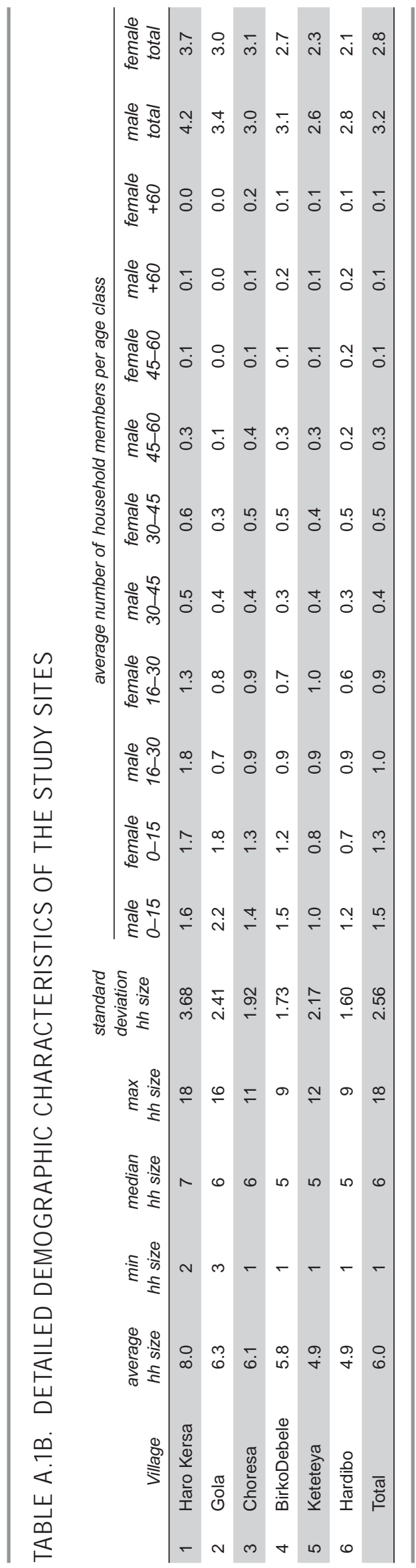




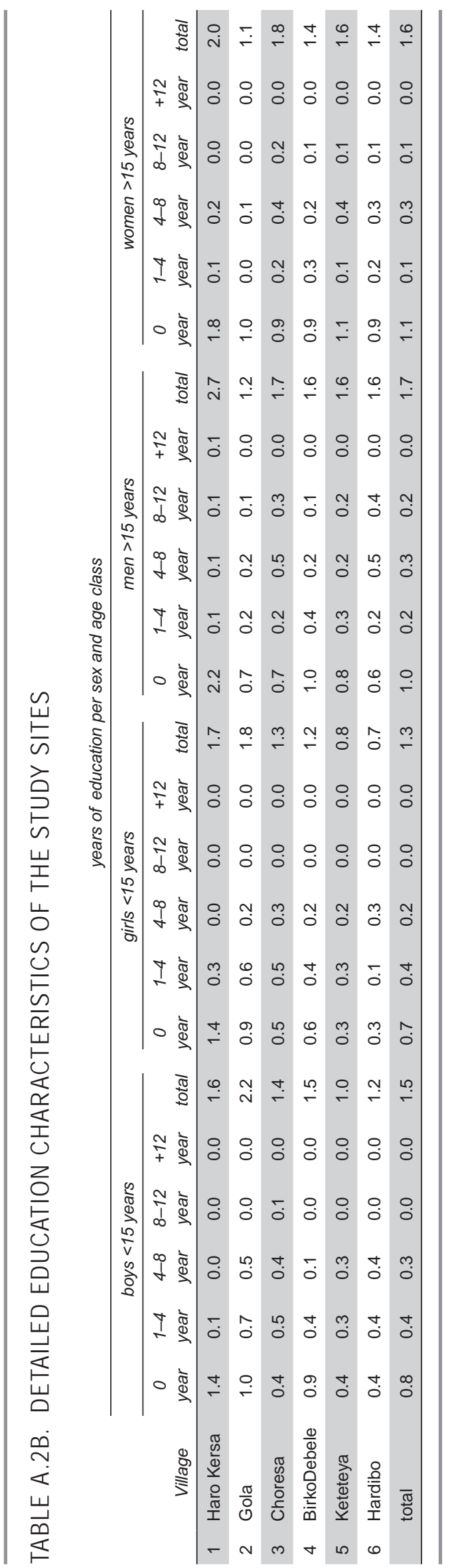




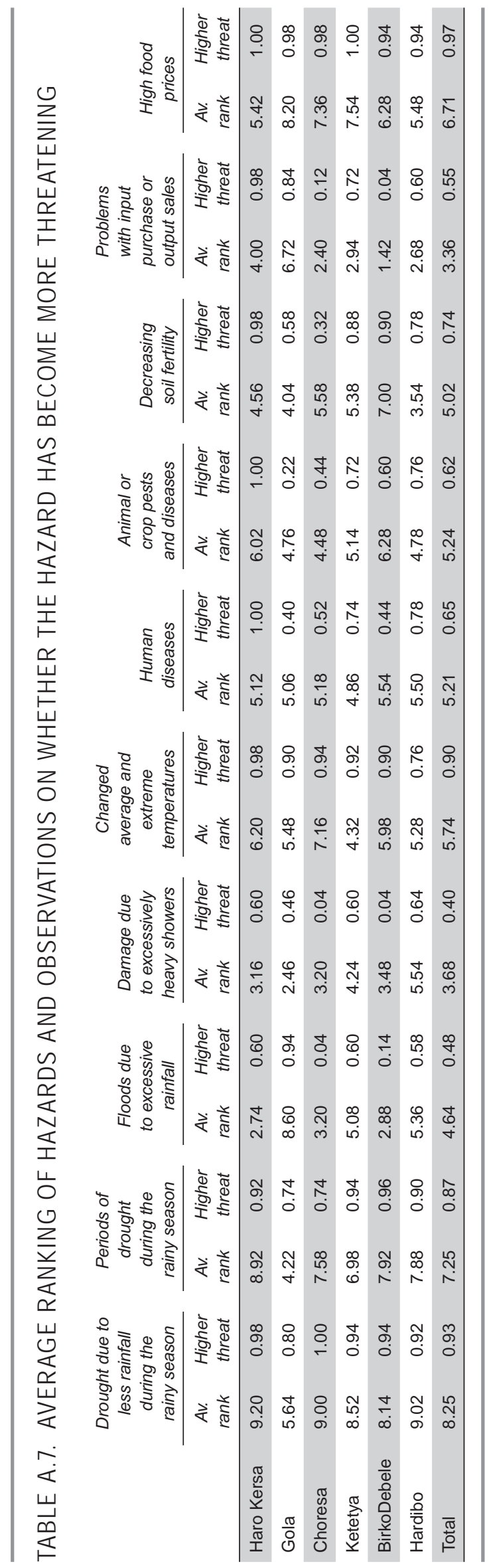




\section{A2.B. DESCRIPTIVE ANALYSIS OF THE CLUSTERS}

\section{TABLE B.1. DISTRIBUTION OF CLUSTERS OVER THE DIFFERENT VILLAGES}

\begin{tabular}{lrrrrrrr} 
Cluster & 1 & 2 & 3 & 4 & 5 & 6 & Total \\
\hline Haro Kersa & 43 & 4 & 2 & 1 & 0 & 0 & 50 \\
Gola & 1 & 37 & 1 & 3 & 6 & 1 & 49 \\
Choresa & 0 & 12 & 1 & 16 & 15 & 6 & 50 \\
BirkoDebele & 0 & 12 & 1 & 6 & 15 & 14 & 50 \\
Keteteya & 0 & 2 & 1 & 6 & 27 & 14 & 48 \\
\hline Hardibo & 0 & 1 & 0 & 13 & 11 & 22 & 47 \\
Total & 44 & 68 & 6 & 45 & 74 & 57 & 294 \\
\hline
\end{tabular}

\section{TABLE B.2. MAIN DEMOGRAPHIC CHARACTERISTICS OF THE CLUSTERS}

\begin{tabular}{|c|c|c|c|c|c|}
\hline Cluster & Average household size & $\%$ male members & $\begin{array}{c}\% \text { female headed } \\
\text { households }\end{array}$ & Dependency ratio ${ }^{1}$ & Average age \\
\hline 1 & 8.3 & 53.2 & 5 & 1.1 & 21.3 \\
\hline 2 & 6.0 & 53.8 & 7 & 1.8 & 17.4 \\
\hline 3 & 9.2 & 52.7 & 0 & 0.3 & 27.2 \\
\hline 4 & 6.6 & 48.2 & 7 & 1.0 & 22.6 \\
\hline 5 & 4.9 & 52.9 & 24 & 1.0 & 26.2 \\
\hline \multirow[t]{2}{*}{6} & 5.0 & 57.4 & 16 & 1.1 & 23.4 \\
\hline & 6.0 & 53.2 & 14 & 1.2 & 22.5 \\
\hline
\end{tabular}

Notes: 1 . Dependency ratio = (number of children under the age of 16 plus elderly people above 60) / (number of adults in between 16 and 60 years).

\section{TABLE B.3. HOUSEHOLD CHARACTERISTICS}

\begin{tabular}{|c|c|c|c|c|c|c|c|c|c|c|}
\hline \multirow[b]{2}{*}{ Cluster } & \multirow{2}{*}{$\begin{array}{l}\text { Households } \\
\text { per cluster }\end{array}$} & \multirow{2}{*}{$\begin{array}{l}\% \text { of total } \\
\text { number of } \\
\text { households }\end{array}$} & \multicolumn{2}{|c|}{$\begin{array}{l}\text { Share of children } \\
\text { in household } \\
\text { (<15 years) }\end{array}$} & \multicolumn{2}{|c|}{$\begin{array}{l}\text { Share of males } \\
\text { in household } \\
\text { (>=15 years) }\end{array}$} & \multicolumn{2}{|c|}{$\begin{array}{l}\text { Share of females } \\
\text { in household } \\
(>=15 \text { years) }\end{array}$} & \multicolumn{2}{|c|}{ Asset score } \\
\hline & & & Mean & $S D$ & Mean & $S D$ & Mean & $S D$ & Mean & $S D$ \\
\hline 1 & 44 & 14.7 & 35.20 & 19.75 & 24.98 & 14.53 & 39.81 & 25.70 & 10.05 & 7.79 \\
\hline 2 & 68 & 22.7 & 22.03 & 12.79 & 19.66 & 6.53 & 58.32 & 15.68 & 19.74 & 17.32 \\
\hline 3 & 6 & 2.0 & 39.96 & 11.33 & 39.27 & 21.88 & 20.77 & 16.48 & 24.33 & 22.58 \\
\hline 4 & 45 & 15.0 & 26.00 & 10.88 & 30.24 & 13.65 & 41.53 & 14.78 & 39.04 & 26.70 \\
\hline 5 & 74 & 24.7 & 35.81 & 23.04 & 32.38 & 17.85 & 31.81 & 25.70 & 13.61 & 11.27 \\
\hline \multirow[t]{2}{*}{6} & 57 & 19.0 & 31.60 & 19.45 & 27.20 & 14.88 & 41.20 & 21.34 & 26.77 & 27.04 \\
\hline & 294 & 98.0 & 30.30 & 18.74 & 27.14 & 14.96 & 42.22 & 23.24 & 21.16 & 21.30 \\
\hline
\end{tabular}

Note: $\mathrm{SD}=$ standard deviation . 


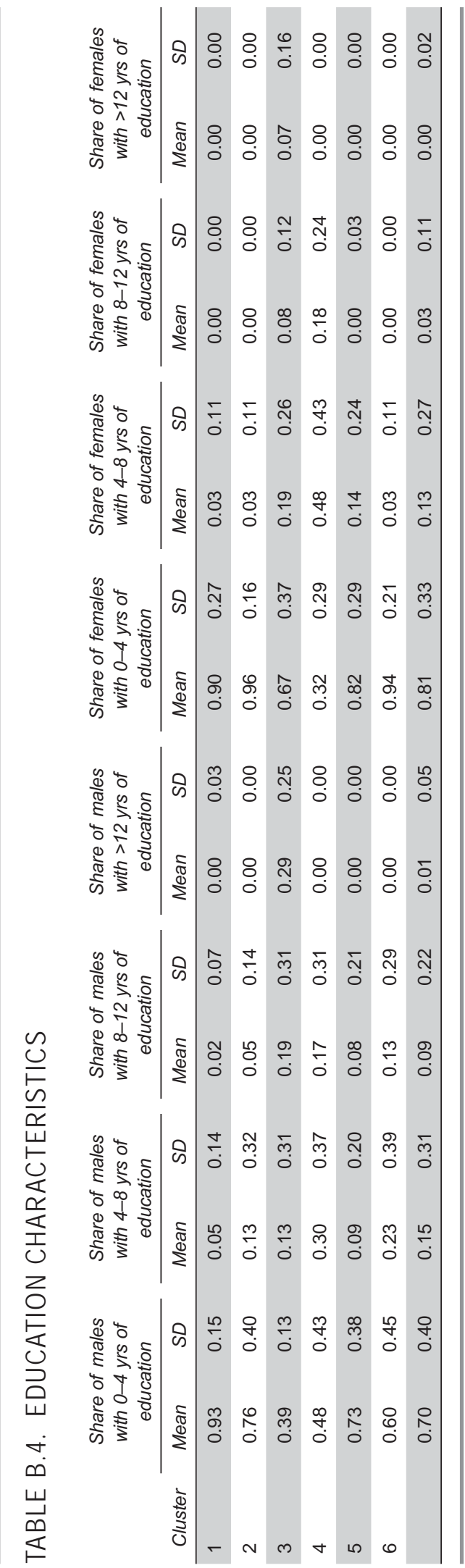


TABLE B.5. AGRICULTURAL CHARACTERISTICS

\begin{tabular}{|c|c|c|c|c|c|c|c|c|c|c|}
\hline & \multirow{2}{*}{$\begin{array}{l}\text { average } \\
\text { area per } \\
\text { household } \\
\text { (ha) }\end{array}$} & \multicolumn{9}{|c|}{ Average acreage planted with (ha) } \\
\hline & & Grain (ha) & $\begin{array}{l}\text { Legumes } \\
\text { (ha) }\end{array}$ & $\begin{array}{l}\text { Potatoes } \\
\text { (ha) }\end{array}$ & $\begin{array}{l}\text { Vegetables } \\
\text { (ha) }\end{array}$ & $\begin{array}{c}\text { Cash crop } \\
\text { (ha) }\end{array}$ & $\begin{array}{l}\text { Oil crop } \\
\text { (ha) }\end{array}$ & Rest (ha) & $\begin{array}{l}\text { Fruit trees } \\
\text { (no.) }\end{array}$ & $\begin{array}{c}\text { Other trees } \\
\text { (no.) }\end{array}$ \\
\hline 1 & 0.89 & 0.63 & 0.11 & 0.00 & 0.01 & 0.00 & 0.15 & 0.00 & 0.00 & 0.00 \\
\hline 2 & 1.25 & 0.86 & 0.01 & 0.00 & 0.33 & 0.01 & 0.01 & 0.03 & 2.32 & 1.93 \\
\hline 3 & 3.84 & 0.90 & 0.50 & 2.04 & 0.19 & 0.03 & 0.17 & 0.02 & 9.50 & 3.83 \\
\hline 4 & 1.20 & 0.88 & 0.08 & 0.01 & 0.14 & 0.06 & 0.01 & 0.02 & 3.84 & 22.62 \\
\hline 5 & 0.76 & 0.63 & 0.04 & 0.00 & 0.02 & 0.07 & 0.00 & 0.01 & 1.43 & 7.76 \\
\hline \multirow[t]{4}{*}{6} & 0.84 & 0.68 & 0.03 & 0.01 & 0.01 & 0.09 & 0.01 & 0.01 & 0.91 & 15.67 \\
\hline & 1.05 & 0.74 & 0.06 & 0.05 & 0.11 & 0.05 & 0.03 & 0.01 & 1.86 & 9.02 \\
\hline & \multirow{2}{*}{$\begin{array}{l}\text { average } \\
\text { number of } \\
\text { trees (no.) }\end{array}$} & \multicolumn{9}{|c|}{$\%$ of households cultivating } \\
\hline & & Grain & legumes & potatoes & vegetables & Cash crop & Oil crops & rest & fruit & trees \\
\hline 1 & 0.00 & 57 & 30 & 0 & 2 & 0 & 0 & 0 & 39 & 0 \\
\hline 2 & 4.25 & 97 & 6 & 0 & 59 & 12 & 15 & 16 & 4 & 18 \\
\hline 3 & 13.33 & 83 & 17 & 33 & 50 & 33 & 33 & 33 & 17 & 17 \\
\hline 4 & 26.47 & 100 & 33 & 9 & 31 & 51 & 24 & 60 & 2 & 13 \\
\hline 5 & 9.19 & 97 & 23 & 0 & 18 & 57 & 23 & 49 & 0 & 5 \\
\hline \multirow[t]{4}{*}{6} & 16.58 & 100 & 16 & 14 & 9 & 67 & 19 & 63 & 2 & 7 \\
\hline & 10.88 & 94 & 21 & 5 & 26 & 39 & 17 & 39 & 8 & 9 \\
\hline & $\%$ of & \multicolumn{9}{|c|}{$\%$ of producing households who sold any of their } \\
\hline & who sold & Grain & legumes & potatoes & vegetables & Cash crop & Oil crops & rest & fruit & trees \\
\hline 1 & 27 & 4 & 15 & & 0 & & & & 65 & \\
\hline 2 & 85 & 30 & 100 & & 95 & 38 & 40 & 18 & 67 & 33 \\
\hline 3 & 83 & 20 & 0 & 100 & 100 & 50 & 50 & 50 & 100 & 100 \\
\hline 4 & 84 & 44 & 40 & 100 & 86 & 87 & 18 & 44 & 0 & 17 \\
\hline 5 & 82 & 42 & 53 & & 92 & 81 & 41 & 39 & & 50 \\
\hline \multirow[t]{2}{*}{6} & 91 & 61 & 89 & 100 & 80 & 87 & 27 & 42 & 100 & 50 \\
\hline & 78 & 39 & 48 & 100 & 91 & 80 & 33 & 38 & 65 & 37 \\
\hline
\end{tabular}

Note: In the questionnaires some observations on cash crops (coffee and qat), fruit trees and other trees were in hectares, others were in number of trees. In order to put all crop types under the same unit, number of coffee and qat plants was transformed into hectares using a conversion factor of 1 plant per $2 \mathrm{~m}^{2}=0.0002$ ha. For fruit trees and other trees, the observations per hectare were transformed into estimates of number of trees using a conversion factor of 1 tree per 0.015625 ha or 64 trees per hectare. This factor was derived from the survey data. 
TABLE B.5B. DETAILS AND AREA CULTIVATED

\begin{tabular}{lccccccccc} 
cluster & $\begin{array}{c}\text { average } \\
\text { acreage } \\
\text { (ha) }\end{array}$ & $\begin{array}{c}\text { Standard } \\
\text { deviation }\end{array}$ & $\begin{array}{c}\text { Minimum } \\
\text { acreage } \\
\text { (ha) }\end{array}$ & $\begin{array}{c}25 \% \\
\text { percentile } \\
\text { (ha) }\end{array}$ & $\begin{array}{c}50 \%=\text { median } \\
\text { (ha) }\end{array}$ & $\begin{array}{c}75 \% \\
\text { percentile } \\
\text { (ha) }\end{array}$ & $\begin{array}{c}\text { Maximum } \\
\text { acreage } \\
\text { (ha) }\end{array}$ & $\begin{array}{c}\text { households } \\
\text { cultivating no } \\
\text { crops (\%) }\end{array}$ \\
\hline 1 & 0.89 & 0.93 & 0.00 & 0.00 & 1.00 & 1.50 & 4.00 & 41 \\
\hline 2 & 1.25 & 0.83 & 0.00 & 0.74 & 1.13 & 1.50 & 5.00 & 1 \\
3 & 3.84 & 3.78 & 0.00 & 0.56 & 3.25 & 7.27 & 8.25 & 17 \\
\hline 4 & 1.19 & 0.81 & 0.25 & 0.63 & 1.00 & 1.61 & 4.50 & 0 \\
\hline 5 & 0.77 & 0.47 & 0.00 & 0.50 & 0.63 & 0.88 & 2.50 & 1 \\
\hline 6 & 0.84 & 0.51 & 0.13 & 0.50 & 0.75 & 1.00 & 2.19 & 0 \\
\hline
\end{tabular}




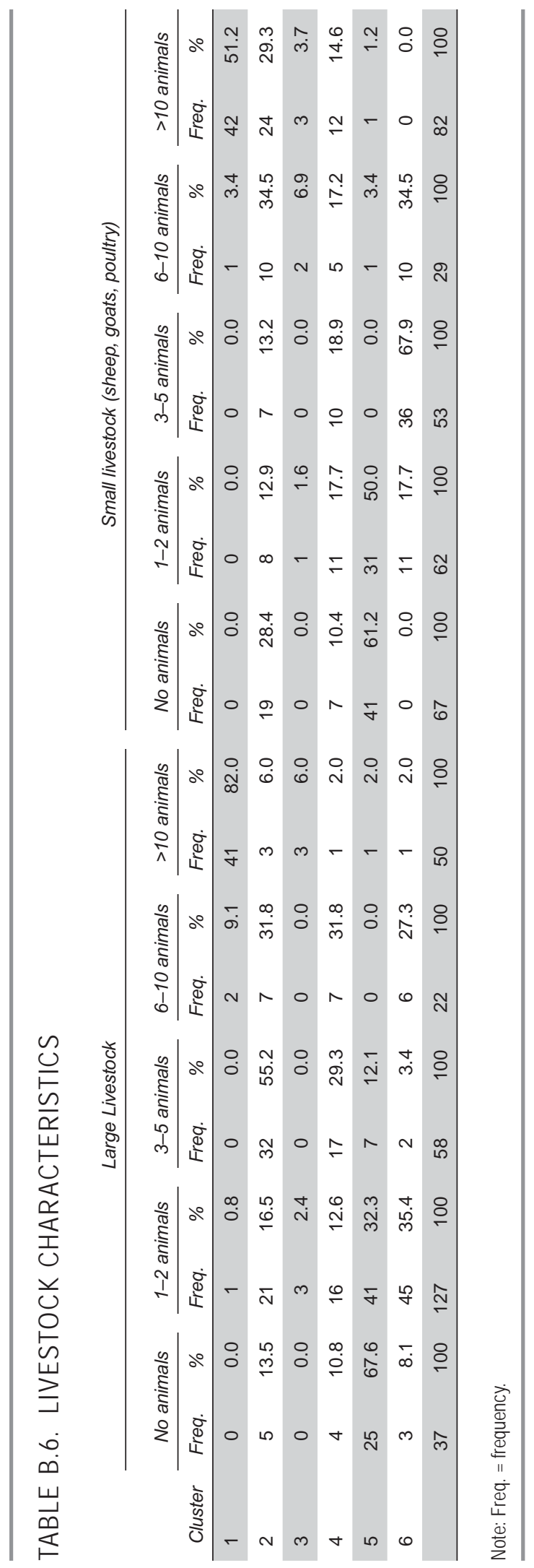




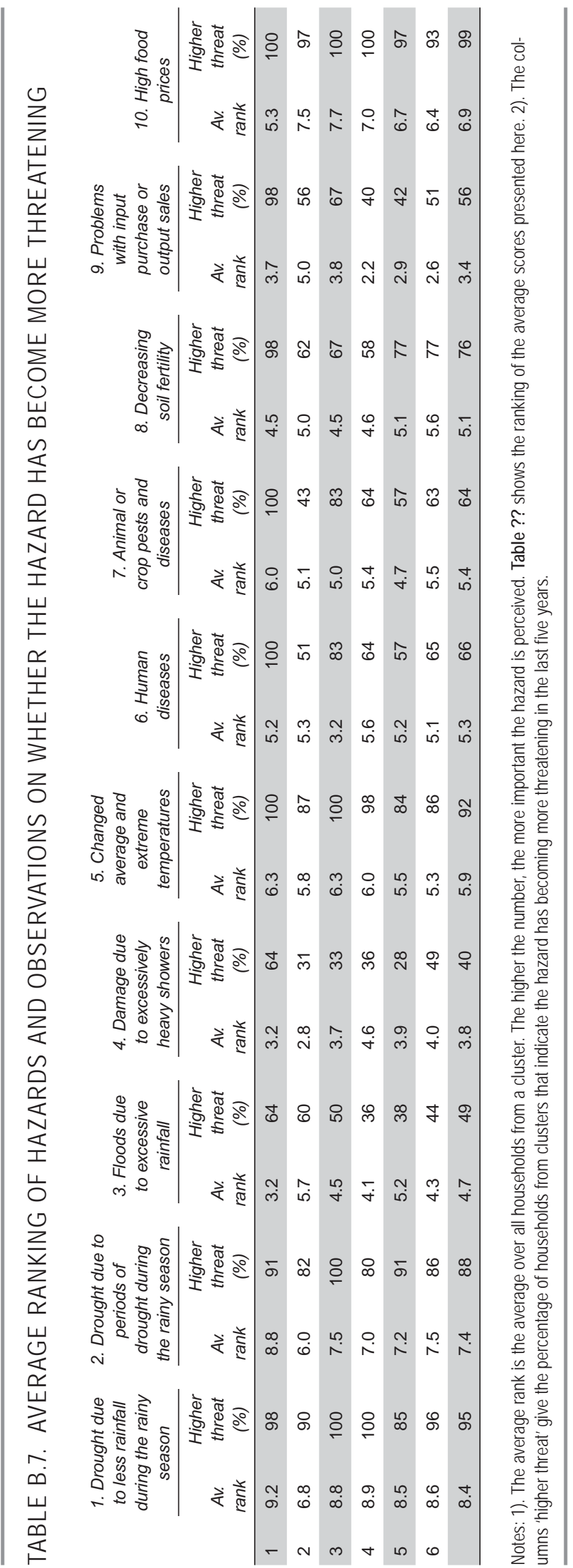


TABLE B.8. HOUSEHOLDS FACING FOOD SHORTAGES IN PARTICULAR MONTHS (\%)

\begin{tabular}{|c|c|c|c|c|c|c|c|c|c|c|c|c|c|c|}
\hline & $\begin{array}{c}\% \text { household } \\
\text { with food } \\
\text { shortage }\end{array}$ & $\begin{array}{c}\text { number of } \\
\text { months in } \\
\text { shortage }\end{array}$ & may & june & july & august & sept & oct & nov & dec & jan & $f e b$ & march & april \\
\hline 1 & 98 & 4.0 & 86 & 37 & 5 & 0 & 2 & 2 & 2 & 37 & 88 & 60 & 42 & 49 \\
\hline 2 & 81 & 2.7 & 40 & 45 & 53 & 51 & 45 & 22 & 5 & 4 & 15 & 5 & 13 & 31 \\
\hline 3 & 83 & 2.5 & 40 & 0 & 40 & 40 & 20 & 0 & 0 & 20 & 60 & 40 & 20 & 20 \\
\hline 4 & 76 & 2.4 & 38 & 35 & 79 & 82 & 59 & 12 & 0 & 0 & 3 & 0 & 3 & 3 \\
\hline 5 & 95 & 3.2 & 27 & 41 & 86 & 84 & 59 & 17 & 1 & 3 & 3 & 4 & 6 & 6 \\
\hline \multirow[t]{2}{*}{6} & 72 & 2.2 & 34 & 24 & 90 & 93 & 51 & 12 & 0 & 0 & 0 & 0 & 0 & 0 \\
\hline & 84 & 2.9 & 43 & 37 & 63 & 63 & 44 & 14 & 2 & 8 & 21 & 14 & 13 & 18 \\
\hline
\end{tabular}




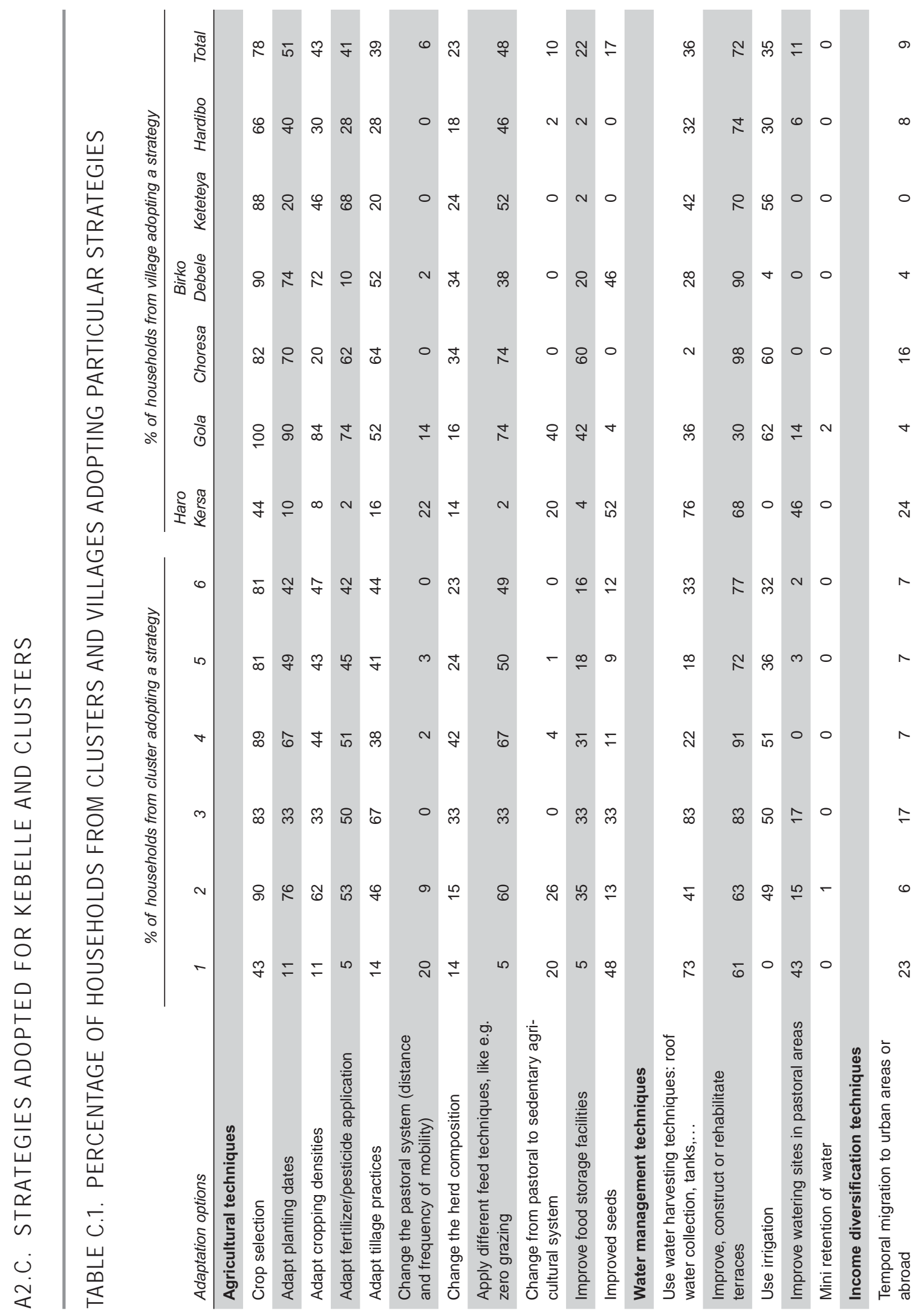




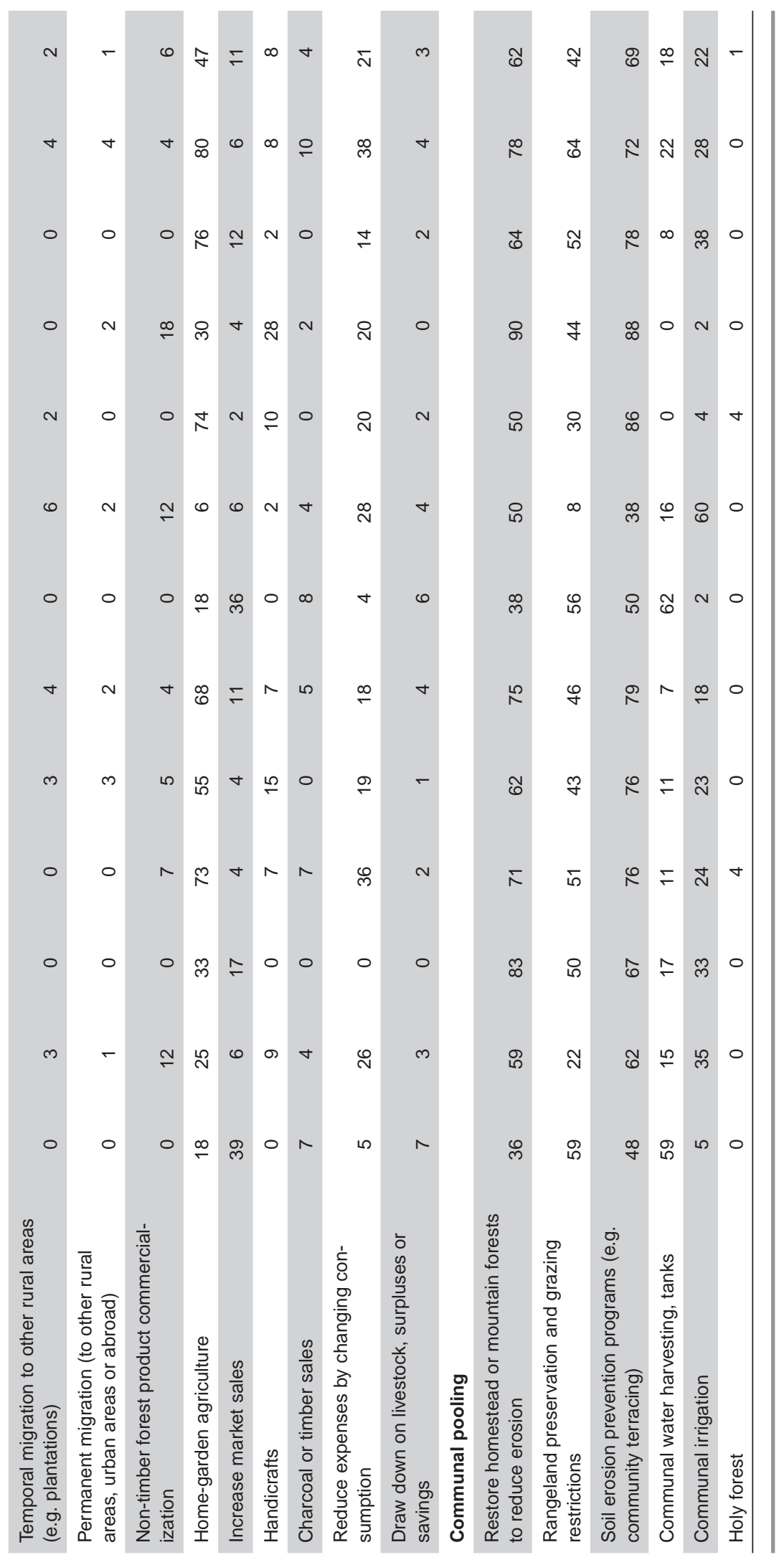




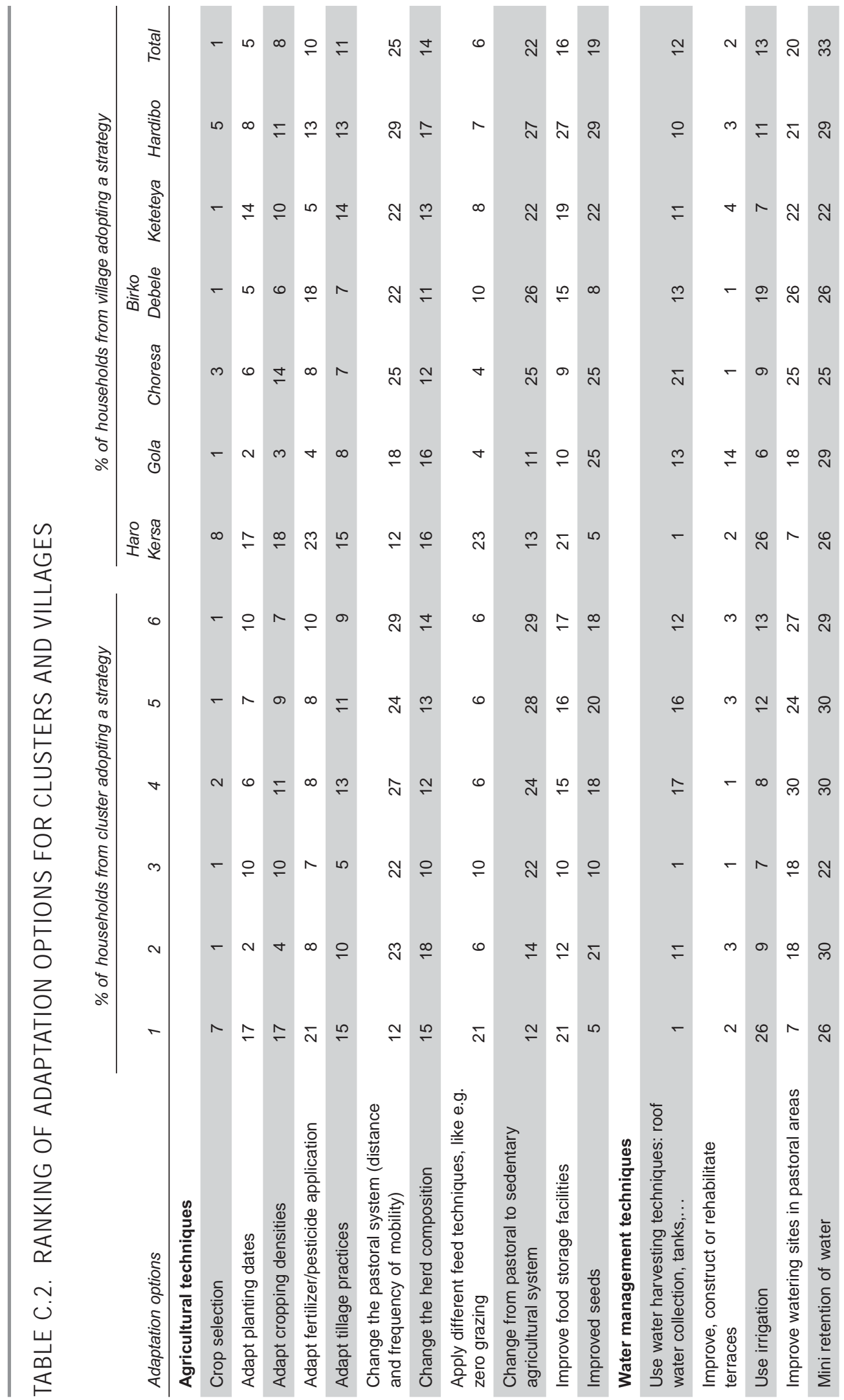




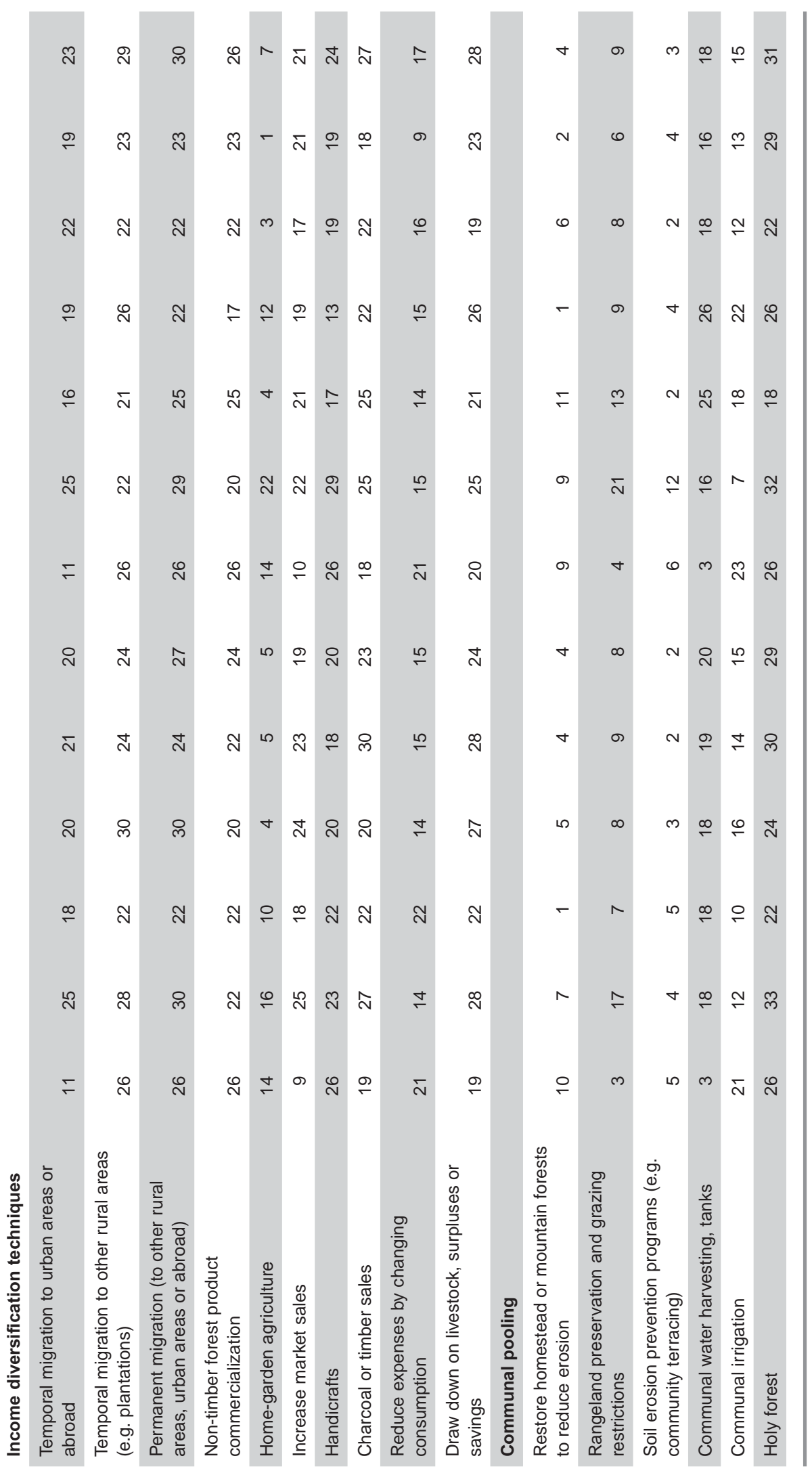




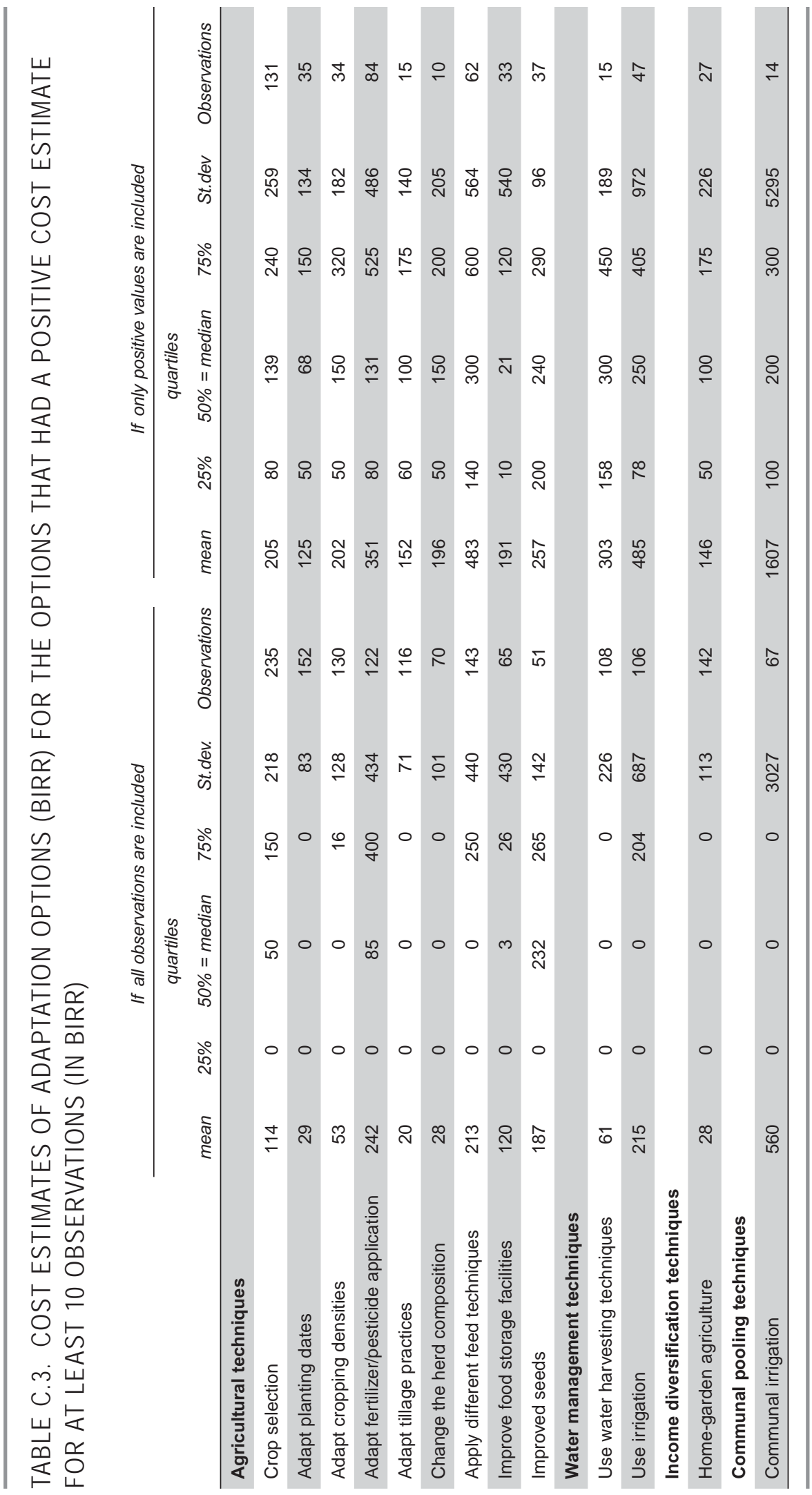




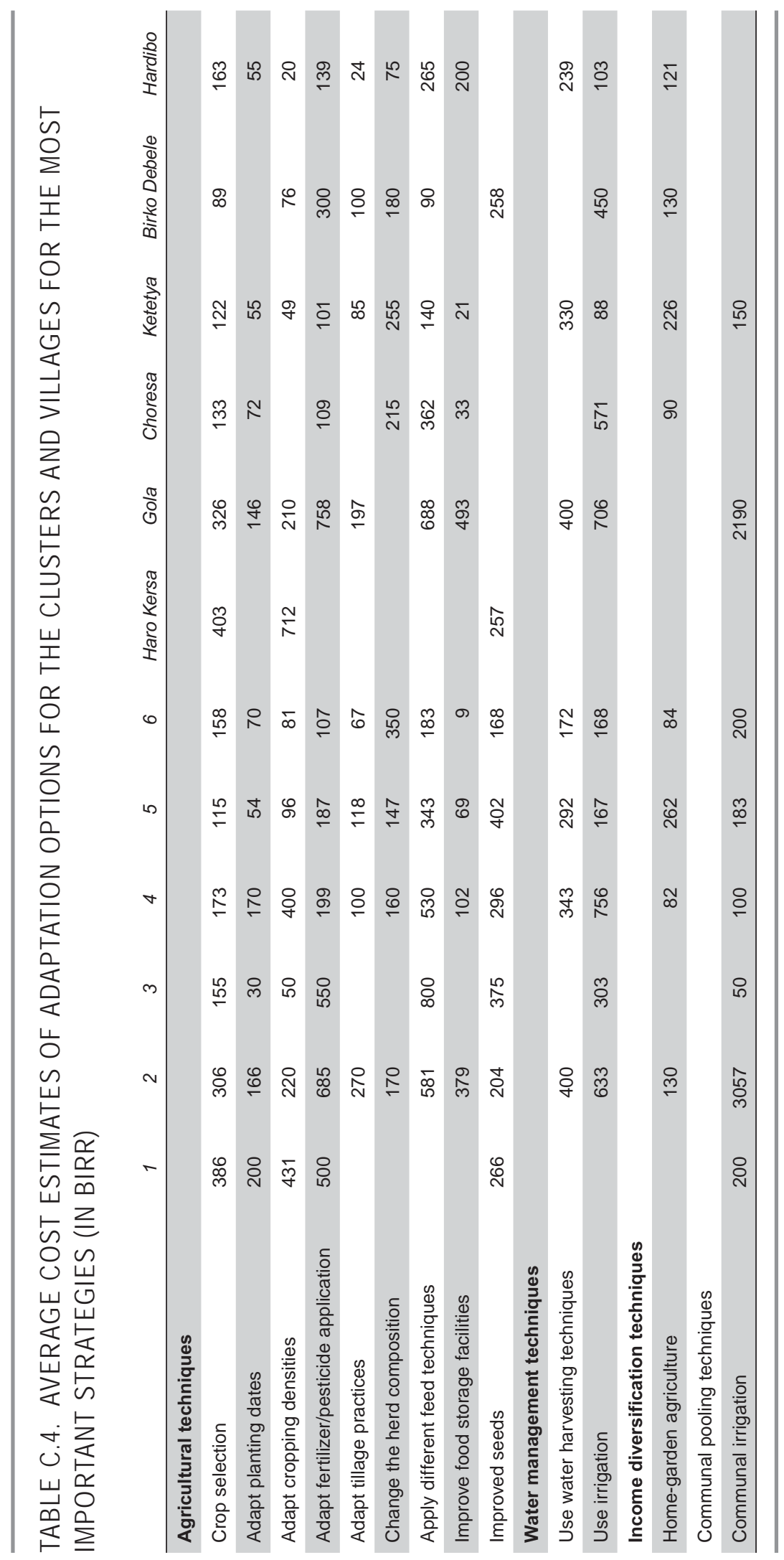




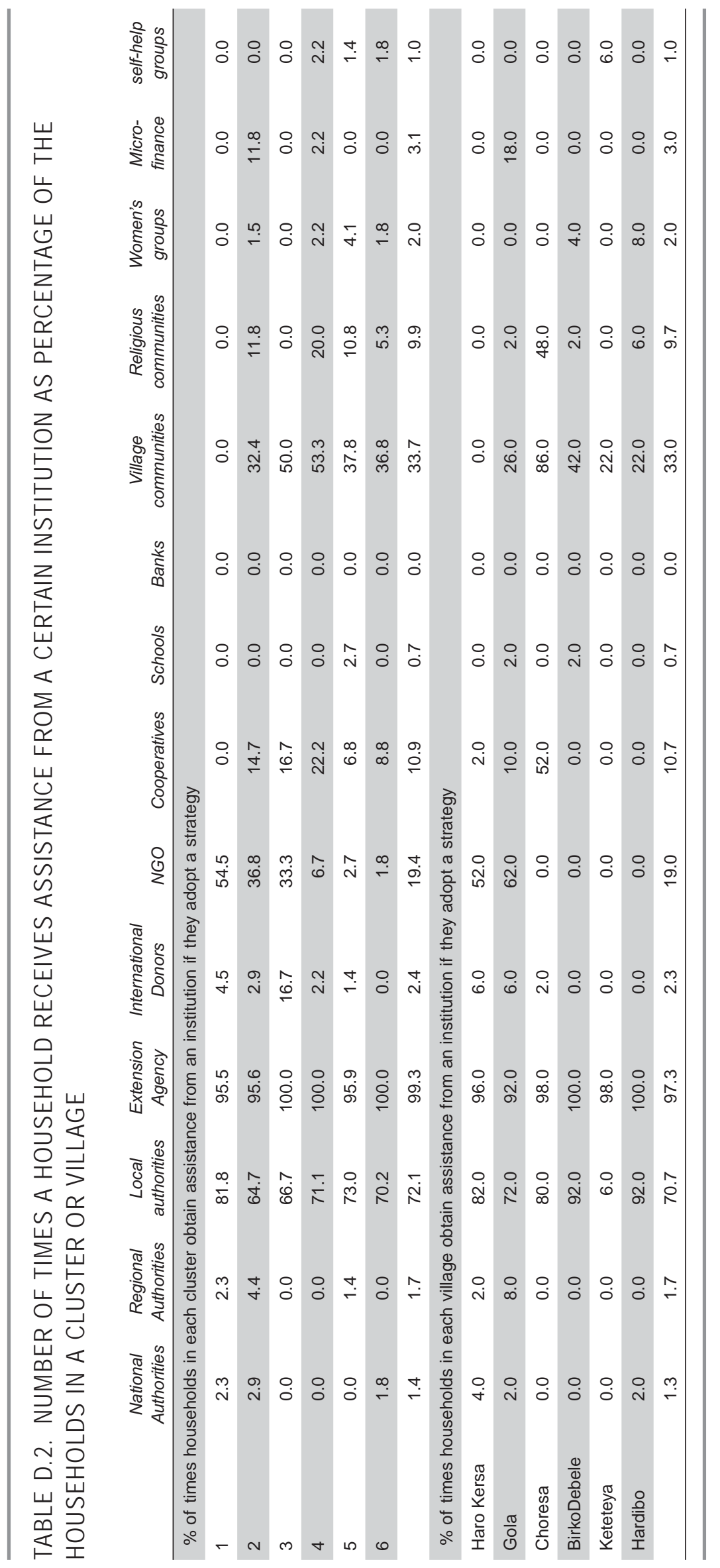




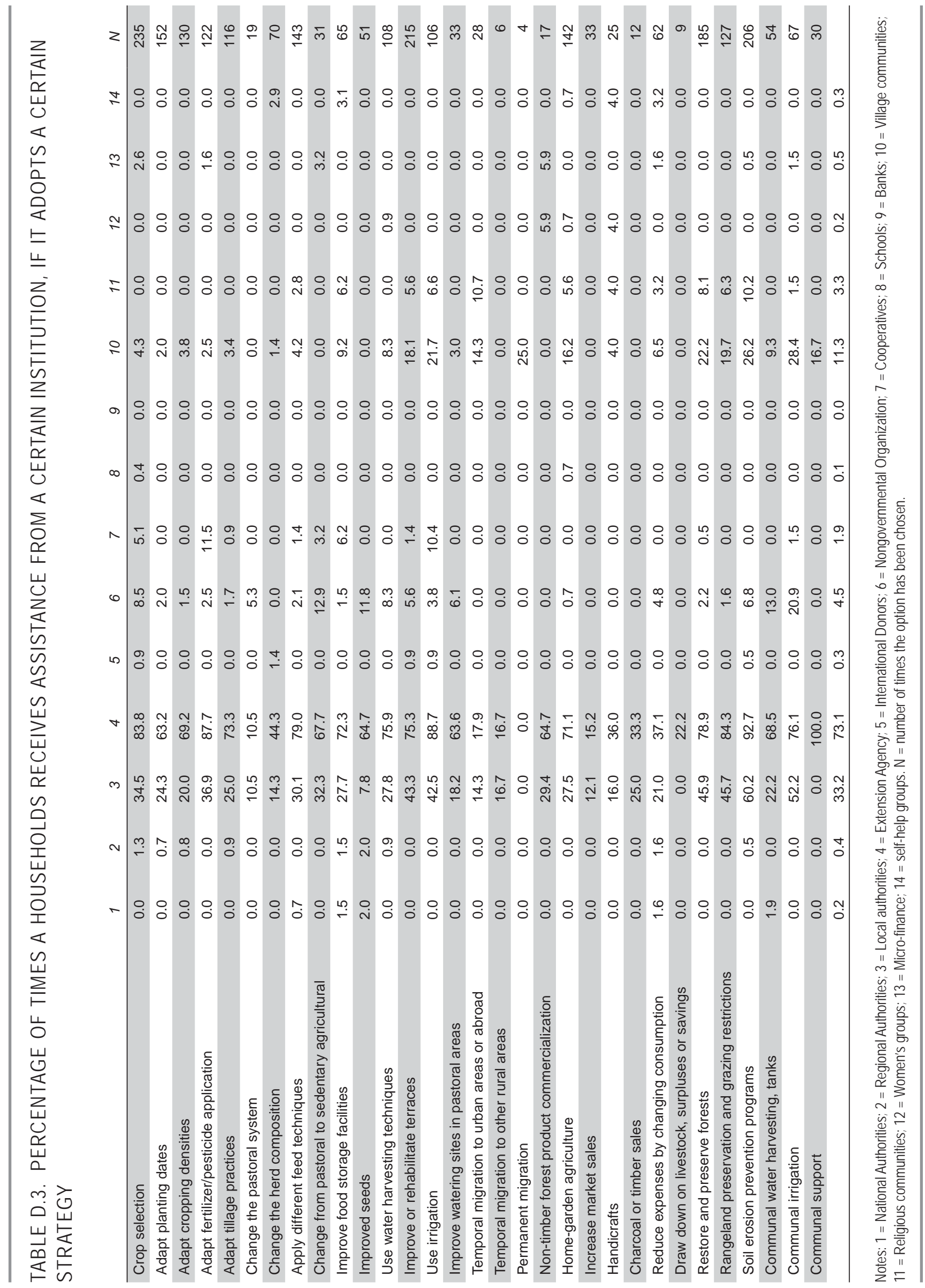




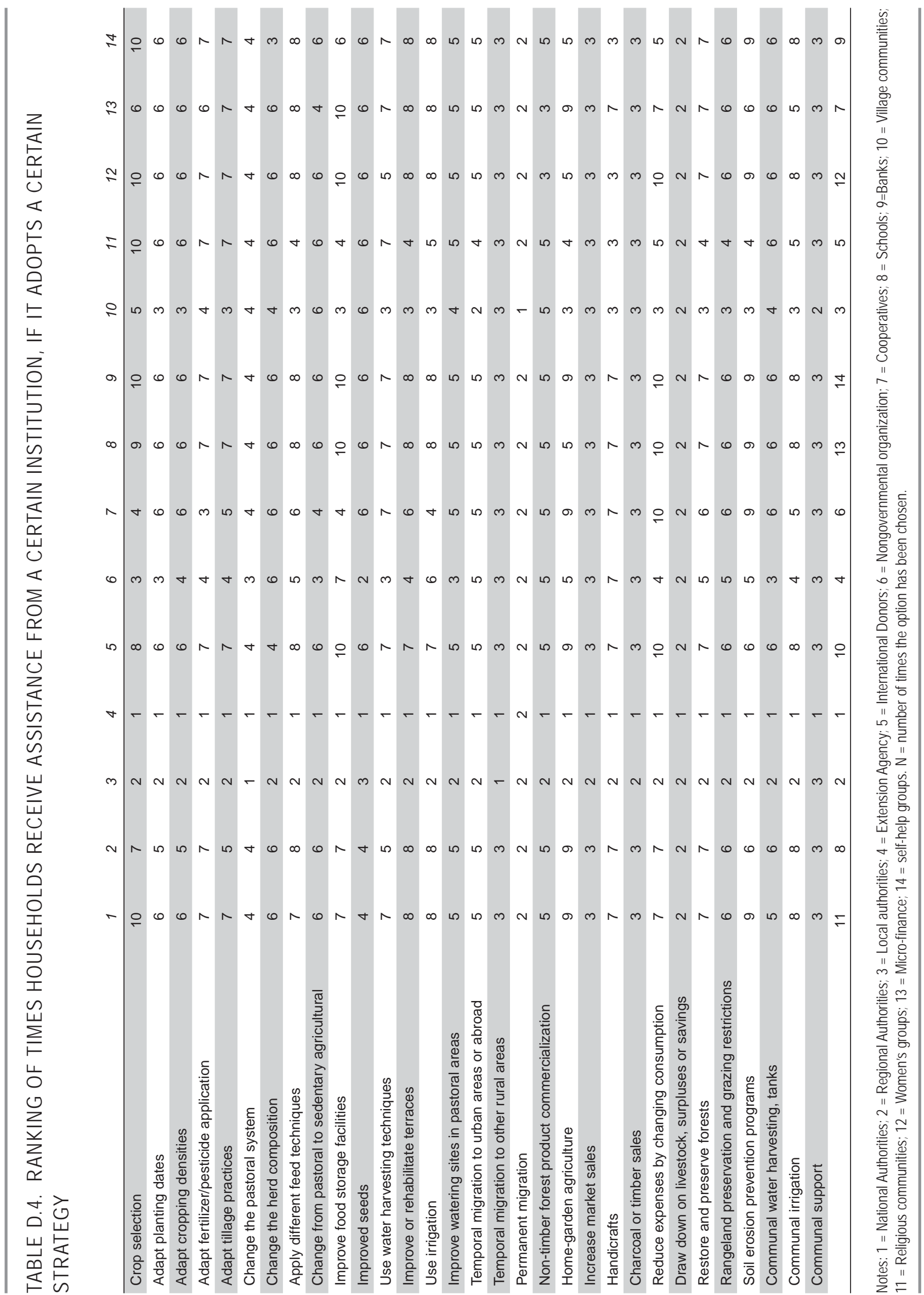


TABLE D.5. NUMBER OF TIMES A CERTAIN TYPE OF ASSISTANCE IS RECEIVED AS \% OF THE TIMES ASSISTANCE IS GIVEN

\begin{tabular}{lccccccccccc} 
Cluster & Training & Labor & Inputs $^{1}$ & Cash & Food & Village & Training & Labor & Inputs $^{1}$ & Cash $^{\text {Food }}$ \\
\hline 1 & 58.8 & 11.5 & 20.4 & 3.9 & 5.4 & Haro Kersa & 58.5 & 11.3 & 21.3 & 3.7 & 5.2 \\
2 & 67.0 & 17.6 & 10.9 & 2.8 & 1.8 & Gola & 68.8 & 15.6 & 9.3 & 3.9 & 2.4 \\
3 & 75.5 & 4.1 & 18.4 & 0.0 & 2.0 & Choresa & 77.3 & 13.0 & 9.3 & 0.4 & 0.0 \\
4 & 66.7 & 15.0 & 17.4 & 0.9 & 0.0 & BirkoDebele & 57.4 & 14.5 & 27.0 & 0.9 & 0.2 \\
5 & 74.2 & 11.7 & 13.7 & 0.3 & 0.0 & Keteteya & 59.8 & 16.4 & 23.5 & 0.3 & 0.0 \\
\hline 6 & 63.9 & 11.4 & 23.8 & 0.7 & 0.2 & Hardibo & 81.1 & 9.0 & 9.0 & 0.8 & 0.0 \\
& 67.3 & 13.5 & 16.4 & 1.6 & 1.2 & & 67.3 & 13.5 & 16.4 & 1.6 & 1.2 \\
\hline
\end{tabular}

Note: Inputs includes seeds, equipment, wood, machinery, bricks, etc.

TABLE D.6. NUMBER OF TIMES A CERTAIN TYPE OF ASSISTANCE IS RECEIVED AS \% OF THE NUMBER OF HOUSEHOLDS

\begin{tabular}{lccccccccccc} 
Cluster & Training & Labor & Inputs $^{1}$ & Cash & Food & Village & Training & Labor & Inputs $^{1}$ & Cash $^{\text {Food }}$ \\
\hline 1 & 95.5 & 50.0 & 72.7 & 22.7 & 25.0 & Haro Kersa & 96.0 & 50.0 & 74.0 & 22.0 & 26.0 \\
2 & 95.6 & 48.5 & 51.5 & 17.6 & 8.8 & Gola & 92.0 & 44.0 & 46.0 & 22.0 & 12.0 \\
3 & 100.0 & 33.3 & 66.7 & 0.0 & 16.7 & Choresa & 98.0 & 46.0 & 48.0 & 4.0 & 0.0 \\
\hline 4 & 97.8 & 44.4 & 51.1 & 8.9 & 0.0 & BirkoDebele & 96.0 & 46.0 & 46.0 & 6.0 & 2.0 \\
\hline 5 & 94.6 & 31.1 & 33.8 & 2.7 & 0.0 & Keteteya & 98.0 & 34.0 & 68.0 & 2.0 & 0.0 \\
6 & 98.2 & 36.8 & 57.9 & 3.5 & 1.8 & Hardibo & 96.0 & 26.0 & 26.0 & 6.0 & 0.0 \\
& 98.0 & 41.8 & 52.4 & 10.5 & 6.8 & & 96.0 & 41.0 & 51.3 & 10.3 & 6.7 \\
\hline
\end{tabular}

Note: Inputs includes seeds, equipment, wood, machinery, bricks, etc. 


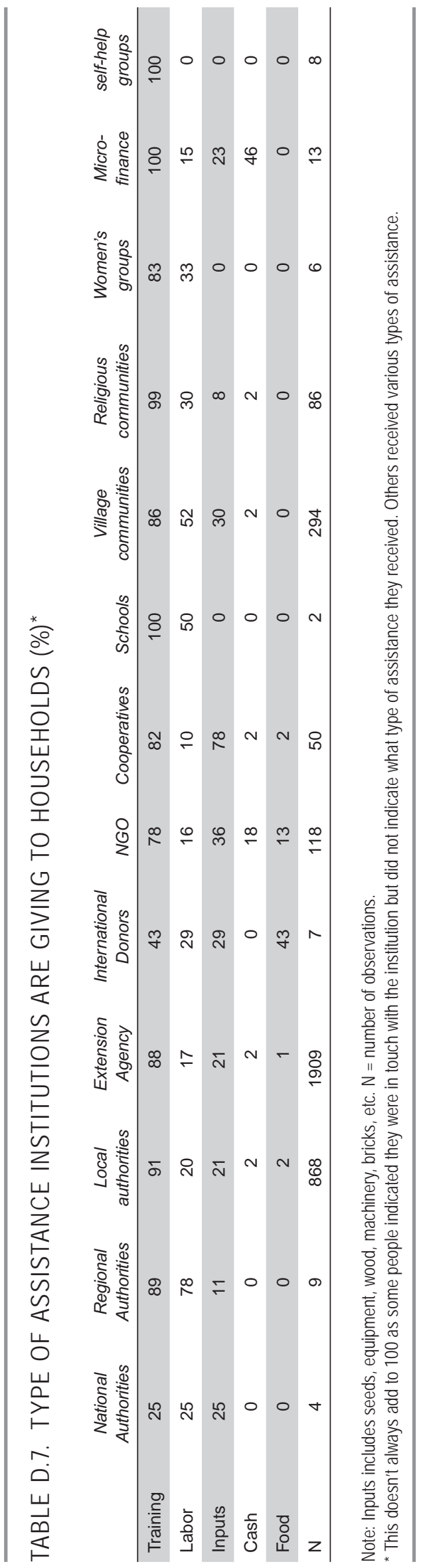


TABLE D.8. TYPE OF ASSISTANCE HOUSEHOLDS RECEIVE, IF IT ADOPTS A CERTAIN STRATEGY (\%)

\begin{tabular}{|c|c|c|c|c|c|}
\hline & Training & Labor & Inputs & Cash & Food \\
\hline Crop selection & 79.6 & 12.8 & 20.0 & 3.8 & 0.9 \\
\hline Adapt planting dates & 57.9 & 7.9 & 4.6 & 0.7 & 0.0 \\
\hline Adapt cropping densities & 66.2 & 9.2 & 10.8 & 0.8 & 0.8 \\
\hline Adapt fertilizer/pesticide application & 84.4 & 8.2 & 27.9 & 0.0 & 0.8 \\
\hline Adapt tillage practices & 66.4 & 6.0 & 3.4 & 0.9 & 1.7 \\
\hline Change the pastoral system & 15.8 & 5.3 & 0.0 & 0.0 & 0.0 \\
\hline Change the herd composition & 42.9 & 5.7 & 7.1 & 0.0 & 0.0 \\
\hline Apply different feed techniques & 72.0 & 7.0 & 7.7 & 1.4 & 0.0 \\
\hline Change from pastoral to sedentary agricultural & 64.5 & 12.9 & 19.4 & 9.7 & 0.0 \\
\hline Improve food storage facilities & 72.3 & 4.6 & 9.2 & 0.0 & 0.0 \\
\hline Improved seeds & 52.9 & 33.3 & 3.9 & 11.8 & 0.0 \\
\hline Use water harvesting techniques & 72.2 & 6.5 & 19.4 & 0.0 & 1.9 \\
\hline Improve or rehabilitate terraces & 61.4 & 17.7 & 20.5 & 1.4 & 6.0 \\
\hline Use irrigation & 82.1 & 21.7 & 25.5 & 2.8 & 0.0 \\
\hline Improve watering sites in pastoral areas & 60.6 & 0.0 & 6.1 & 6.1 & 0.0 \\
\hline Temporal migration to urban areas or abroad & 28.6 & 0.0 & 0.0 & 0.0 & 0.0 \\
\hline Temporal migration to other rural areas & 16.7 & 0.0 & 0.0 & 0.0 & 0.0 \\
\hline Permanent migration & 25.0 & 0.0 & 0.0 & 0.0 & 0.0 \\
\hline Non-timber forest product commercialization & 58.8 & 23.5 & 0.0 & 5.9 & 0.0 \\
\hline Home-garden agriculture & 62.0 & 10.6 & 11.3 & 0.0 & 0.0 \\
\hline Increase market sales & 18.2 & 0.0 & 3.0 & 0.0 & 0.0 \\
\hline Handicrafts & 40.0 & 20.0 & 0.0 & 0.0 & 0.0 \\
\hline Charcoal or timber sales & 25.0 & 0.0 & 0.0 & 0.0 & 0.0 \\
\hline Reduce expenses by changing consumption & 45.2 & 12.9 & 6.5 & 0.0 & 0.0 \\
\hline Draw down on livestock, surpluses or savings & 22.2 & 11.1 & 0.0 & 0.0 & 0.0 \\
\hline Restore and preserve forests & 73.0 & 22.2 & 21.1 & 0.0 & 1.1 \\
\hline Rangeland preservation and grazing restrictions & 83.5 & 15.7 & 18.1 & 0.0 & 0.8 \\
\hline Soil erosion prevention programs & 76.7 & 23.3 & 32.5 & 1.0 & 1.9 \\
\hline Communal water harvesting, tanks & 57.4 & 13.0 & 29.6 & 3.7 & 3.7 \\
\hline Communal irrigation & 68.7 & 28.4 & 26.9 & 4.5 & 0.0 \\
\hline \multirow[t]{2}{*}{ Communal support } & 86.7 & 16.7 & 43.3 & 3.3 & 0.0 \\
\hline & 67.06 & 13.44 & 16.39 & 1.61 & 1.15 \\
\hline
\end{tabular}




\section{APPENDIX 3. SUMMARY OF FOCUS GROUP DISCUSSIONS}

\section{A. SELECTION OF VILLAGES AND PARTICIPANTS}

The study was conducted in Kalu woreda of the South Wollo zone of the Amhara Region and Fentale woreda in the eastern Shoa zone of the Oromiya region. The villages were selected in consultation with the woreda rural development office representatives. The selection of villages aimed at obtaining a fair representation of highland, midland, and lowland areas of the woredas. We also considered the criteria of diverse climate hazards, socioeconomic circumstances, and road accessibility in the selection of villages. Accordingly, we selected Hardibo and Keteteya representing the highland villages, Choresa and Birko-Debele representing the midland villages, and Gola and Haro Kersa representing the lowland villages.

In each village, one focus group discussion consisting of 15-25 participants was held. Participants for the focus group discussion were selected in consultation with extension agents and village administration, based on the following criteria:

- being a resident in the locality

- obtaining a fair representation of important age categories (elderly, middle age, and youth)

- obtaining a fair representation of the different wealth categories

- obtaining a fair representation of gender distribution
- containing a fair representation of the community leaders, village officials, and extension agents working in the village

- willingness to participate in the discussion.

A focus group approach was used so that the participants would feel comfortable and free to state their opinions and disclose their practices and thoughts with minimal interference. The facilitated discussion lasted approximately two-and-a-half hours in each village. The facilitator encouraged participants to express what they were thinking and why; differences were encouraged. Their comments and answers were recorded collectively as a group. Participants were then asked to identify and rank hazards using cards that portray different kinds of hazards at the end of the focus group, which mirrored the facilitated discussion.

The discussions were very dynamic and participants expressed their ideas freely. In most cases the participants argued thoroughly to respond to each point raised in the discussion. Though there were a few participants who tended to rule over the discussion, they were managed cautiously and all participants were able to speak their opinion without any hindrance. The level and interest of participation was very high as they considered the issue to be among their most important concerns. Despite the fact that the objective of the study was clearly explained to the participants, they still remained with high expectation that the discussion and the study results would bring about some positive development interventions from government and international organizations to their village to assist them to mitigate the impact of climate change on their livelihood. 
Below is a summary of the main findings of the focus group discussion and stakeholders' interview.

\section{B. MANIFESTATIONS AND EFFECTS OF CLIMATE-RELATED HAZARDS}

Based on the focus group discussions, climate-related hazards in the midlands and highland areas are mainly manifested through declining and variable rainfall and rising heat. Minor manifestations of climate-related hazards include heavy and stormy rain, which is rarely observed in the highlands. The effects of the decrease and variability of rainfall and rising heat include water shortages, pasture shortages, flourishing of crop pests, and food shortages in the household, many of which have effects based on gender. For the lowland areas, their major concerns included drought due to less rainfall, extreme temperature and animal and human diseases, which result in food shortages, death of animals, crop loss, lack of grazing land, and conflict. Participants cited that the sustainability of their livelihoods is their major concern. They emphasized that climate change is the most important contributing factor in the deterioration of their livelihoods in the past 20-25 years time. For Gola, in addition to the above-mentioned hazards, flood risk is a major hazard.

\section{Declining and Variable Rainfall and Effects}

The households in the area notice that the amount and the calendar of rainfall have been changing over the past few decades. The situation seems to vary between the highland, midland, and lowland areas. The highland area is known to have two rainy seasons, namely the belg rain (i.e. the short rainy season extending from January to June) and the kiremt rain (i.e. the long rainy season extending from July to September) which allows the highland area to have two production seasons and as a result to be better-off than much of the midland and lowland areas. These days, however, the belg rain is almost disappearing from the highlands, especially during the last five years. One highlander expressed this trend as follows:

"before, we used to produce twice during the year but these days we are not seeing belg rain regularly; and the amount of kiremt rain that we are getting in the past five years does not even amount of the belg rain that we used to get like ten years ago.”
The midland and lowland areas, which are characterized by the main kiremt rain, are mainly affected through a decline in the amount of rainfall and fluctuations in the onset of rainfall. In both cases, there is irregularity in the start and finish of rainfall. The farmers in the areas normally suffer from the delayed start of rain during the sowing and interruption of rain during the flowering season, which may cause loss of labor, material service, seed, and harvest. In the lowland pastoralist areas, declining and variable rainfall levels also result in water shortages for their livestock and therefore increased incidence of animal diseases and deaths.

\section{Rising Heat and Effects}

One elderly farmer and a mosque leader in Choresa village expressed the recent rise in temperature as follows:

"before (like 10 years ago), the farmer plowing his field and his plow oxen as well as those livestock feeding on the pasture used to start seeking shade at around noon but these days they do it around 10:00 AM in the morning."

In a focus group discussion in Hardibo village, farmers made the link between rainfall shortage, increase in temperature, and incidence of crop pests as follows:

"the rising heat coupled with the inadequate rain is only good for the flourishing of crop pests which again causes crop loss."

As a result, the farmer has to deal with the shortening of the number of productive working hours during the day (both for him and his plowing oxen), the effect of crop pests, and the need to increase food production as insurance against the drought.

\section{Flood Risk and Effects}

Unlike Haro Kersa, for Gola, flood is the first most important climate hazard affecting their livelihood. Drought and food shortages are more attributed to flooding as expressed by participants in the Gola focus group discussion. They explained that they actually get very little rainfall in their area throughout the year. They are usually flooded from the rains in the highland areas of neighboring districts. They also blame the dike built by an adjacent sugar plantation for blocking the natural path of the flow of floods and consequent overflow of the village farm land. They are worried that 
the frequency of the flooding has now become twice a year, which limits their capability to farm agricultural produce. Among the damages brought to them by the flood, they indicated that the flood damages crops, fruits, and vegetables, washes away planted crops, creates sand piles and spoils land structure, and covers the land surface with water, which makes it difficult to grow crops.

\section{Other Hazards and Effects}

In Haro Kersa, though the death of animals and extreme temperatures are the greatest hazard events in their village, they also have concerns about conflicts with neighboring clans. They state that the frequency of conflicts and fighting for grazing land with the neighboring clans and ethnic groups has increased and resulted in loss of human life and cattle.

The resultant impacts of the major climate hazards as identified by participants are summarized as follows. Drought due to less rainfall results in damages to planted crops, food shortages, a decreased number of meals and hunger, and lack of grazing lands. The impact of the death of animals and crop loss is that livestock holdings decrease, milk supply decreases, food supplies are in shortage, food prices increase, household income decreases, and children become malnourished. Extreme temperature results in skin problems for the children, weakened health and therefore loss of productivity, higher infant mortality and pregnancy miscarriages, scorching of planted seeds, and crop and animal diseases.

\section{GENDERED EFFECTS OF DROUGHT AND FOOD SHORTAGE IN THE HOUSEHOLD}

The effect of water and food shortage in the household as a result of a change in the rainfall patterns appears to be gendered. In the area, women are normally responsible for providing water and cooked food for their household. In a focus group discussion in Choresa village, women emotionally expressed the effect of water shortage as follows:

"everyday we fight over the ever weakening spring water in the area especially during the dry season. This coupled with the long queue, it takes us more than three hours to get about 20 liters of water from a nearby spring for domestic chores which is about double the time it used to take us 10 years ago. This causes reduced sanitation in the household especially for the children."

It may, therefore, be useful to scale up the spring development and the water harvesting and moisture conservation efforts already in place for better outcomes. In a focus group discussion in Birko-Debele village, a male farmer expressed that women suffer the most as a result of food shortage in the household:

"when I realize that there is not enough food in the house, I go out to the nearby town or to my friends. The woman cannot go out because the children will be waiting on her to get some food. In such cases, it is common that she cooks the little she has in the house and gives to her children and puts some aside for the husband and go hungry for herself. As a result the women get sick easily."

Thus, female parents are less mobile than their male counterparts during such harsh conditions. This indicates that local off-farm employment opportunities around the house may be useful interventions to assist female parents in income diversification. It also shows that reducing food consumption is one strategy, although women may be more affected by it.

\section{ADAPTATION STRATEGIES}

Important adaptation strategies include selection of crops or varieties, applying early and late sowing, selling livestock, water harvesting, runoff diversion techniques, terracing, stone bunds, soil and moisture conservation techniques (e.g. tie ridging), casual labor hiring, migration, sales of charcoal and household assets, and productive safety-net opportunities.

\section{Crop Selection}

The farmers in the area select the species or varieties of crops they sow. For example, in the midland villages, an early maturing sorghum variety is commonly preferred to the late maturing traditional one so as to make maximum use of the unreliable duration of the rainy period. In some cases, the crop species is changed temporarily or permanently depending on the rainfall pattern. For instance, in the highland villages qat production has 
been expanding over the past few years along with the increase in water harvesting practices.

\section{Early and Late Tillage Practices}

In an effort to minimize the risk of crop loss due to the less predictable timing of the onset and duration of rainfall, farmers in the area practice early and late sowing. In doing so, it is common that they lose one or more of the sown seeds, labor, and material service. Whenever the farmers lose the early sown one due to late rainfall, they may be forced to partly or fully re-till the land for the new sowing. It may also happen that the farmers are required to change the crop for the late sowing, which may require a different tillage practice.

Although it is important that the farmers adjust the cropping calendar according to the changed rainfall patterns as they do, designing a more precise weather forecast system and ensuring accessibility of forecast information is useful to assist household adaptation efforts.

\section{Livestock Production and Sales}

Livestock reared in the area include cattle, sheep, goats, camels, donkeys/horses, and poultry. It is common to observe in the highland Kalu the plowing oxen being fattened during the slack period and sold out to make profit after buying the replacement oxen for the following production season. Shared livestock production is common, particularly in the midland part whereby a household keeps and takes care of another's livestock with an agreement of equal sharing of the milk and offspring.

In all villages, livestock may also be sold as a strategy to cope with drought. It may happen that livestock could be in excess supply in the local market, fetching lower prices during severe drought periods, when many farmers want to sell livestock at the same time. The poor households are mostly pressed by the need to sell their livestock soon in the local market so as to meet their immediate cash needs. As a result, those who do not own oxen enter into different kinds of arrangements to get access to plowing oxen, including exchanging plowing oxen for plowing labor, exchanging fodder for plowing oxen and sharecropping out land (usually for 50 harvest share). Interestingly, those who own oxen normally get their land cultivated through sharecropping or renting out their land instead renting oxen. This is because the oxen market is not well developed, partly due to the risk associated. As a result, it is not very common to have more than two oxen among those who own oxen. Rainfed agriculture means that all the farm households in the village need to prepare their land at the same rain starting time and hence a household would need their few oxen to till their own land instead of renting them out. This is an indication that making plowing oxen available even for rent at a reasonable price during land preparation could be an intervention strategy to consider.

In the lowland village, livestock production is threatened by droughts causing shortages of water and grazing lands. Some households try to cope with this by experimenting with zero grazing and water harvesting techniques or by changing the livestock diet to sugar cane. Other households increase the distances over which they search for water and grazing lands due to which they are away from their homes longer than in the past.

\section{Migration}

Migration is also an important adaptation strategy to climate-related hazards. At least a quarter of the participants in each of the midlands and highland focus group discussions have experienced migration of at least one household member extending from the nearby towns to the distant ones during the last year. In the lowland village, it seems to be a less important strategy. Many expressed that quite a number of youngsters in the area travel to Afdera town (Afar region) i.e. about $400-500 \mathrm{~km}$ from their location for salt mining work, but also travel to the nearby towns of Kombolcha, Dessie and Addis. There are a few females who travel to countries like Dubai and Saudi Arabia. Quite a number of the migrants were able to send remittances back home, although this may not always be the case. In a focus group discussion in Keteteya, the downside of the situation is expressed as follows:

"due to food shortage in the households, some girls are forced to drop out of school and travel to the nearby 
towns to look for work. Some of the girls ended up in prostitution and came back home with HIV/AIDS."

\section{Child Labor Hiring}

Some households are also forced to employ their children within the locality, such as herding livestock for the rich in order to generate some cash. This is normally done at the expense of schooling.

\section{Water Harvesting and Irrigation Practices}

It is common to see water harvesting wells around the house among the households in the highland villages, which is not common in the drier midland ones. The water harvesting practice has been integrated with home-garden production activities such as qat and vegetables, which are manually irrigated from the harvested well water. Along with this, there are runoff diversion, as well as soil and water conservation (e.g. terracing, basin making) practices in the fields.

\section{Credit}

There are small interest-free lending activities (in cash and in kind) among the households in the area. However, a substantial amount of credit is obtained from the local moneylenders who offer an arrangement to exchange cash for crop harvest at about $>500$ interest rate. In a focus group discussion in Hardibo village it is mentioned that

"there are moneylenders in the area who provide farmers a credit of $\mathrm{Br} 1$ to be repaid in $1 \mathrm{Kg}$ grain (equivalent to Br 5-7) during the harvest season. The arrangement is called Ye kitel."

Some better-off households may also be involved in buying crops from the farmers at a cheap price during the harvest season and then selling it back to the farmers at very high price later during the slack period.

Firewood and Charcoal Selling

There are households who sell firewood and charcoal in order to diversify income. In a focus group discussion in Choresa village one farmer expressed the situation as follows:

"I am aware of the use of the forest for the environment, for the soil and rainfall situation in the area but I can't let my family die when there are some trees around to cut and make money out of it."

Although charcoal selling activity is forbidden by the government, in the absence of alternative strategies for the households, charcoal still continues to be smuggled. Next to charcoal selling, some households in the lowland village of Gola indicate that in extreme distress situations, they also sell household assets.

\section{E. INSTITUTIONAL ASSISTANCE}

Many of the adaptation strategies discussed during the focus group discussions are household-level strategies. Extension agencies, local authorities, and some NGOs (in the lowland village) provide assistance in terms of improved seeds and health and educational services. Next to that, also emergency support and safety net support (especially in Haro Kersa rated to be important) is provided by the government institutions. Productive safety-net activities are run mainly on cashfor-work basis. The activities include mountain terracing, water harvesting and moisture conservation techniques, and tree planting. In the lowland village, the NGOs also provide training in water management and animal husbandry and for some households also credit support. 


\section{APPENDIX 4. SUMMARY OF INSTITUTIONAL STAKEHOLDER INTERVIEWS}

\section{A. MAIN CLIMATE-RELATED HAZARDS IN THE AREA}

The stakeholders from the highland villages rate rainfall variability, high food prices, and heavy/stormy rain, changed average and extreme temperatures, and problems with input purchase and output sales as the most important problems that most consider to have been increasing over the past years. For the stakeholders from the midland villages, rainfall variability, drought, changed average and extreme temperatures, high food prices, and animal/crop pests and diseases are rated as important problems in the selected villages. The lowland village rate changed temperature, diseases (human/ animal/crop), droughts, high food prices, and decreasing soil fertility as the most important hazards. It is striking that rainfall variability and droughts are rated lower than hazards related to diseases. For pastoralists, who depend more on the availability of watering points than on regular showers, having prolonged periods of drought may be less of a problem as long as the watering points are filled from time to time.

The cross-woreda stakeholders (representations from CONCERN, Meteorology Agency, Kalu woreda agricultural and rural development office, health officers, the water office), who talked about Kalu and Fentale woreda and surroundings in general, rate rainfall variability, drought and decreasing soil fertility as more important climate hazards than the institutions focusing on the village level.

\section{B. INSTITUTIONS INVOLVED}

For the highlanders, the institutions that play a role in climate adaptation include extension agents (safety net programs, watershed management, water harvesting techniques, home garden production), local administration, NGOs (CONCERN), cooperatives, schools, village communities (e.g. Got), religious communities, women's groups, micro-financing groups (Amhara Saving and Credit Institution), and self-help groups (e.g. edir/kire). Of these, the rural development office through the extension agents, local administration, and NGOs are the most helpful. For the stakeholders from the midland kebeles, the institutions that play a role in climate adaptation are extension agents (safety net programs, watershed management), NGOs (CONCERN, SIDA), local administration, cooperatives, schools, village communities (e.g. Got), women's groups, micro-financing groups, and self-help groups. They identify the Kalu woreda rural development office (through the extension agents) and the local administration as playing the most prominent roles in climate adaptation. For the lowland village, the extension agency, local authorities, NGOs, cooperatives (Gamachu Saving \& Credit Cooperative in Gola and Abdi Fentale Multipurpose Cooperative Society in Haro Kersa), and women's groups are rated the most important. Extension agencies and NGOs are considered to be important for adapting to the effects of climate change. 
The cross-woreda stakeholders identified the following institutions as dealing with climate adaptation: extension agents, international donors, development organizations, NGOs, local administration, village communities, religious communities, women's groups, micro-financing groups, and the National Meteorology Agency. Of these institutions, extension agents, local administration, and NGOs were rated as making medium to very important contributions for adaptation by all the cross-cutting institutions, whereas the role of the meteorology agency was stressed by the representative from the agency. Specifically, agricultural and rural development offices, the national program on safety net and food security, WFP, Water Action, and SIDA are rated as important institutions for climate adaptation.

\section{TYPE OF ASSISTANCE THE HOUSEHOLDS NEED TO ADAPT}

The stakeholders identified the following support households need to improve their coping capacity to climate hazards:

- interest-free credit and financial support to buy farm inputs at reasonable prices (plowing oxen, improved seeds, communal tractors);

- timely availability of farm inputs (improved seeds, fertilizers, improved equipment);

- irrigation and water harvesting equipment (water pump, stone cutter, stone digger, geo-membrane) and enhanced farmer-to-farmer training for farmers who did well in watershed management;

- access to fishing equipment and materials, and training on fishing techniques and fish behavior;

- food aid during the severe shortage months;

- fair and timely payment for cash-for-work participants;

- small income generating activities and off-farm employment opportunities;

- improved access to health care facilities and personnel;

- veterinary clinics;

- an all-weather road network, rural electrification, and improved telecommunication systems;

- kebele-level courts and timely justice;

- awareness and capacity building on the effect of climate change and adaptation options.
These areas of support include on the one hand options intended to realize a better functioning social and market system, such as improved roads, electricity, telecommunications, markets for farm inputs, credit facilities, courts, health care, and veterinary facilities. These options provide the enabling environment and the basic facilities needed for a well-functioning society. Most of these options require public investments to create an environment in which private businesses and traders can operate. Moreover, the areas of support include training, financial support, and techniques and inputs that give households the opportunity to improve their situation in a sustainable way. This type of support gives households the opportunity to improve their situation.

Next to the above-mentioned adaptation options, the cross-woreda institutions identified the following options:

- improved weather forecasting;

- disaster assessment and disaster risk reduction interventions;

- training on effects and causes of climate change;

- training and inputs for improved water management (integrated watershed management, construction of irrigation works along with provision of the necessary inputs, water harvesting, moisture conservation);

- improved animal husbandry practices;

- improved access to non-agricultural income sources.

\section{MAIN CONSTRAINTS ON INSTITUTIONAL ACTIVITIES}

The constraints to the activities of institutions can be summarized as follows:

- budget constraints (including inadequate office facilities, not enough skilled personnel, late payments);

- excess bureaucracy (many meetings, hierarchical management, inadequate supervision);

- lack of coordination between and responsiveness to local needs by the regional, zonal, and woreda-level administrations;

- the tendency of donors toward spending more money after a disaster occurs; 
- lack of an adequate road network and transportation for the extension agents to travel;

- lack of adequate telecommunications facilities;

- lack of meteorological information;

- lack of improved and area-specific technologies;

- lack of farmers' training and close follow-up;

- lack of farmers' awareness;

- reluctance of farmers to adopt new technologies;

- political constraints.

The first four constraints are related to managerial and financial constraints. For institutions to function properly, adequate resources are required, adequate managerial skills are required, and institutions have to cooperate closely in order to assure that the right assistance is given to the right places. National and zonal authorities play an important role here, to assure, organize, and maintain this coordinating task. The fifth, sixth, and seventh constraints are related to an adequate infrastructure, both in terms of road networks and research and information dissemination networks. Adequate infrastructure provides the enabling environment for the institutions to properly perform their tasks. The eight through tenth constraints are directly related to the tasks of the institutions. Realizing sustainable growth in the village requires the continuous presence of the institutions in the regions so that they develop trustworthy relationships with households and have to opportunity to follow up activities and observe the most pressing needs of the households. The widespread presence of extension agencies in Ethiopia, combined with long-term safety net programs financed by multiple donors, provides a good basis for this and reduces the risk that changing donor preferences result in short-term and small-scale initiatives. Realizing trustworthy relationships with farmers and raising awareness among stakeholders requires specific training from extension workers on sociological and psychological processes among farm households.

Finally, some institutions indicated that some government policies are restrictive. These include:

- the policy of minimum saving as a requirement to obtain financial support from external sources (NGO or government);

- the rule that sector offices (agriculture, health, education) need to be included in the kebele cabinet given that the sector representations are normally too busy to handle activities at the cabinet;

- lack of compensation for the kebele officials, which reduces their incentive;

- occasional interference of kebele authorities in the activities of institutions;

- inadequate budget allocation;

- the current Civil Societies law, which may affect the role of NGOs, as well as land tenure (ownership) and rights issues.

As for the first four constraints, these governmental rules and regulations may prevent institutions from efficiently performing their tasks. On the other hand, some of these policies are set up in order to assure that not everybody can start institutional activities. They are part of the role of the authorities to coordinate or monitor institutional activities that may affect social structures in the country.

A number of institutional stakeholders stressed their role in making available farm inputs at reasonable prices or even for free for starters of new farming practices. They see a strategy in which farms are directly subsidized or provided new inputs and new technologies as the best way to spread good practices. An alternative and perhaps more sustainable strategy is to create an environment in which private traders or businesses can successfully operate. This requires adequate infrastructure, telecommunications, and well-functioning financial and legal systems. If national, regional, and local authorities provide these services, an environment is created in which input supply and output purchase by private traders can be sustainable.

\section{E. EFFECT OF CLIMATE HAZARDS ON STAKEHOLDERS' ACTIVITIES}

The effect of climate-related hazards on the activities of the institutional stakeholders include:

- increasing demand for credit among clients and a reduced repayment rate;

- increased demand for food aid;

- less demand for farm inputs and hence loss of inputs;

- reduced active membership;

- reduced community participation in watershed management (due to the increased movement of local people in search of employment, water, and food); 
- inability to pay an annual membership contribution and attend meetings;

- diversion of attention toward emergency activities;

- inability to work in the office during the regular working hours.

Some of these effects are related to changed aid requests from the households (changing from help in terms of productive investments to help in terms of emergency relief). Other effects refer to reduced participation opportunities because households lack the means or shift their attention to emergency relief activities. The final effect refers to changes in the activities of the institutions themselves because of changing circumstances in their working conditions.

In order to cope with the climate hazards, the institutional stakeholders employ the following adaptation strategies:

- accommodate increased movement of members in search of employment;
- identify the most affected and report to the woreda administration;

- call off some of the activities;

- provide some food aid and safety net assistance;

- provide credit;

- plan to buy inputs from cheaper sources and sell where they fetch higher prices;

- enhance group accountability to ensure loan repayment;

- increase food aid.

Some stakeholders indicated that most of the activities and information dissemination are changed in response to the weather change. These include changing agronomic practices/cropping patterns, use of early maturing varieties, pest management, water harvesting and moisture conservation practices, improving livestock productivity by reducing stock size, integrated watershed management and land rehabilitation, improving disaster management and adaptation capacity, attentive follow-up, and an early warning system. 

THE WORLD BANK

1818 H Street, NW

Washington, D.C. 20433 USA

Tel: 202-473-1000

Fax: 202-477-6391

Internet: www.worldbank.org/sdcc 